NOTE TO USERS

This reproduction is the best copy available. 



\title{
Access to Cochlear Implant Technology: a structurationist approach.
}

\author{
by \\ Julia A. Worswick \\ A thesis submitted to the Faculty of Graduate Studies and Research in partial \\ fulfillment of the requirements for the degree of \\ Master of Arts \\ $\ln$ \\ Geography \\ Carleton University \\ Ottawa, Ontario
}

(C) Julia A. Worswick 2010 
Library and Archives

Canada

Published Heritage

Branch

395 Wellington Street

Ottawa ON K1A ON4

Canada
Bibliothèque et

Archives Canada

Direction du

Patrimoine de l'édition

395, rue Wellington

Ottawa ON K1A ON4

Canada
Your file Votre référence

ISBN: 978-0-494-71706-6

Our file Notre référence

ISBN: $978-0-494-71706-6$
NOTICE:

The author has granted a nonexclusive license allowing Library and Archives Canada to reproduce, publish, archive, preserve, conserve, communicate to the public by telecommunication or on the Internet, loan, distribute and sell theses worldwide, for commercial or noncommercial purposes, in microform, paper, electronic and/or any other formats.

The author retains copyright ownership and moral rights in this thesis. Neither the thesis nor substantial extracts from it may be printed or otherwise reproduced without the author's permission.

\section{AVIS:}

L'auteur a accordé une licence non exclusive permettant à la Bibliothèque et Archives Canada de reproduire, publier, archiver, sauvegarder, conserver, transmettre au public par télécommunication ou par l'internet, prêter, distribuer et vendre des thèses partout dans le monde, à des fins commerciales ou autres, sur support microforme, papier, électronique et/ou autres formats.

L'auteur conserve la propriété du droit d'auteur et des droits moraux qui protège cette thèse. $\mathrm{Ni}$ la thèse ni des extraits substantiels de celle-ci ne doivent être imprimés ou autrement reproduits sans son autorisation.
In compliance with the Canadian Privacy Act some supporting forms may have been removed from this thesis.

While these forms may be included in the document page count, their removal does not represent any loss of content from the thesis.
Conformément à la loi canadienne sur la protection de la vie privée, quelques formulaires secondaires ont été enlevés de cette thèse.

Bien que ces formulaires aient inclus dans la pagination, il n'y aura aucun contenu manquant. 


\begin{abstract}
This study explores issues of agency and structure as they influence access to a locationally delivered resource - cochlear implant technology. Little consideration has been given to its availability, recognition and access, as they are produced by the intersection of personal geographies with those of the health care system. Using a structurationist framework, this study employs a case study approach to examine issues of access to this technology by those with a severe or profound hearing loss. From thirteen accounts of accessibility, access to cochlear implant technology is weighed down with temporal, spatial, structural and other constraints that make access easy for some and difficult for others. Research on access to cochlear implant technology in Canada is sparse. There are currently no structural processes in place to promote efficient access; consequently, there is a need for regular screening of adults for hearing loss and guidelines or strategies for evaluating all possible technological solutions.
\end{abstract}




\section{Acknowledgements}

"At times our own light goes out and is rekindled by a spark from another person. Each of us has cause to think with deep gratitude of those who have lighted the flame within us." Albert Schweitzer (date unknown).

There are a number of people who have "sparked a flame" in my life and during the writing of this thesis and to whom I am grateful.

I met Professor David Bennett, my thesis supervisor in a second year undergraduate class he was teaching. By the end of that class I was hooked by his intelligence and rational approach to teaching. As well, his interest in geography and health matched mine, making him a natural choice to supervise this research. I am very grateful for Professor Bennett's tireless support and dedication to this thesis project. He has been a wonderful mentor, with utmost patience he has provided me with sensible advice, solid direction and critical appraisal of the value and relevance of my work.

This thesis was born out of my experience obtaining a cochlear implant. From the Ottawa Hospital's Audiology and Cochlear Implant Program I would like to thank Shelly Armstrong, my principal audiologist. It was Shelly who changed my life suggesting I consider the cochlear implant when I was desperate for a stronger hearing aid. Not realizing the severity of hearing loss I was experiencing and the limitations of hearing aid technology, I stumbled into this technology like many others in similar circumstances. Shelly has been instrumental in my rehabilitation and is a great supporter of this project. In addition, Christiane Séguin, the Cochlear Implant Program Coordinator at the Ottawa Hospital has also been invaluable and has given her time and efforts that contributed to the success of this project. Christiane generously offered to be the Principal Investigator for this research project as it was imperative that ethics approval be obtained from the Ottawa Hospital Research Ethics Board in order to interview cochlear implant patients - whose stories are the basis of this research. As well, I would also like to thank audiologists Elizabeth Fitzpatrick and Josée Chouinard who were very helpful in motivating me and providing guidance, resources and feedback for this project.

From Advanced Bionics, the manufacturer of my cochlear implant device - 1 would like to express appreciation to Renée Lefrançois, the Regional Manager for Canada. Renée was involved in reviewing portions of the thesis, and provided valuable background data on the current status of cochlear implantation in Canada which is fragmented or non-existent in the literature.

I interviewed fifteen people who have been implanted with a cochlear implant device as part of this research. Their stories were personal, emotional, and often quite touching. I would like to thank these wonderful people for taking the time to share their stories with me. I wish them every success with their implants and hearing. 
I met my best friend just before starting graduate studies. When he came into my life he brought such a positive attitude and became a much needed calming influence on me. My thanks to Aldo for his love and support.

Finally, I would like to thank my mother who passed away in the latter stages of writing this thesis. When at a crossroad in my life, she was the "spark" who encouraged and supported my return to school. Her support was tireless and unwavering - "when will you get it finished?" was a frequent question. 


\section{Table of Contents}

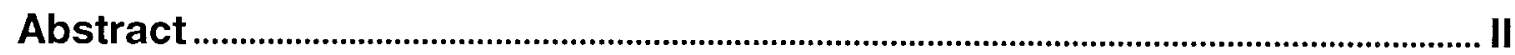

Acknowledgements..........................................................................................................ii

Table of contents ............................................................................................................ v

List of figures ................................................................................................................ vii

List of tables .................................................................................................................. vii

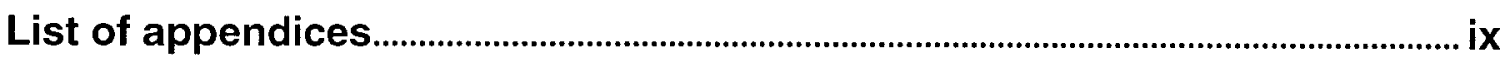

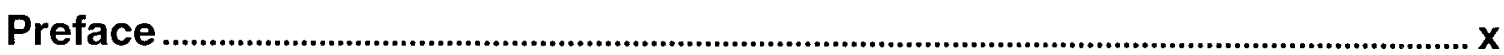

Chapter 1: The Research Question .............................................................................. 1

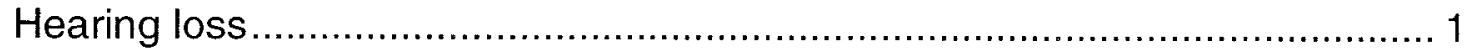

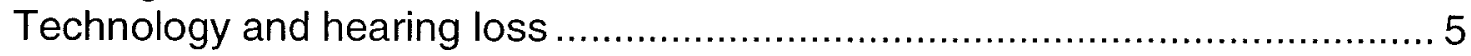

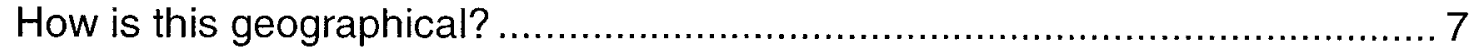

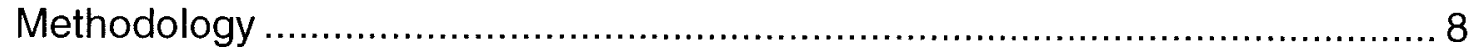

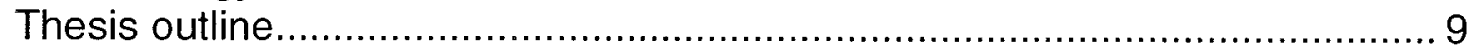

Chapter 2: Constructions of Accessibility in Geographies of Health .............11

Medical geography to geographies of health ........................................... 12

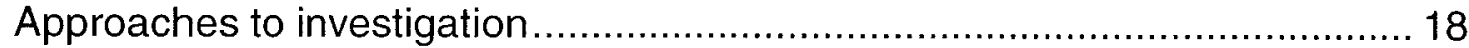

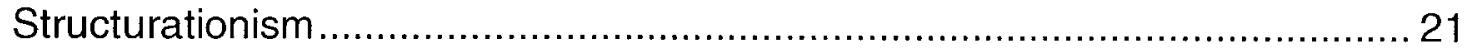

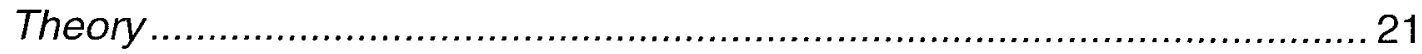

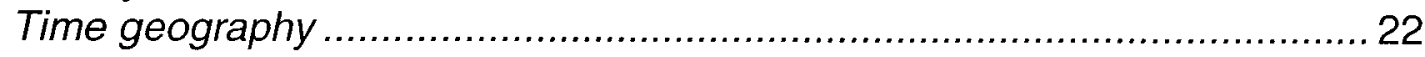

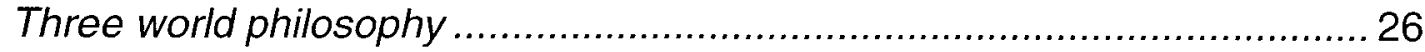

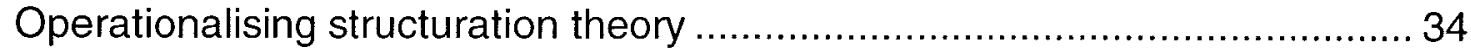

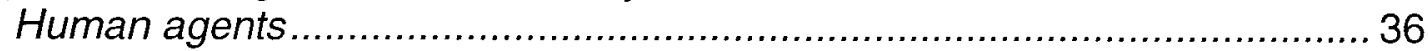

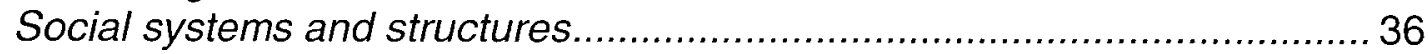

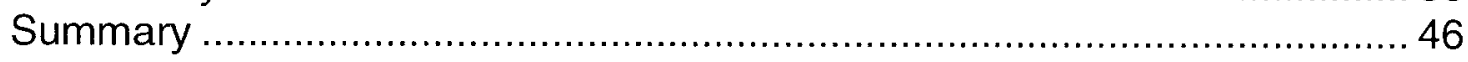

Chapter 3: Methodology and Research Design ........................................................48

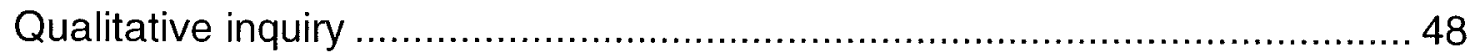

Strategies to conduct structurationist research ......................................... 52

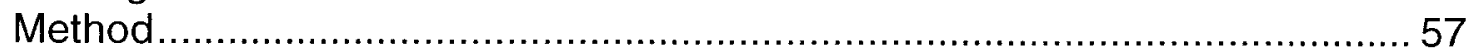

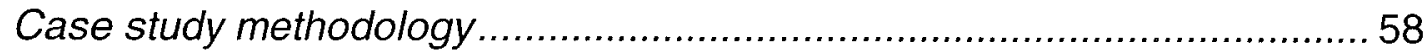

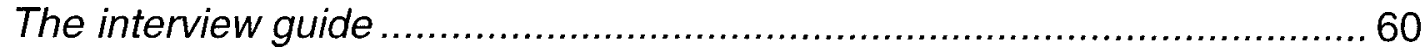

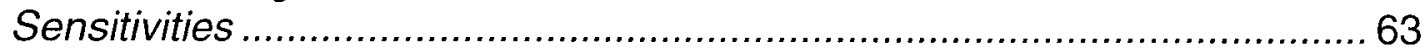

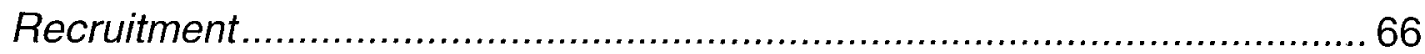

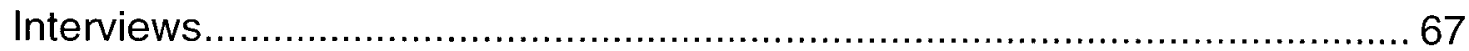

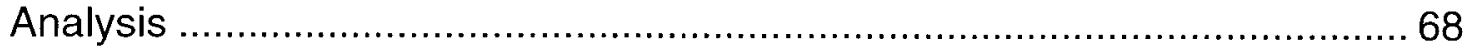

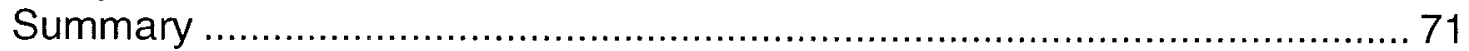


Chapter 4: The Narratives ............................................................................................72

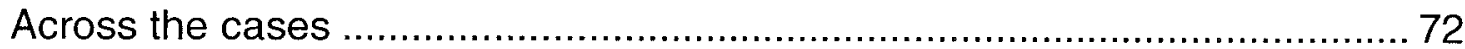

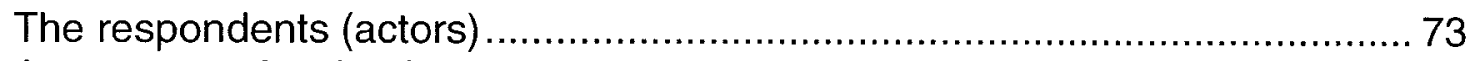

Awareness of technology and access pathways........................................ 83

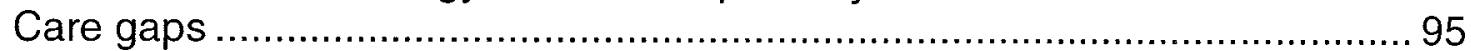

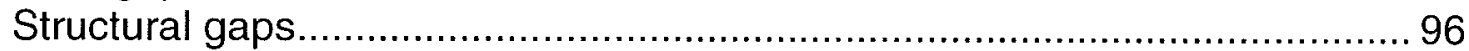

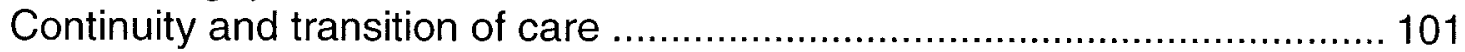

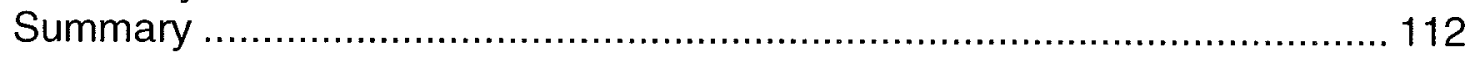

Chapter 5: Summary, Conclusions and Future Work........................................... 118

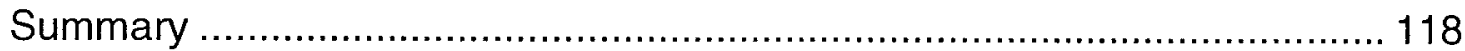

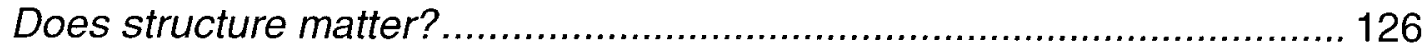

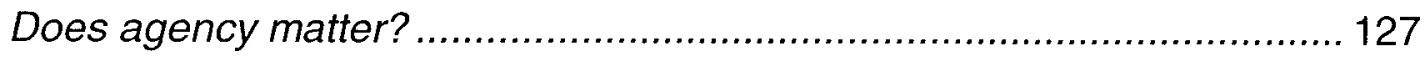

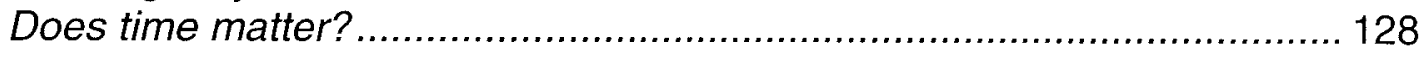

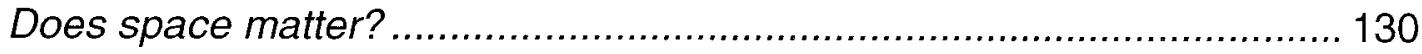

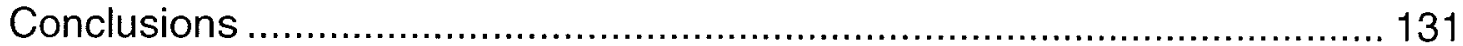

Influence of structural processes on hearing care .................................. 131

Motivations of access - interactions in time and space......................... 133

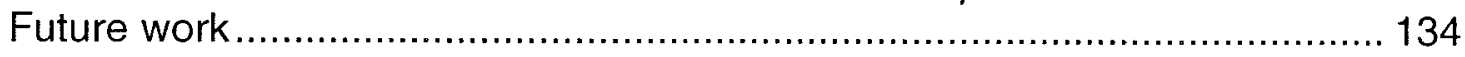

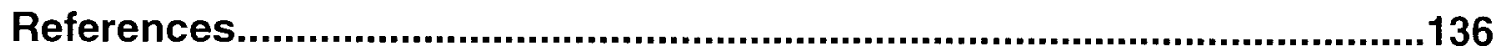




\section{List of Figures}

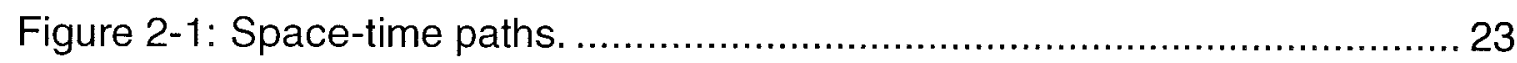

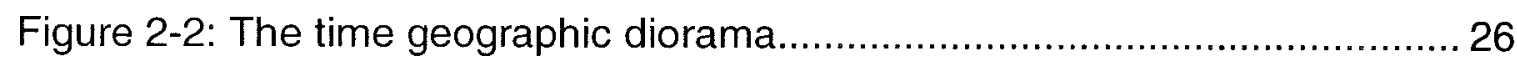

Figure 2-3: Three world "Popperian" model...................................................... 27

Figure 2-4: Access to cochlear implanation: using the "Popperian" framework to

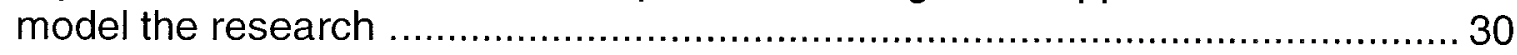

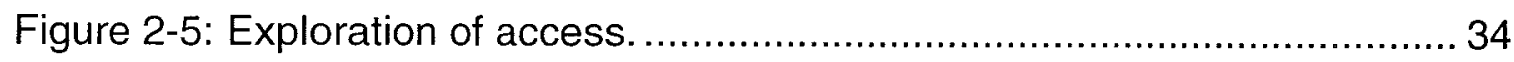

Figure 2-6: Central elements of structurationist theory: a model to organize accounts of accessibility to cochlear implantation. .......................................... 36

Figure 3-1: A repertoire of strategies for use in structuration theory.................. 54

Figure 3-2: Strategies to be particularly mobilized in structurationist theory ....... 55

Figure 5-1: Organizing accounts of accessibility to cochlear implantation: redrawing the model. 


\section{List of Tables}

Table 1-1: Thresholds of hearing: classification system.................................. 5

Table 2-1: Cochlear implant centres across Canada. .................................... 43

Table 4-1: Overall themes identified from the narratives............................... 113 


\section{List of Appendices}

Appendix A: Information Sheet and Consent Form .....................................143

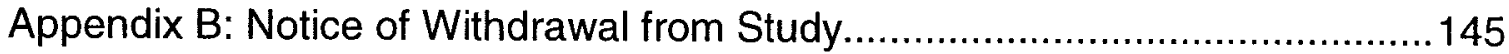

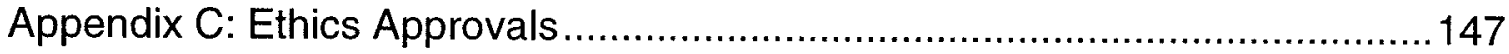

Appendix D: Interview Guide for Study Respondents ..................................148

Appendix E: Recommended Wait Times for Speech-Language Pathology and

Audiology Related Services ......................................................................152 


\section{Preface}

My life has been structured around deafness since I was three years old. In early 2004, at the age of forty-three, I received a cochlear implant, and my life has since been transformed. From my experience obtaining a cochlear implant, I feel lucky, yet uncomfortable in that luck seemed to play such a large role, luck that others may not have had. I have channelled my emotions into practical action to be a resource and advocate for others who might benefit from the cochlear implant. Participating in a local cochlear implant support group has allowed me to share and obtain information about the technology and the experiences of hearing with the implant. In addition, I have volunteered time to co-edit the Canadian Hard of Hearing Association Ontario Chapter newsletter and this allowed me to increase the awareness of the cochlear implant to hard of hearing Ontarians. Through networking of family, friends and audiologists, I also talk with people who are considering the cochlear implant so as to share my story and knowledge.

The biomedical aspects of cochlear implantation $(\mathrm{Cl})$ and the impact of medical technology in general on quality of life have been well reported (Hawthorne 2004; Hawthorne 2002; Kaplan 2003; Cohen 2004; Hinderink 2000; Kunimoto 1999; Krabbe 2000; Saxon 2001). However, little consideration has been given to the availability, information and access to the technology, as they are produced by the intersection of personal geographies with those of the health care system. This geographic interpretation was reinforced, when I discovered that there are 
quota systems in place across Canada that limit the number of cochlear implant surgeries that can be performed in different jurisdictions in a given time period.

Additionally, there are candidate screening criteria that act to restrict access. Furthermore, this surgery can only be performed at certain geographical locations due to the specialized nature of the procedure and skills and training of the surgeons. Access to surgical sites and follow-up visits could prove to be barriers to access for some implant candidates living distant from the implant centres. Knowledge about the availability and candidacy of access to the technology may not be widely or evenly distributed among health care professionals and consumers.

It appeared that I met the candidate criteria, there were what I perceived to be available resources for the surgery, I lived close by and had access to transport and a benefits package through work to buffer the loss of income during the time required to recuperate. Motivated by questions that emerged from my own experience, I developed this research project that is conceptualized around issues of agency and structure as they influence access to a locationally delivered resource - cochlear implant technology. 


\section{Chapter 1: \\ The Research Question}

This paper explores geographical aspects of access to cochlear implant technology by those with a severe or profound hearing loss in Canada. It examines how these individuals have accessed cochlear implant technology, what barriers they have encountered, and assesses their awareness of the technology. The availability of cochlear implants varies across Canada, but no geographic studies have been done to examine how Canadians with a severe to profound hearing loss differentially obtain or do not obtain this technology.

A structurationist framework within the realm of health geography is developed as a conceptual model so as to understand the process or journey that people with a severe or profound hearing loss may undertake. It will only be by listening to and understanding the individual stories within the context of the current health care structures, that ways to improve access and availability will be accomplished. By examining the stories of these people, patterns of accessibility may emerge and provide an explanation as to how and why access to this technology varies between people in time and space.

\section{Hearing Loss}

Hearing loss is the total or partial inability to hear sound in one or both ears (Rakel 2005). Exact figures on the prevalence of hearing loss are hard to determine as figures are typically based on self-reporting (Agrawal 2008) which often leads to underestimation of the true prevalence (Agrawal 2008). 
Nevertheless, in 2005, the World Health Organization (WHO) estimated that 278 million people worldwide had a moderate to profound hearing loss in both ears (WHO. 2006). In the United States, approximately 29 million people, or one in nine, are hard of hearing (Kochkin 2005; Agrawal 2008) and in the United Kingdom (UK), the prevalence is nearly 9 million people ( 1 in every 7 ) (Davis 1989). In Europe, studies of adult hearing loss over the past 20 years found that $16.9 \%$ of Europeans suffer from mild hearing loss, $4.6 \%$ have moderate hearing loss and $0.9 \%$ have severe or profound hearing loss (Phonak 2009).

Not surprisingly, the prevalence of hearing loss increases with age. People (2003) found that more than $90 \%$ of UK residents age 80 or older suffer from some degree of hearing loss (People 2003). According to the American Academy of Audiology, hearing loss is the third most significant, but treatable, health problem for American seniors, behind arthritis and hypertension (AAA No date). As populations gradually age, age-related progressive hearing loss rates will increase.

In Canada, one in every 10 Canadians has some form of hearing loss (PHAC 2006) and according to the Canadian Association for the Deaf (CAD), there are approximately 2.8 million hard of hearing Canadians (CAD 2007). These figures are based on a "one in ten" formula the CAD uses for statistical estimation with "strong disclaimers" (CAD 2007). Prevalence data on the current status of hearing loss in Canadians is difficult to locate due to variations in degree of 
hearing loss and issues of self-reporting. In addition, reporting methods vary between stakeholders, making comparisons over time difficult, if not impossible, to get a single, definitive picture. Statistics Canada, in the 1986 Post Censal survey, reported that $10 \%$, or 2.8 million Canadians between the ages of $0-99$ has a hearing loss (Statistics 1989). In 1991, Statistics Canada conducted a Health and Activities Limitations Survey (HALS) and indicated that 1 in $25^{1}$ Canadians have "impaired hearing" based on a questionnaire that asked participants if they had "difficulty hearing what is being said in a conversation with one other person, in a conversation with three or more persons or in a telephone conversation" (Statistics 1994).

According to the World Health Organization, "hearing impairment and deafness are serious disabilities that can impose a heavy social and economic burden on individuals, families, communities and countries" (WHO. 2006). In adults, hearing loss and impairment can "make it difficult to obtain, perform and keep employment" and it can also contribute to social stigmatization and isolation (WHO. 2006; WHO 1998). Many people with hearing loss or impairment can benefit from using hearing aids. However, with varying degrees of hearing loss, no one solution fits all.

There are two main types of hearing loss; conductive and sensorineural hearing loss. Conductive hearing loss is caused by some mechanical problem in the

\footnotetext{
1 The population in Canada was 27,296,859 in 1991, thus 1 in 25 translates to 1,091,874 Canadians with "impaired hearing" JW.
} 
external or middle ear that prevents the conduction of sound to the cochlear nerve and it is usually reversible by surgical or medical treatment (WHO. 2006; ASLHA 2008). Sensorineural hearing loss occurs when there is damage to the inner ear (cochlea) or to the nerve pathways from the inner ear to the brain. Sensorineural hearing loss not only involves a reduction in sound level and the ability to hear faint sounds, it also affects the ability to understand speech as well as the capacity to hear clearly. Sensorineural hearing loss can be caused by disease, birth injury, drugs and genetic syndromes. This type of hearing loss may also occur as a result of noise exposure, viruses, head trauma, aging, and tumors. Sensorineural hearing loss is usually permanent; it can degenerate over time, and requires rehabilitation depending on the degree and severity of the loss.

Examples of sensorineural hearing loss include inherited or genetic disorders for example osteogenesis imperfecta or congenital conditions like Rubella syndrome and it can also be caused by infections such as meningitis or trauma to the ear, such as a perforated eardrum. There are also toxic causes of hearing loss that can be attributed to ototoxic drugs like aspirin and quinine if incorrectly dispensed. Occupational hazards such as excessive and loud noises from machinery can damage the inner ear and lessen hearing ability. Finally, the normal ageing process, accumulated noise exposures and other factors can contribute to hearing loss and impairment. 


\section{Technology and Hearing Loss}

Hearing aids amplify sounds so they may be detected by damaged ears. While it has been demonstrated that amplification of sound through the assistance of hearing aids does help those with mild to moderate sensorineural hearing loss

(table 1.1) with respect to health related quality of life benefits (Chisholm and Newman 2007), there is still a small population of profoundly deaf and severely hard of hearing people who do not obtain substantial benefit from amplification through hearing aids.

Table 1-1 Thresholds of hearing: classification system.

\begin{tabular}{|l|l|}
\hline \multicolumn{1}{|c|}{$\begin{array}{c}\text { Degree of } \\
\text { hearing loss }\end{array}$} & \multicolumn{1}{|c|}{$\begin{array}{c}\text { Hearing loss range in dB HL } \\
\text { (type of noise) }\end{array}$} \\
\hline Normal & -10 to 15 \\
\hline Slight & 16 to 25 (weak sounds) \\
\hline Mild & 26 to 40 (whisper) \\
\hline Moderate & 41 to 55 (moderate rainfall) \\
\hline Moderately severe & 56 to 70 (conversation, dishwasher) \\
\hline Severe & 71 to 90 (alarm clock, lawnmower) \\
\hline Profound & $91+$ (chainsaw, jet plane) \\
\hline
\end{tabular}

This classification system is used to categorize the degrees of hearing (Clark 1981). The threshold ranges of hearing are presented in decibels $(d B)$, a unit of measurement that reflects the "softest intensity at which sound is perceived" (ASLHA 2008). In addition to the threshold ranges, the ability to detect certain speech or speech sounds depends also on the range of high and low frequencies that can be heard. More hearing loss in one frequency range than another will affect the ability to hear sounds in that range.

It is this group, those with a severe to profound hearing loss that is the population of interest for this study. When hearing loss reaches these levels, the 
amplification provided by even the most powerful hearing aid is normally not sufficient to enable those patients to sufficiently comprehend speech. When amplification is not a viable option, a cochlear implant becomes a consideration.

A cochlear implant does not simply amplify sound into the ear as a hearing aid does, rather it bypasses the damaged portions of the ear and directly stimulates the auditory nerve (NIDCD 2007). The cochlear implant is a small and complex electronic device that can provide a sense of sound to those who have a severe to profound hearing loss. The cochlear implant consists of a microphone, which picks up sound from the environment; a speech processor, which selects and arranges sounds gathered by the microphone; a transmitter and receiver/stimulator which receive signals from the speech processor and converts them into electrical impulses and finally, an electrode array which collects the impulses from the stimulator and sends them to different regions of the auditory nerve (NIDCD 2007). The cochlear implant requires a specialized surgical procedure to implant the electrode array component of the device as well as specific follow-up processes and therapy to ensure proper adjustments to and of the devices.

For most adults who have lost all or most of their hearing later in life, the cochlear implant can be quite beneficial. Most will be able to learn to associate the signals provided by the implanted device with sounds they remember. In most instances, this often provides implant users with the ability to understand speech solely by 
listening through the implant, without requiring any visual cues such as those provided by lip reading or sign language (NIDCD 2007).

\section{How is this Geographical?}

Worldwide, by 2006, 112,000 children and adults with a severe to profound hearing loss had received a cochlear implant; 38,500 in the United States alone (NIDCD 2007). In Canada, as of 2009, between 540-580 surgical implants were being performed annually (Lefrançois 2009) and in Ottawa, over 567 cochlear implant surgeries have been performed since 1993 (TOH 2008). While still a relatively rare surgical procedure globally due to the specialized nature of the technology and the associated costs, here in Canada and in other countries with state administered health insurance, cochlear implants have seemingly become a "more routine treatment option for children and adults with severe to profound hearing loss, essentially replacing conventional amplification as the hearing technology of choice" (Fitzpatrick 2006).

In Canada, access and availability to the cochlear implant has been limited "with certain provinces allocating devices on a quota system" (Fitzpatrick 2006). Thus, across Canada, access to the cochlear implant technology varies dependent on

provincially mandated candidacy criteria, different levels of access (number of devices) and various standards of care (Fitzpatrick 2006). Even within the context of socialized medicine, there are instances of rationing access to the cochlear implant devices due to the high costs associated with surgery and subsequent follow-up and rehabilitation. 
In health geography, temporal and spatial concepts interrelate with ideas or theories of human health within which there are a number of explanatory approaches (Gatrell 2002). There was a temporal and spatial element to the meeting between the audiologist and me in December of 2003 that opened a window of opportunity to a cochlear implant. What happened at that moment was the result of structural processes and human agency coming together at a particular location at a particular time.

Conceived in this manner, a structurationist approach to explain access to cochlear implant technology in Canada would be appropriate (Gatrell 2002). Structurationism posits a duality of structure and human agency; that is the economic, social and political structures that influence or determine health and health care provision interact with human agency and this can be expressed in "time geography". Gatrell (2002), states ... "social structures require that particular activities can only be carried out at particular times and in particular settings, but, equally, such structures may themselves be transformed by social action". Thus, my access to cochlear implant technology could be conceptualized as the outcome of the space-time intersection of two agents - the audiologist and me and the structures of the health care system as expressed locally.

\section{Methodology}

To explore the issues of availability, information and access to the cochlear implant technology, this research uses qualitative research methods employing a case study approach to elicit the experiences of individuals who have had 
cochlear implant surgery in the past five years. Primary data were collected through recorded interviews with fifteen adults from Eastern Ontario recruited with the assistance of Christiane Sèguin, the Cochlear Implant Program Coordinator at the Ottawa Hospital. From the questions asked of the participants, the responses serve as the basis for constructing a model to explain the current situation on accessibility to cochlear implant technology. In addition, a review of cochlear implant programs in Canada is outlined with particular attention to the Cochlear Implant Program in Ottawa.

\section{Thesis Outline}

The theoretical framework for this research is outlined in chapter two. The chapter begins with an exploration of the theme of accessibility in relation to geographical concepts and introduces health geography as a methodological approach to study accessibility to health care technology. Health geography integrates a number of philosophical concepts to the study of health, disease and health care. Here, the concepts of structure and agency are discussed in relation to access to resources in time and space. Further, this chapter identifies the structures and agents that are involved in the provision of this technology today in Canada. The research design is developed in chapter three. Using methodological strategies for applying structuration theory in empirical work, an accessibility model is presented that is used to explore the phenomena of access using a case study approach. This chapter also describes how the data were collected and analyzed. In chapter four, the abbreviated narratives of the case study are presented along with a discussion of the major themes and findings of 
the research. The accessibility model is re-drawn to include the findings, and a critical analysis of the results is presented. In chapter five, there is a discussion that recapitulates the main points, identifies the strengths and limitations of the study and findings, and presents areas for further research enquiry. 


\section{Chapter 2: \\ Constructions of Accessibility in Geographies of Health}

This research focuses on geographical aspects of accessibility to high-level medical technology, namely cochlear implantation in Canada. In geography, accessibility has multiple meanings depending on the context within which it is being framed. Johnston's (1994) definition of accessibility as "...the ease with which one place can be reached from another' seems straightforward, but when he goes on to say that accessibility is a combination of "location" within a study area, the form of the transport system, and the location within the study, we can see that accessibility is being framed solely within the spatialist tradition. There are other traditions and other philosophical approaches - implicit or explicit - in geography and accessibility is framed differently within each.

This chapter identifies, describes and assesses the traditions and approaches that intersect in and apply to geographies of health, showing how each constructs the notion of accessibility. It is argued that a structurationist framework best fits the empirical reality of access to a specific medical technology, wherein everyday personal space-time geographies intersect with geographically distributed health care structures. 


\section{Medical Geography to Geographies of Health}

From the 1950's to the early1990's, medical geography was disease ecology. Influenced by the works of British and French geographers, researchers investigated infectious and chronic diseases using models based on human ecology that include habitat, population and behaviour, to frame health. Medical geography of this period was concerned with examining patterns of diffusion and change, seeking to explain the distribution of health and disease towards finding solutions to improve health and eliminate disease. The 1980's, especially in the Unites States, saw the emergence of a geography of health systems that was more concerned with location theory, i.e. the distribution of health care systems and services focused towards planning and providing health care. The 1990's saw the first sign of a paradigm shift within medical geography to bring in social theory and the focus began to sway from a biomedical model of health towards a social model of health that is more concerned with "place theory", than with location theory. It is around this time that the term "medical geography" started to wane and the term "health geography" emerged in the academic literature (Bennett 2003). Kearns has been instrumental in shaping this social geography of health which attempts to examine a "humanistic understanding of place" (Gatrell 2002). This last trend is having a divisive impact among medical and health geographers, who see the discipline as loosening its biomedical roots and questioning its validity as an legitimate area of medical/health geographical research (Bennett 2003). 
Like geography, medical geography has evolved through many incarnations since Hippocrates presented the importance of "cultural-environmental interactions" over two thousand years ago (Meade 1988). Medical geography follows the same four traditions of geography as described by Pattison (1964), that is, using "the concepts and techniques of the discipline of geography to investigate health-related topics" (Meade 1988; Pattison 1964). There is a spatial tradition that examines the question of why there is variation in healthrelated phenomena, looking at where they are distributed across the earth's surface. There is also a chorological tradition, examining the nature of place as it relates to health, asking why particular health outcomes occur in one place but not another, and developing regional expressions of culture and environment towards recognising variations in health outcomes. Medical geography also seeks to examine the interrelations between humans and the environment in the "man-land" tradition. This area of medical geography evolved out of the environmental determinism ideology, which gave way to the notion of possibilism (Meade 1988). From possibilism, there grew the notion of behavioural ecology which in turn has shifted to cultural ecology and this idea "considers humans to be cultural beings whose existence is inextricably interwoven with the environment" (Meade 1988). Finally, medical geography also borrows from the earth-science tradition as it looks at the natural processes of the earth towards understanding their effects on health outcomes. 
Medical geography then, like geography, is pluralistic; it has felt the same philosophical underpinnings and borrowings from other disciplines such as biology, ecology, anthropology and medicine, etc. towards explaining health (Meade 1988).

If medical geography uses the concepts and techniques of the discipline of geography to investigate health-related topics (Meade 1988), then one needs to examine notions of health in order to understand the various approaches to the subject.

Research and investigation in contemporary medical geography can be grouped into three main streams: disease ecology, health services and social theory. Until the 1950's, medical geography had a dominant ecological perspective that was rooted in the disease mapping activities that were part of colonialism's explorations, strongly influenced by works of regional geographers (Barrett 2002; Meade 1988; Bennett 2003).

In the 1950's, Jacques May, a physician in French Indo-China introduced a disease ecology framework to counter the medically dominant germ theory that stated infectious diseases were "caused" solely by germs. He based his doctrine of specific aetiology on his definition of disease, whereby disease is "that alteration of living cells or tissues that jeopardizes survival in their environment" (Meade 1988). This definition is attributed to his experiences working in a tropical 
environment noting particularly the links between climate and disease (Akhtar 2003). From May's initial disease ecology framework there have been other inclusions and refinements that have resulted from further developments in medical and health geography towards examining "different levels of health", not alluded to in May's definition.

Dubos (1965), a biologist, defined health by saying "states of health or disease are the expressions of the success or failure experienced by the organism in its efforts to respond adaptively to environmental challenges" (Meade 1988). This definition was revisited in 1971, by Audy, who stated that "health is a continuing property that can be measured by the individual's ability to rally from a wide range and considerable amplitude of insults, the insults being chemical, physical, infectious, psychological and social" (Meade 1988). The Audy definition, according to McKinlay (1995) and Mechanic (1993), reflects the emergence of the "conceptual and political individualism" that was evolving in industrialized countries in the post 1950 era (Macintyre 2002) and is perhaps the most influential and comprehensively used among medical and health geographers today. It not only reflects the "analysis of the epidemiological transitions, which emphasises the role in chronic disease of individual lifestyle choices" (Macintyre 2002) but also the structural and environmental conditions that affect human health. 
Within the disease ecology framework are atlases of disease such as those produced in the 1980's and early 1990's by Cliff and Haggett (Rosenberg 1998). In these atlases, "epidemiological models of disease spread " are given "geographical expression" by way of mapping and modelling using "complex regression and logit models" (Rosenberg 1998).

The health services framework in medical geography is one that is based on turning location theory which "seeks to account for the location of economic activities" towards examining questions of access to health care services and providers (Bennett 2003). Within this framework, the economic and political underpinnings of health care delivery systems are examined, with emerging issues of equality of access to services, geographical distribution of services, distances to providers, quality of care, etc. Here, population variables such as age and socio-economic status are used in the research of health care access and in the delivery and planning of health care services (Rosenberg 1998). Immigration and the impacts of traditional medicine practices on the health care system are also considered within the health services framework as is the current restructuring of health care services in response to political and economic changes (Rosenberg 1998).

The appearance of powerful and relatively inexpensive computing technology and the introduction of geographical information systems in the late 1980's was a significant boost for research in the spatial analysis of diseases and health care 
systems. Both of these frameworks favoured mapping and used statistical methodologies in their investigations. The new technologies made the investigative process easier, allowing for spatial modelling of disease and health care delivery patterns, yet it also became more complex as mountains of data were organized and incorporated in ever increasingly complicated statistical models.

In 1984, Dear "called on medical geographers to adopt a "social theory of health" focusing on three primary concerns: the origins and evolution of the institution of health care; the organisation and practice of health care; and the political sphere" (Rosenberg 1998). In 1992, Kearns repeated Dear's message to “incorporate social theory into a post-medical geography of health" (Rosenberg 1998). This call to develop a social theory of health resulted in a split among medical/health geographers that remains to this day. Kearns and Dear proposed a geographical framework of health that incorporated "various elements of the current theoretical debates investing cultural and social geography" (Rosenberg 1998). What Kearns proposed, was a shift away from the disease ecology/biomedical tradition, arguing that "medical and health geography is part of a larger enterprise and should attract more researchers from the rest of human geography" than it does under the narrow "medical geography" speciality (Rosenberg 1998). This new framework investigates "peoples' experiences of their health and use of health services" using ethnographic and other qualitative approaches such as participant observation and informal interviews (Rosenberg 1998). 


\section{Approaches to Investigation}

There are five major approaches to inquiry in human geography (Gatrell 2002), each based on some fundamental epistemology or ideology that characterizes the different types of investigations and research undertaken. Researchers can investigate issues within human and health geography from a positivist epidemiological stance, using statistical methodologies or they can take an interactionist approach to enquiry in which they explore and interpret the "authentic lived experiences" in specific places (Gatrell 2002). The five approaches used to explain the geography of health are: the positivist, social interactionist, structuralist, structurationist and post-structuralist approaches.

The positivist approach to health explanation is perhaps the most "classical" (Gatrell 2002). It is scientific in that it uses methods typical of natural science towards identifying spatial patterns among data. It "relies on accurate measurement and recording and searches for statistical regularities and association" (Gatrell 2002). The positivist approach uses the technologies of mapping and spatial analysis to measure and observe data towards creating a testable hypothesis in order to explore causal factors to explain the distribution of health or disease. The positivist approach is used not only in exploring health and disease but it is also used in the study of health systems - health care and delivery in urban planning (Gatrell 2002). The positivist approach is reductionist, which allows for the investigation of behaviour through the identification of attributes of lifestyle and environment, which can then be used in statistical 
analysis. This method favours the use of quantitative data and employs statistical and epidemiological methods such as population sampling and seeks to generalize from the sample to the population (Gatrell 2002).

The purpose of the social interactionist approach towards explanation in health geography is to "uncover or interpret the understandings and meanings that make" disease or health "rational" (Gatrell 2002). This method attempts to examine the subjective experience of health and illness to the individual as they construct meanings out of interactions in everyday life. This is a humanistic approach, one that addresses human beliefs, values, meanings and intentions. Research in this approach is conducted with small numbers of people such as those in small communities or neighbourhoods (Gatrell 2002). Methods employed are qualitative and include interviews to record the beliefs and values etc. of the local population. The goal of the social interactionist approach is to obtain an empathetic understanding that is rooted in the social rather than the scientific world.

The structuralist approach seeks to identify the "political and historical factors that shape disease and health" (Gatrell 2002) and is based on studies using Marxist theories of oppression, domination and class conflict to show that disease causality is necessarily embedded in political and economic systems. Thus, explanation is found at the broader social context in this approach, whereby "economic relations and structure underpin all areas of human activity, 
including health and access to health care" (Gatrell 2002). This approach uses quantitative and survey data to evaluate political and economic conditions relating to health.

The structurationist approach seeks to examine the time-varying exposure to environmental problems and social stresses that have health impacts on individuals. This approach recognizes that there is a duality of structure and agency that shapes social practices and actions (Gatrell 2002). It is based on the idea that in our daily lives, we travel between places in time and that the daily exposures can have positive or negative health impacts. British social theorist Anthony Giddens developed this approach and it is primarily used in epidemiological time-exposure studies. This approach is also used to examine health policy because policy often doesn't include the constraints such as the spatial organisation of networks that individuals deal with in making health care decisions (i.e. accessibility) on a daily basis, such as the transportation, shopping and health care services networks (Gatrell 2002).

Also called post-modern, the post-structuralist approach is mainly concerned with how knowledge and experience are constructed in the context of power relations and questions the rational assumptions on which most public health research is based - that is empirical, science based "truths" (Gatrell 2002). Peterson and Lupton (1996) suggest the idea that through creating healthy and sustainable environments and promoting healthy lifestyles, we are exercising our power 
gained through expert knowledge and this is the new public health (Gatrell 2002). This approach seeks to expose the "uncertainties and ambiguities" that exist in public health that are often overlooked in the quest for obtaining "expert knowledge" that is based on scientific "truths". Post-structuralism is often used to frame health risk, where conflict arises between those asserting a positivist approach to examining risk using quantitative estimates and those poststructuralists who question the validity of the data, and expose the uncertainties that underlie the issues (Gatrell 2002).

\section{Structurationism}

\section{Theory}

Structuration theory is "an approach to social theory concerned with the intersection between knowledgeable and capable human agents and the wider social systems and structures in which they are implicated. The dualism between "agent" and "structure" is focal to both social theory and social life" (Johnston 1994).

Giddens developed structuration theory during the 1970's and 1980's to "address fundamental problems in the social sciences" and "provide an account of the constitution of social life that departed from and challenged established theoretical positions and traditions" of the time (Pozzebon 2005). Rather than conceptualizing structure as an externality, Giddens views it as "what gives form and shape to social life", and posits that while the structural properties of 
societies and social systems are real, they have no physical existence; instead they depend on the regularities of social reproduction. Thus, structure exists only in and through the activities of human agents (Pozzebon 2005). Giddens idea of agency refers to the "flow or pattern of people's actions" and "action, which has strongly routinized aspects, is both conditioned by existing cultural structures and both creates and recreates those structures through the enactment process" (Pozzebon 2005). Humans are seen as "knowledgeable agents", meaning that each "social actor knows a great deal about the conditions of reproduction of the society of which he or she is a member" (Johnston 1994). This dualism of agency and structure can be "expressed" through the "language" of time geography (Gatrell 2002).

\section{Time Geography}

Time-geography was developed and refined by Hägerstrand and his associates at the Lund school in Sweden in the late 1960's and early 1970's while involved in studies undertaken to improve Sweden's transport system (Lenntorp 1999). They used a mathematical time-notation system "to describe behaviour and biography in time and space and for conducting accessibility constraint analyses" (Pred 1981). The concept is based on the idea that "each of the actions and events consecutively occurring between the birth and death of an individual has both temporal and spatial attributes" (Pred 1981). That is, we all, individually as we move through time and space, form and dissolve "bundles" or aggregations. Thus, an individual biography or life path of movement in time and space can be conceptualized and diagrammed at various scales (figure 2.1). Pred (1981) 
argues that in time geography it is possible "to cast new light on the intimate and intricate interconnectedness of different biographies that is an essential part of the everyday process of social reproduction (Pred 1981).

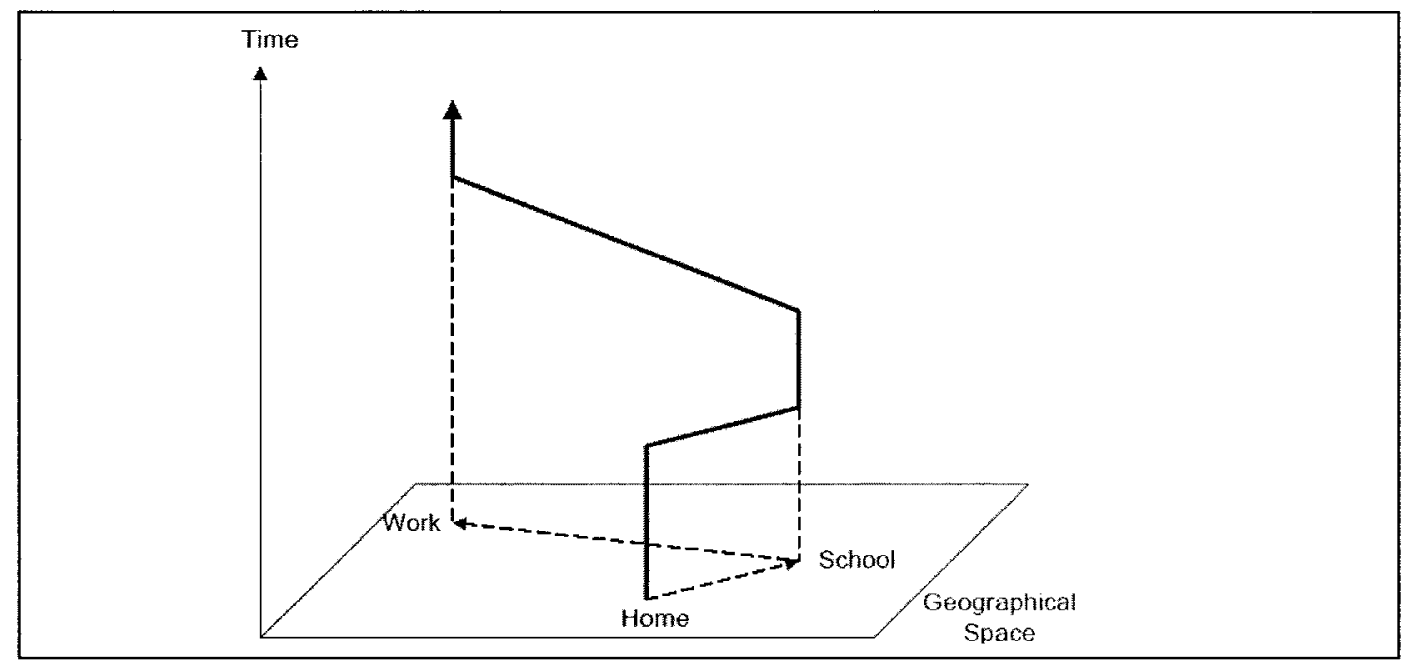

Figure 2-1 Space-time paths.

Two-dimensional representation "tracing" the movement of an individual in time and space. (Miller 2004)

Time geography studies of the 1970's and 1980's used this basic concept pictured above. Increasingly, it involved the use of mechanistic tools such as time space flowcharts and diagrams, using statistics to show mobility patterns of individuals in time and space (Aitken 1988; Lenntorp 1999). Miller (2005) calls this mathematical application of time geography "classical time geography" and he states that in classical time geography, there are two fundamental components: the space-time path and the space-time prism. Miller (2005) explains that the space-time path is used to trace the movement of an individual in space and time and can be represented in two-dimensional space. Additionally, Miller (2005) asserts that the space-time prism "is an extension of 
the path... and measures the ability to reach locations in space and time given the location and duration of fixed activities" (Miller 2005).

Per Olof Hallin (1994) used time-geography as a conceptual framework for a study of household energy behaviour. While few studies existed that studied the relationships between individuals and their physical-technical environments, Hallin was able to use the concept of "project" as outlined by Hägerstrand and Lenntorp (1974) to examine how lifestyle (values, attitudes, actions) can change over time in reaction to economic and physical-technical environments (Hallin 1994). Hallin's rationale for using time-geography is that within this framework there is the recognition that "each and every one of an individual's actions and every event have both temporal and spatial attributes" and that "people's actions are limited by various constraints, especially where the physical restrictions are emphasized" (Hallin 1994). Using graphs to show price development for heating oil and electricity over time, Hallin grouped the development into three phases to correlate how lifestyle changes or adapts in response to price increases for each commodity depending on the technical environment of the household. Hallin used "time" in a questionnaire to get at men's and women's use of time on different everyday activities in order to "examine which everyday projects the individuals and the households preferred" (Hallin 1994). In doing so, Hallin was able to state that existing lifestyles influence energy solutions. When there is stimulus (price increases) households become motivated to take action. It is lifestyle of the individuals of the household that influence which way the action is 
taken as does the geographical location of the household which dictates the types of resources available to choose from.

In "Pathogenic Paths", Schærstrom (1997) took the time-notation tool and used it to follow the "life-paths" of individuals for describing the health consequences of "time varying exposure to various environmental problems and social stresses". Using the time geographic "technique", Schærstrom shows that in our every day life, "our life-paths wind through society and are intertwined with each other; we come into contact with many other people and with other organic or inorganic components of the landscape of processes" (Schaerström 1997). The following diagram (figure 2-2) illustrates the pathogenic influences that an imaginary family of four encounters during the course of a working day, as they travel from one place to another, encountering perhaps tens or possibly hundreds of other people. The potential risk of making contact with pathogens is increased with the increase in physical proximity to others (Schaerström 1997). This diagram shows that in everyday life, there are a number of "situations that pose physical, chemical, or immaterial exposures that could possibly affect the physical, mental or social well being of people involved" (Schaerström 1997). 


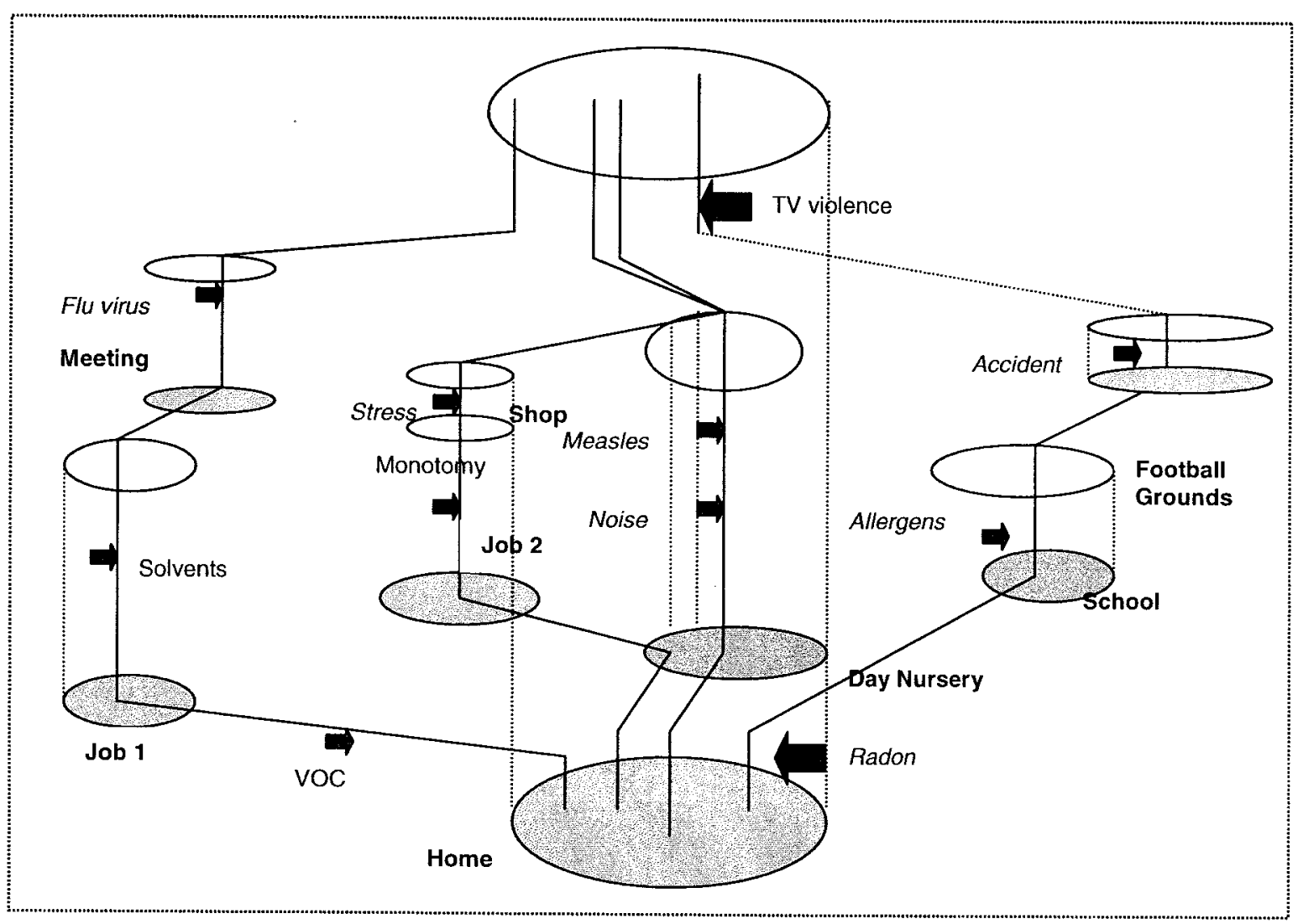

Figure 2-2 The time geographic diorama.

A day in the life of an "imaginary" family: The time-geographic diorama illustrates some of the pathogenic risks in our daily environment. Trajectories of two grown-ups and two children are shown. Bold "type" indicates "stations" in the diorama. Black arrows indicate risk factors. (Schaerström 1997)

\section{Three World Philosophy}

While classical time-geography was initially conceived to bring together knowledge from "highly scientific areas and from everyday praxis and secondly to reveal relations", it was a valuable analytical tool for specialist planners and developers. Lenntorp (1999) argued that there was a need to revisit the initial concept as the notion of revealing relations had been overlooked. Using the term 'life as drama', Lenntorp drew on the "three worlds" philosophy of Popper and Eccles' to show how the drama can be played out using this worldview. Lenntorp states that "time-geography constitutes a foundation for a general geographical 
perspective" and allows a "framework for fulfilling two tasks. First, to receive and bring into contact knowledge from highly distinct scientific areas and from everyday praxis. The second is to reveal relations, the nature of which escape researchers as soon as the object of research is separated from its given milieu in order to study it in isolation" (Lenntorp 1999). By using this simple "life as drama" metaphor, the duality of structure and agency can be presented in the basic component of the drama; "the actors, the roles that are expressed by behaviours and activities and the scene" (Lenntorp 1999).

The tripartite world Lenntorp alludes to is the three-world model of Popper (1978), a worldview that is representative of an interaction of the physical world, the mental and psychological world and the products of the human mind (figure 2-3).

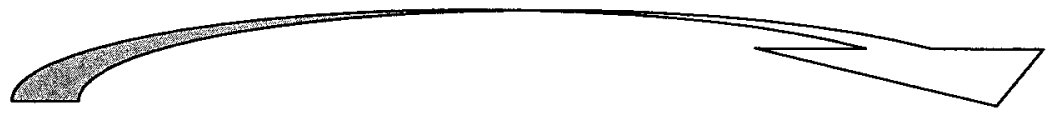

\section{First World}

- Physical

- Geography

- Structure

- Where we live, work, play, learn, heal, etc.

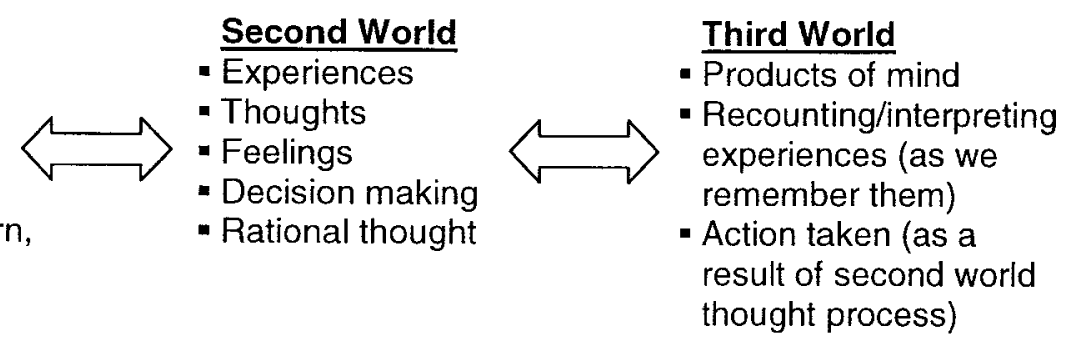

Second World

- Experiences

- Thoughts

Feelings

- Decision making

- Rational thought

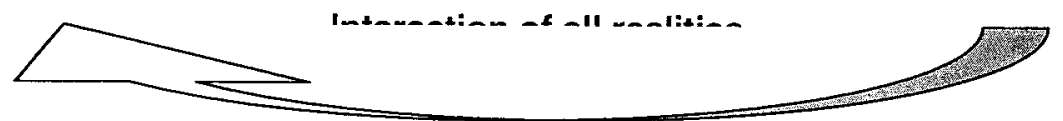

Figure 2-3 Three world "Popperian" model.

"Seeing the world in all its realities": this model illustrates the interactionism between the three worlds as described by Popper.

Rather than being treated as separate entities for examination and study, Popper suggests that in order to gain some level of understanding as is the goal of 
scientific enquiry; we view the world in all its realities. The first world is the physical world, that which "consists of physical bodies: of stones and of stars; of plants and of animals; but also of radiation, and of other forms of physical energy" (Popper 1978). This physical world is made up of living and non-living objects that we can touch and see, and this physical world is where we live, go to school, work, and play. It is the structures that we visit; it is what we perceive to be our "reality". The second world, the mental or psychological world is "the world of our feelings of pain and of pleasure, of our thoughts, of our decisions, or our perceptions and our observations; that is the world of mental or psychological states or process, or of subjective experiences" (Popper 1978). The third world objects reflect the possibility of objective knowledge, and include stories, myths, tools, scientific theories, social institutions and works of art, all of which are representative of "contents of thought" or "products of the human mind"(Popper 1978). Most, but not all of these abstract third world objects can be "physically realized" or "embodied" in a first world state.

Lenntorp says that in the 'drama' there are three key features; the actors, the roles and the scene (Lenntorp 1999). He states that while "the actors can be observed physically and portrayed by a trajectory in a time-geographic notation as they move around - saying and doing things....their thoughts, their experiences, expectations, aims etc., are not directly observable" (Lenntorp 1999). The roles that actors in the 'drama' play are revealed in their activities and behaviour, and it is these roles that Lenntorp states is what "the social sciences 
are concerned with, as roles express what is called the underlying structure" (Lenntorp 1999). The interest here is to understand how roles are developed and shaped - that is - by culture, values, institutional frameworks, power structures, etc. (Lenntorp 1999). Finally, the scene is described as "the sum of all physical objects" (Lenntorp 1999), the milieu where activity takes place. Thus, in order to reveal relations or at least say something about the relations in time and space, it is necessary to integrate 'all worlds (the drama) together'. Time-geography as a perspective, tries to bring all these worlds together into a common framework (Lenntorp 1999).

Lenntorp (1999) points to an interview by Giddens (1984) to reinforce this point, where Giddens states that "I've come to believe that contextuality of time-space, and especially the connections between time-space location and physical milieu of action, are just not uninteresting boundaries of social life, but inherently involved in its constitution, or reproduction" (Lenntorp 1999) ${ }^{2}$. Thus, Lenntorp contends that time-geography is now more widely accepted as an approach to integrating the features of the drama as a result of this recognition by important researchers outside of the 'social engineering' domain. While Harvey (1989) has opined that "time-geography ignores the importance and the capacity of human agency and gives no answers to a lot of question on how and why" (Lenntorp 1999), Lenntorp responds that Harvey is looking for explanation that is more appropriate to methods in social theory and that researchers should get on and

\footnotetext{
${ }^{2}$ Interview between Gregory and Giddens as quoted in Lenntorp.
} 
utilize time-geography as an approach and "connect it to theoretical considerations in their own way" (Lenntorp 1999).

\section{Considerations and Conceptualising the Research Framework}

Hallin's concept of lifestyle and how people feel pressure to change in response to some internal or external "shock" offered a potential framework for this research. Would it be possible to show what the stimulus or "shock" was (or where it happened in time and space) that fuelled an individuals' "project" of accessibility? Or, would it be possible to use Popper's tripartite worldview to conceptually capture the research project to understand access to this specialized technology? The following diagram (figure 2-4) builds on Popper's tripartite worldview with my conceptualization of this project within that

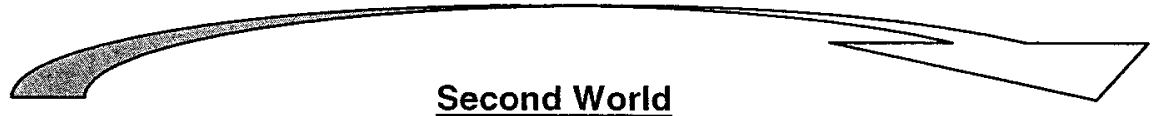

First World

- Physical

- Geography: eastern Ontario

- Structures: Health care $\longrightarrow$ communication, and other social structures

- Where we live, work, play, learn, etc.
- On being deaf or loss of hearing

- Experiences, feeling, thoughts

- Barriers, frustration

- Thought process to deal, cope with limitations, experience of process - gaining access

- Decision making

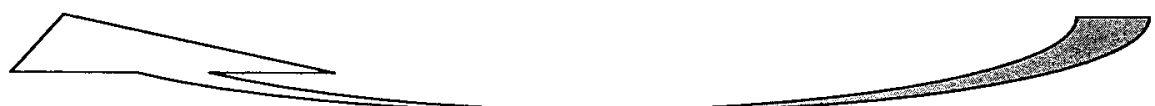

framework.

Figure 2-4 Access to cochlear implantation: Using the "Popperian" framework to model the research (à priori). 
This diagram shows the interactionism at play between the three worlds as described by Popper. The physical world is where we live, go to school, work, play, etc., and where we interact with agents of the health and other social service systems, etc. This world includes the structures built to perform specialized activities or obtain some specialized services such as hospitals, schools, day care facilities, etc. In the case of this study, it also includes access to health care practitioners in health care facilities - the structures and agents that hold the keys to accessing the cochlear technology. The mental world of feelings, thoughts and experiences, Popper's second world, can reflect those of deafened persons as they navigate the physical world with a physical limitation. These experiences can include their frustrations, thoughts on being deaf, or the coping skills developed in order to navigate the physical world. These experiences can lead to third world constructions, such as stories or narratives relating the experiences, coping mechanisms employed, mental barriers or blocks that have formed in response to some adverse experience. The social institutions of Canadian health care are perceived to be third world and first world objects; they are the physical institutions created in response to early $20^{\text {th }}$ century ideas of social justice and universal access to health care in Canada.

Ellegård (1999) put forward a method, based in the time-geographical framework, that is suitable for empirical studies of individuals' everyday life activities (Ellegård 1999). Ellegård, like Lenntorp, recognized that the timenotation system of Hägerstrand that is most often used in time-geography studies was lacking in depth, looking at activity and not the context within which it occurs. 
Thus, Ellegård suggests that an individual's activities can be viewed from a micro or macro perspective and that by using these views, a deeper examination is possible (Ellegård 1999). The micro level includes those activities that "constitute part of the everyday life of an individual and the opportunities that are available to an individual to perform those daily activities are limited by the constraints that evolve from earlier decisions, social obligations, organizational structure, the location and the availability of resources" (Ellegård 1999), and these are timegeographical constraints. The macro level, Ellegård posits, is where "human societies are located, formed by the continuous process of individuals performing activities to live their everyday lives" (Ellegård 1999). From this examination of the micro and macro level of activities, "the basic structure of society is revealed by the structure of the activities that are actually performed given the economic, emotional, conceptual and social restrictions in the material, physical environment where the individual lives" (Ellegård 1999). Ellegård moves on to what is described as "working out a method" that is directed at individual and household empowerment and "as a means for describing and analyzing a society as a whole in terms of the activities performed by its members" (Ellegård 1999). Here, Ellegård advocates the use of diaries to collect time and activity related data and presents a table to display different perspectives on time and a diagram of activity categorization to show a hierarchal categorization scheme, and states that there are "four contexts that can be dealt with in this methodological framework", including an everyday context, a project context, social context, and geographical context (Ellegård 1999). Together, these contexts "constitute the 
specific culture of a society mirrored in the activities of the individuals and show which one of the potential opportunities available to an individual s/he can actually chooses at every moment of time" (Ellegård 1999). Finally, Ellegård concludes that the framework put forward is intended to be used as a tool for the systematic investigation of activities towards "increasing our understanding of the human use of time, place and resources" (Ellegård 1999).

Considering Ellegård's work, the micro-macro framework also has merit for this research project. By obtaining "diaries" through interviews with deafened people who have encountered access to cochlear implant technology; the re-telling could provide an idea or a sense of the restrictions and/or opportunities at the micro and macro scales. Though Ellegård did not present a visual description of the framework, by using the contexts presented, would it be possible to "paint" the whole picture of the journey to accessibility in time and space? The following sketch (figure 2-5) is an attempt to illustrate the contexts that also incorporate Hallin's "drama" metaphor as it would play out within the four contexts suggested by Ellegård. The illustrations shows the interaction within and between contexts the everyday context - what goes on daily (activities and how they can be impacted by being deaf) - and this is the individual experience. This is followed by the project context - what activities are being performed to achieve short or long term goals such as getting a job, completing an educational course, having a family, etc. The social context which consists of all individuals whose activities are interwoven with the individual, the friends and family, groups or associations 
and any other social contacts and finally, the geographical context - where it (the drama) all takes place (how, when, how long).

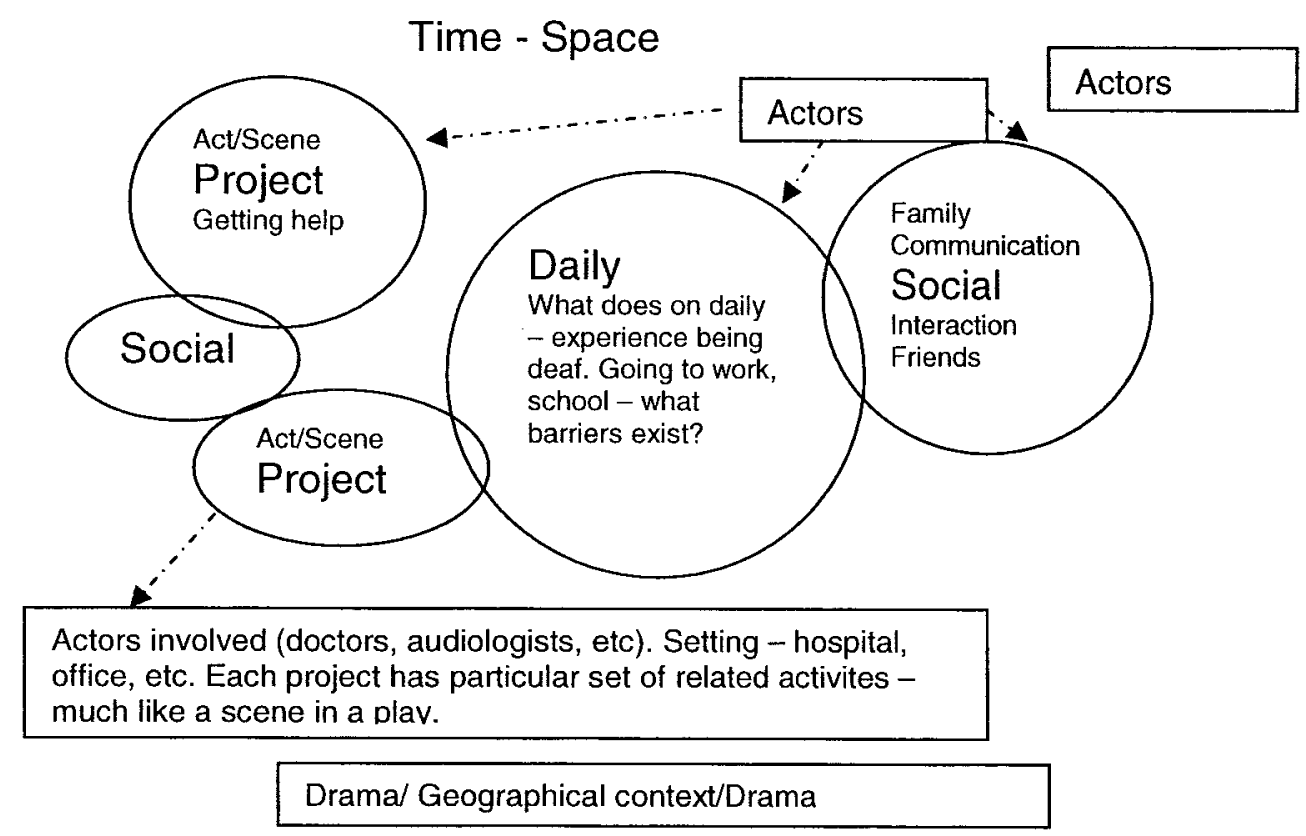

Figure 2-5 Exploration of access.

This model combines Ellegård's "four contexts" with Hallin's "drama" metaphor to reflect the activities of individuals, which can be used to reveal social structures.

\section{Operationalising Structuration Theory}

Researchers have found it difficult to operationalize structuration theory.

Pozzebon and Pinsonneault (2005) examined how structuration theory is used empirically within their field of expertise, information technology. Their paper is significant in that they sought out studies that were conducted using structurationist theory to show what strategies are being used to conduct research within a structurationist framework. While limited to the information technology sector, their research has implications across the social science disciplines. Reviewing the work of Giddens, they claim that there are three 
central elements to structurationist theory that guide empirical work. These elements or concepts can be used as devices for "both planning of an investigation and the interpretation of its results" (Pozzebon 2005). The first element is the concept of duality of structure (agency-structure) and it is the basis for structurationist theory and this involves the "constitution and reconstitution of social practices" (Pozzebon 2005). Rose (2001) explains that "there is a recursive character to the dimensions of the duality of structure... as human actors communicate, they draw on interpretive schemes to help make sense of the interactions; at the same time those interactions reproduce and modify those interpretative schemes which are embedded in social structure as meaning of signification". The second is the concept of time and space, both elements of the process within which the duality of structure evolves (Rose 2001). The third element is the idea that social actors are knowledgeable and reflexive. Giddens stated that no study of the structural properties of social systems can successfully be carried out, or its results interpreted, without reference to the knowledgeability of the relevant actors. On this, he was uncompromising.

Using the work of Pozzebon et al. as a framework within which to structure this research, the following model (figure 2.6) was developed. This model presents the three central elements of structurationist theory; the human agents, the social systems and structures and the interaction between them in time and space as they relate to this research question. This model will be used to organize 
accounts of accessibility to cochlear implant technology by those with a severe to profound hearing loss.

\begin{tabular}{|c|c|c|}
\hline Human Agents & $\begin{array}{l}\text { Interaction - Duality } \\
\text { (happens and evolves in) }\end{array}$ & $\begin{array}{l}\text { Social Systems \& } \\
\text { Structures }\end{array}$ \\
\hline $\begin{array}{l}\text { Actors: } \\
\text { - Those with hearing loss } \\
\text { Within the system - } \\
\text { politicians, } \\
\text { administrators, } \\
\text { audiologists, physicians, } \\
\text { hearing aid specialists. }\end{array}$ & $\begin{array}{l}\leftarrow \text { Time and Space } \longrightarrow \\
\text { Where they are situated } \\
\text { (agents and structures) }\end{array}$ & $\begin{array}{l}\text { Political System: } \\
\text { Distribution of Power and } \\
\text { Money } \\
\text { - Federal } \\
\text { - Provincial } \\
\text { - Municipal }\end{array}$ \\
\hline 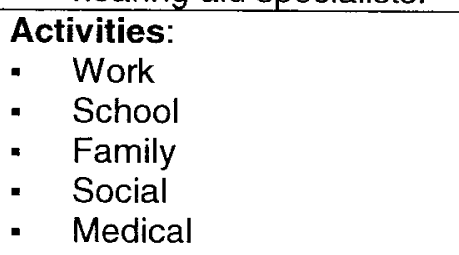 & $\begin{array}{l}\text { Can be obtained through } \\
\text { stories or narratives of agents }\end{array}$ & $\begin{array}{l}\text { Health Care System: } \\
\text { Distribution of Health Care } \\
\text { - Provincial (ADP) } \\
\text { - } \quad \text { Hospital } \\
\text { - } \quad \text { Private }\end{array}$ \\
\hline
\end{tabular}

Figure 2-6 Central elements of structurationist theory: A model to organize accounts of accessibility to cochlear implantation.

Human Agents

For the purpose of this research, the primary human agents of interest are those actors that have a hearing loss and could benefit from a cochlear implant. Other and influential agents are those individuals who are denizens of the social systems and structures within which access takes place. At the macro scale, this includes politicians at various levels of government who are involved in policy making and funding of programs that support access to health care services and technology such as the cochlear implant. It also includes the administrators of provincial health programs, hospital services and private health care services. At the micro level, family members, friends, co-workers, teachers, and therapists are other influential actors in the lives of those with hearing loss. There are also other and distant individual agents that carry out specific activities within the 
structures that support them. Examples of these actors include family practitioners, ENT's, audiologists, hearing aid specialists, and other hard of hearing service providers.

Social Systems and Structures

The Canadian political structure

The political structure of the Canadian federation was created based on the British parliamentary democracy system (Cameron 2001). The British North America Act (BNA) of 1867 gave the federal government responsibility for the "peace, order and good government of the country" along with the constitutional responsibility to "make payments to individuals, institutions or other governments for purposes that Parliament does not necessarily have the power to regulate" (Torjman 2001). This meant that there was a division of powers; the federal government was constitutionally responsible for areas that affect the well being of the entire country while the provinces were constitutionally responsible for the health and welfare of their residents with claims for federal involvement in providing funding and resources affecting availability (Torjman 2001).

The division of constitutional powers means that the federal government presently has an indirect role in the provision of health and social services through "the transfer of funds to other levels of government, organisations and individuals" (Rioux 1992). With the inclusion of the redefined services in 1984 as a result of the Canada Health Act, the provincial and territorial governments 
together are responsible for the "planning, development, implementation and delivery of these health and social services, including the range of personal supports" (Rioux 1992) required by disabled persons. The federal government is involved in these health and social services in three ways. It provides individuals with tax relief for the cost of disability supports through the income tax system; provides health care and social services for Inuit and Aboriginal Canadians who live on reserves; and by transfers of federal funds to the provincial governments for their education, health, welfare and social services programs through the Canada Health and Social Transfer (CHST) program, which was established in 1996 and was the successor to the Established Programs Financing created by the Trudeau government in the early 1970's (Deber 2000; Torjman 2001).

\section{Canadian health care structure}

Canada's health care system was founded primarily on the social theory of "shared vulnerability and collective responsibility" (Armstrong 2003) that was put forward by Leonard Marsh in the 1943 Report on Social Security for Canada (Armstrong 2003). This notion of "pooling of risks" led to the introduction of Medicare. In 1944, the provincial government of Saskatchewan instituted the first universal hospital insurance program in Canada (Armstrong 1998; Browne 2000). This insurance program covered all inhabitants of Saskatchewan for inpatient hospital care as long as it was "medically necessary" (Armstrong 1998). The success of this program led to political pressures, that by 1948 , the federal government responded by helping the provinces to build hospitals to serve their residents (Armstrong 2003). By 1957, the Hospital Insurance and Diagnostic 
Services Act became the first federally legislated universal health care program for all Canadians (Armstrong 2003; Browne 2000; Romanow 2002) and this was followed by the 1966 Medical Care Act (Browne 2000). These Acts allowed the provinces to continue with the provision of health care with the federal government agreeing "to cover half the cost of specified services" (Armstrong 2003). To ensure that the insurance program was equally distributed to all Canadians, the federal government instituted five principles that were conditions for the provinces to receive federal funds. The five principles mandated that "core medical services be universal, portable, accessible, comprehensive and publicly administered" (Armstrong 1998; Armstrong 2003).

The five principles Canadians have come to equate with the health care system in Canada reflect the values of equity, justice and unity that are the basis of social and political thought in Canada (Romanow 2002). Through citizenship and residency, Canadians have the right to universal health coverage in that medically necessary health services will be provided regardless of "ability to pay, age, or illness" (Armstrong 2003). It also means that these services should be equally accessible, as noted by Soderstrom in that there must be "reasonable access to insured services by insured persons" (Soderstrom 1978). Health care services must also be comprehensive, "covering all necessary services" (Armstrong 2003) and the health insurance plan must be portable, so that movement across the country would not hinder coverage. Finally, the health 
insurance plan must be publicly administered, as in a non-profit manner by a "public authority responsible to the provincial government (Armstrong 2003).

\section{Social justice}

Pitt (2005) places the concept of social justice in social theory, specifically drawing on Giddens structurationist theory to address the micro-macro dualism of social justice in contemporary schooling. Pitt remarks "according to structurationist theory, such systems (patterns of relationships across time and space) do not structure the activities of the teachers and pupils because they do not exist outside of them" (Pitt 1995). Thus, without action there is no structure, and without people who have lost some degree of hearing, there would be no research into issues related to hearing loss or therapies or technologies to improve hearing or communication capabilities etc., all of which are produced by structures that are the result of individual and collective actions geared around deafness. Pitt's paper triggered this realization along with another related to allocation of resources, which ties in with the social justice and rationing themes. Pitt mentions that structure, according to Giddens ${ }^{3}$, is "constituted not only by rules but also by resources" and that resources are "either allocative or authoritative". Here, allocative resources are those physical or material resources that are the result of "human domination of nature" while authoritative resources are those non-physical resources that "result from the dominance of some people over others". If there is a way to organize deafness by degree of loss, then material resources such as the cochlear implant are allocated only to those that

\footnotetext{
${ }^{3}$ (Giddens 1984)
} 
have reached some predetermined degree of hearing loss. These allocative resources are managed by authoritative resources, namely the audiologists working within the structure of the cochlear implant program, which is dominated by hospital administrators, community politicians and provincial governments, all of which make up the structure of the health care system. The final point taken from Pitt is the explanation given for dealing with micro-macro dualism and issues of continuity/change, individual/society, and theory/practice as they relate to social justice. In her use of the "river" metaphor to explain the time-space separation, Pitt states that "events that occur at a point on the river can affect people and places in other areas along the rivers course and even places geographically distant from the river" (Pitt 1998). Pitt found that "it is possible for the river to be affected by events distant from its course". This analogy can be applied to the availability of cochlear implant devices. Over the years, the availability of the number of devices has changed, increasing the number of possible candidates for surgery. A case in point is British Columbia. With a population of approximately 4 million, it was initially funding five implants a year up to 2004 , when it was increased to 10 implants a year and through further successful lobbying in 2007 was able to increase the number of surgeries making it comparable to Ontario and other provinces with surgical sites. 


\section{Cochlear Implant Centres}

Provincial governments are responsible for delivering health care services to their residents and within this mandate they deliver funding for cochlear implant devices and surgeries in their respective provinces. It is difficult to present a chronological history of the evolution and progress of cochlear implantation programs and the number of surgeries performed in Canada as there is no central repository of information. From several sources, including the Coordinator of the Ottawa Hospital Cochlear Implant Program and the Regional Manager for Advanced Bionics (one of the manufacturers of the cochlear implant devices), the following is known.

Cochlear implant surgeries in Canada started in the 1980's with the help of private academic research funding. Toronto's Sunnybrook Health Sciences Centre was the site of the first adult cochlear implant centre in Canada. Established in 1984, the Sunnybrook Cochlear Implant Program is now one of the largest centres of its kind in North America, performing between 70 to 80 surgical implantations annually. Recognizing the leading and early role and the unique services of the Sunnybrook program, the Ontario Ministry of Health and Long Term Care designated the centre as the provincial coordination site for implant services in Ontario. Consequently, as the need to expand services across Ontario was warranted, the provincial government was lobbied to establish a cochlear implant centre in Ottawa, to better serve the needs of the residents of Eastern Ontario. 
Among the first provinces to provide provincial funding for cochlear implant surgeries were Québec, Alberta and BC. Ontario provided provincial funding for the first time in 1993 (Lefrançois 2009).

There are currently 18 cochlear implant centres across Canada of which 12 are surgical sites. Those that are not surgical sites offer diagnostic and support services for residents who qualify for the surgical implantation.

Table 2.7 lists the sites by province, the year established and the number of annual surgeries/devices funded for residents as of 2009. In addition, there are a number of "extra" surgical spots allotted for out-of-province residents who do not have access to a surgical site within their province of residence. These "extras" are funded by the provinces or territories of those residents. For example, the Ottawa Hospital is provided funding by the Province of Ontario to perform 27 surgical implants to qualified Ontario residents. In addition, the Ottawa Hospital can also perform three "extra" surgeries for out of province candidates who do not have access to a surgical site in the province or territory of residence. However, it should be recognized that this technology has been around for nearly 25 years, consequently, cochlear implant devices age and can malfunction over time. The number of surgeries performed as listed in the table reflect not only new cochlear implants surgeries, but also re-implantation of new devices to replace older, non-functioning devices (Lefrançois 2009). 
q

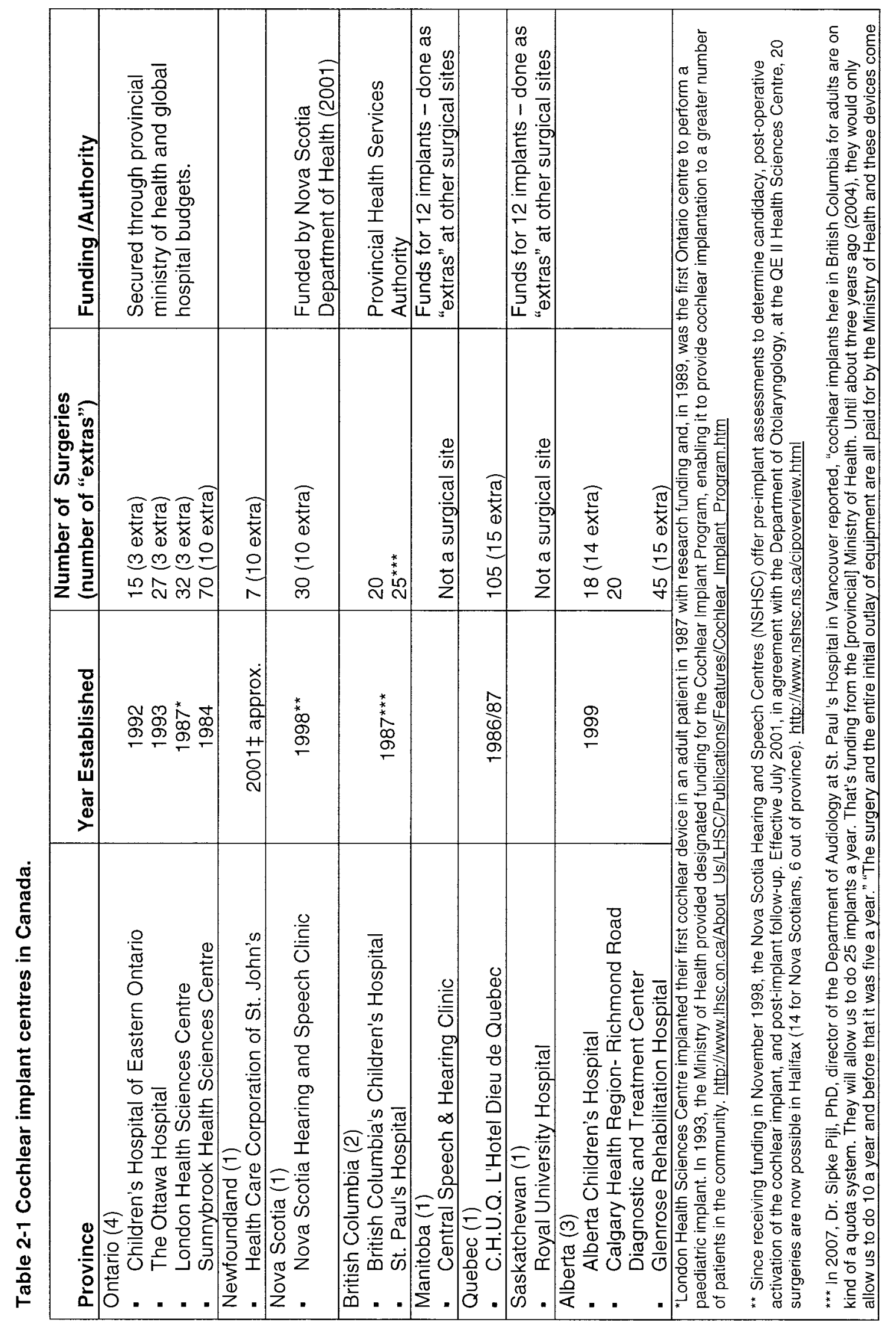


寸

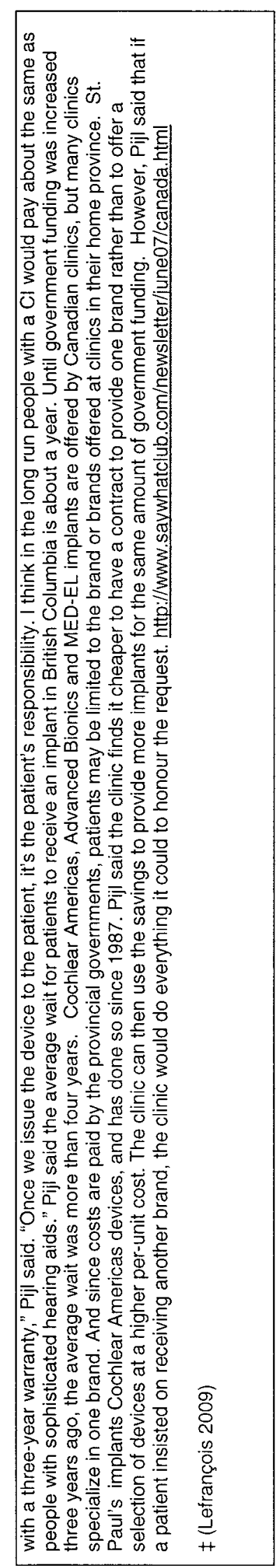




\section{Ottawa Hospital Cochlear Implant Program}

The Ottawa Hospital Cochlear Implant Program, which was established in 1993, had at that time, an informal waiting list of candidates for surgery dating back to 1989. The program, like others across the country, used the Health Canada approved criteria to establish candidacy eligibility for adults over the age of 18 . These criteria are based on the U.S. Food and Drug Administration (FDA) guidelines, and they have evolved over time. When the Sunnybrook program was established in 1984, candidates were required to have been diagnosed with a profound bilateral sensorineural hearing loss and obtain less than $20 \%$ speech recognition on sentence tests. In 1993, the criteria expanded to include candidates with a severe to profound bilateral hearing loss and less than $50 \%$ speech recognition on sentence tests. In addition, candidates must get limited benefit from hearing aids; have difficulty using, and/or find it impossible or have limited use of the telephone; find that speech-reading or note writing is required to understand speech, and be distressed by the inability to communicate efficiently on a daily basis ${ }^{4}$ (TOH 2008). As well, candidates should use spoken language as their primary mode of communication. At the time the Ottawa program was established, the number of surgical implantations performed was limited to five a year. Around 1997, that changed to 12 implantations a year. By 2000 , there was such a back-log of eligible candidates for the surgery that the Sunnybrook Hospital successfully lobbied the provincial government for additional funding. Consequently, the Ottawa hospital saw its annual funding increased to permit 20 surgeries per year in addition to a one-time lump sum to

\footnotetext{
${ }^{4}$ It is not clear how these criteria are defined or measured - JW
} 
cover the costs of an additional 20 implantations to reduce the backlog of patients waiting for this surgery (Séguin 2008). As of 2009, there is again a waiting list for this surgery at the Ottawa Hospital (Lefrançois 2009). There are currently two rooms in the Audiology clinic and three audiologists dedicated to the Cochlear Implant Program. If more money is provided to purchase additional implant devices, additional funds are still needed for further support resources to handle the increased volume. Interestingly, until 2009, funding for cochlear implant devices was based in US dollars - most likely because one of the two major manufacturers of the devices is American. With currency fluctuations between the US and Canadian dollar, the number of implants per year varied such that one or two more surgeries could be performed with a strong Canadian dollar or vice versa with a weak Canadian dollar. From 2009, funding for devices has been provided in Canadian dollars (Lefrançois 2009). Waiting times vary from centre to centre, and currently children have little or no wait time. Adults across Canada wait anywhere from 5 months to 3 years for an available device (Lefrançois 2009). See appendix E for a list of "Recommended Wait Times."

\section{Summary}

The theoretical concepts of structurationism and other related and influential ideas have been discussed. Based on consideration of these concepts and ideas, and an examination of social systems and structures as they relate to accessibility, a model was created to organize accounts of accessibility to implant technology for the purpose of this research. In addition, the macro and micro structural influences that have temporal and spatial attributes that can constrain 
access to the cochlear implant technology was presented. In the next chapter, strategies for operationalising structurationism will be presented and research methods discussed. 


\section{Chapter 3: \\ Methodology and Research Design}

This research attempts to elicit accounts or narratives of the experiences that deafened individuals have undergone with respect to obtaining a cochlear implant. This chapter briefly discusses the nature of qualitative inquiry. In addition, a model to explain access to the cochlear implant by those with a severe to profound hearing loss is presented. The strategies researchers have used to apply structurationist theory in empirical research are outlined. This leads to an overview of the case study approach that will be used to acquire biographies or narratives from those who have accessed the cochlear implant. The biographies provide a retelling of the history of the hearing loss, obstacles that had to be overcome as a result of being deaf in a world that is socially constructed for sound, and the process that led to getting a cochlear implant. From individual biographies, it is anticipated from each unique retelling of the story, patterns or themes will emerge that may lend themselves to creating a knowledge base that currently does not exist regarding access to this technology in Canada.

\section{Qualitative Inquiry}

Research activities historically follow one of two major streams, quantitative or qualitative: extensive or intensive. The relative merit and value of each of the quantitative and qualitative research paradigms is much debated in human geography. These paradigms are the frameworks that represent the "working 
assumptions, procedures and findings routinely accepted by a group of scholars, which together define a stable pattern of scientific activity" (Johnston 1994) ${ }^{5}$. Traditionally, research paradigms have been incorrectly identified as being either positivistic or phenomenological. It is widely, and erroneously claimed that logical positivism is an extension of the scientific Comtéan positivism philosophy. It is also known as quantitative research, and utilizes experimental and quantitative measures to test hypothetical generalizations (Johnston 1994; Hoepfl 1997). This approach contrasts with broadly phenomenological, or qualitative research, where investigators use naturalistic or qualitative approaches towards understanding phenomena in context-specific settings. Within this paradigm, qualitative methods are used to investigate a human experience, that is to elicit individual meaning of some phenomenon or subjective experience by methods of observation, interaction and interpretation.

Arguments arise between the two schools of thought and are attributed to the underlying assumptions that form the basis for each approach. Proponents of a quantitative positivistic approach to inquiry "seek causal determination, prediction, and generalization of findings" (Hoepfl 1997). This approach is based on the idea that "there is a singular material reality" (Patton 2002), consequently statements of findings will either be categorically true or false. This contrasts with a qualitative or phenomenological approach, one that is founded in a philosophy of meaning that seeks "illumination, understanding, and extrapolation to similar situations" (Hoepfl 1997). Proponents of this approach argue that quantitative

\footnotetext{
${ }^{5}$ Cited by Derek Gregory in The Dictionary of Human Geography, Ed. R.J. Johnston, 1994
} 
methodologies have failed to "reflect the complexities of human experience and action" (Gergen 2000). Gephart (1988) found that the fundamental belief of qualitative inquiry is "that what is true depends on one's perspective and is, therefore, inherently definitional, situational and internal" (Patton 2002). Thus, there is no single real world "that exists independently of the relationships between observers and the observed" (Johnston 1994) ${ }^{6}$. Consequently, methods used in qualitative inquiry take a more passive form, from observation, personal reflection and active participation on the part of the investigator.

Quantitative methods continue to be popular due to their seeming neutrality and rigorous application of statistical tests. Yet quantification is also criticized for those very same reasons - that the human subject of the research is overlooked and that investigator objectivity does not exist. The notion that "statistics don't bleed" (Livingstone 1992), leaves the impression that as an applications tool, it is more value neutral, thus it is more rigorous and "valid" than intuitive methods used in qualitative research (Livingstone 1992). Qualitative research as a method of inquiry has broadened the field of investigative research by introducing alternative, humanistic views. Consequently, researchers from many fields can take a number of methodological approaches to their research question borrowing from each of the paradigms.

Both qualitative and quantitative methods are used to tackle current issues in geographies of health (Pearce 2003). The long standing belief that one must

\footnotetext{
${ }^{6}$ Cited by Susan Smith in The Dictionary of Human Geography, Ed. R.J. Johnston, 1994
} 
align oneself with the methods of a single paradigm of inquiry has become blurred as researchers today are choosing to use a variety and mixture of methods from each in their research studies (Hoepfl, 1997) ${ }^{7}$. Patton (2002) argues that while there continues to be an epistemological debate among scientific and methodological philosophers regarding preferred methods for conducting research based on the paradigm that the researcher is operating within, it is acceptable to use different methods from within each paradigm and he calls this view a "paradigm of choices" (Patton 2002). In adopting such a paradigm of choices, researchers have more flexibility to explore the subject of their inquiry with more methods at their disposal. Accepting this argument gives researchers additional creativity and freedom to explore their subject matter in ways that are not typical for their discipline.

As this research is exploratory in nature, in that it seeks to discover how those with a severe to profound hearing loss accessed the cochlear implant, a qualitative approach is more useful. Using a model based on structurationist theory, this research investigates human experiences to elicit individual meanings of the accessibility experience.

\footnotetext{
${ }^{7}$ Strauss and Corbin (1990), Russek and Weinberg (1993) quoted in Hoepfl, 1997
} 


\section{Strategies to Conduct Structurationist Research}

Pozzebon (2005) reviewed twenty empirical IT research studies that used a structurationist theory framework, and asserted that across the board there are four common strategies.

Grounded strategies can "refer to any kind of inductive theorizing" (Pozzebon 2005). Used as a basis for theorizing within a structurationist framework, this is a data driven strategy that inductively grounds or positions concepts, explanations and theories in the "recursive process of collecting and analyzing empirical data" (Pozzebon 2005). It is useful when "researchers are able to collect detailed data from a large number of comparable events or processes" (Pozzebon 2005) and it can involve a recursive process that includes collecting rich data of similar incidences that allows for the systematic comparison and identification of categories or themes. Thus, explanation is inductively grounded from the analysis of the textual data.

Narrative strategies are those that can be used to organize and analyze research data. Pozzebon (2005) found that narratives are being used in empirical work not only to frame the chronology of the phases of the research but also as a tool for the analysis of the order of various phases and the connections between them. Additionally, the narrative is often used as the main product of the research. 
To expand general theories or patterns, visual mapping strategies can be used. These strategies require that the researcher has several cases that have a good degree of detail or description in order that they may be able to comprehend "how events shape processes across numerous cases or a few cases with several embedded events" (Pozzebon 2005).

The last strategy, temporal bracketing, can be further refined as fine-grained or broad-grained bracketing. The fine-grained or micro bracketing reduces events "into the effects of action on structures on the one hand, and the effects of institutional constraints on the other" over time (Pozzebon 2005). This micromacro bracketing technique allows for a breakdown of events over time. Broadranged or macro bracketing on the other hand, is "based on the analysis of sequences of events over time" without reducing the events to the micro level and this usually involves one or more cases that are detailed and can be followed over a longer period of time.

Pozzebon (2005) found that the strategies were usually combined and rarely used alone in empirical works, as each strategy gives "different and complementary understandings of processes". Referring to Langley (1999), he states that "some strategies seem best adapted to the detection of patterns in processes (e.g. visual mapping) whereas others seem more appropriate to examine driving mechanisms (e.g. temporal bracketing) and others are better for 
analyzing the meaning of the process for the people involved (e.g. narrative)" (Pozzebon 2005)

Figure 3.1 presents what Pozzebon et al. call a Repertoire of Strategies for Applying Structuration Theory in Empirical IT Research. Here, they have taken the four strategies that were found to be common among the studies examined and combined them to reflect the common methodological processes of each strategy. This model shows the interrelationships that exist between the sensitizing devices of structurationist theory; that is the duality of structure and agency in time and space and the strategies that can be used to understand or explain the process or phenomenon under investigation (Pozzebon 2005).

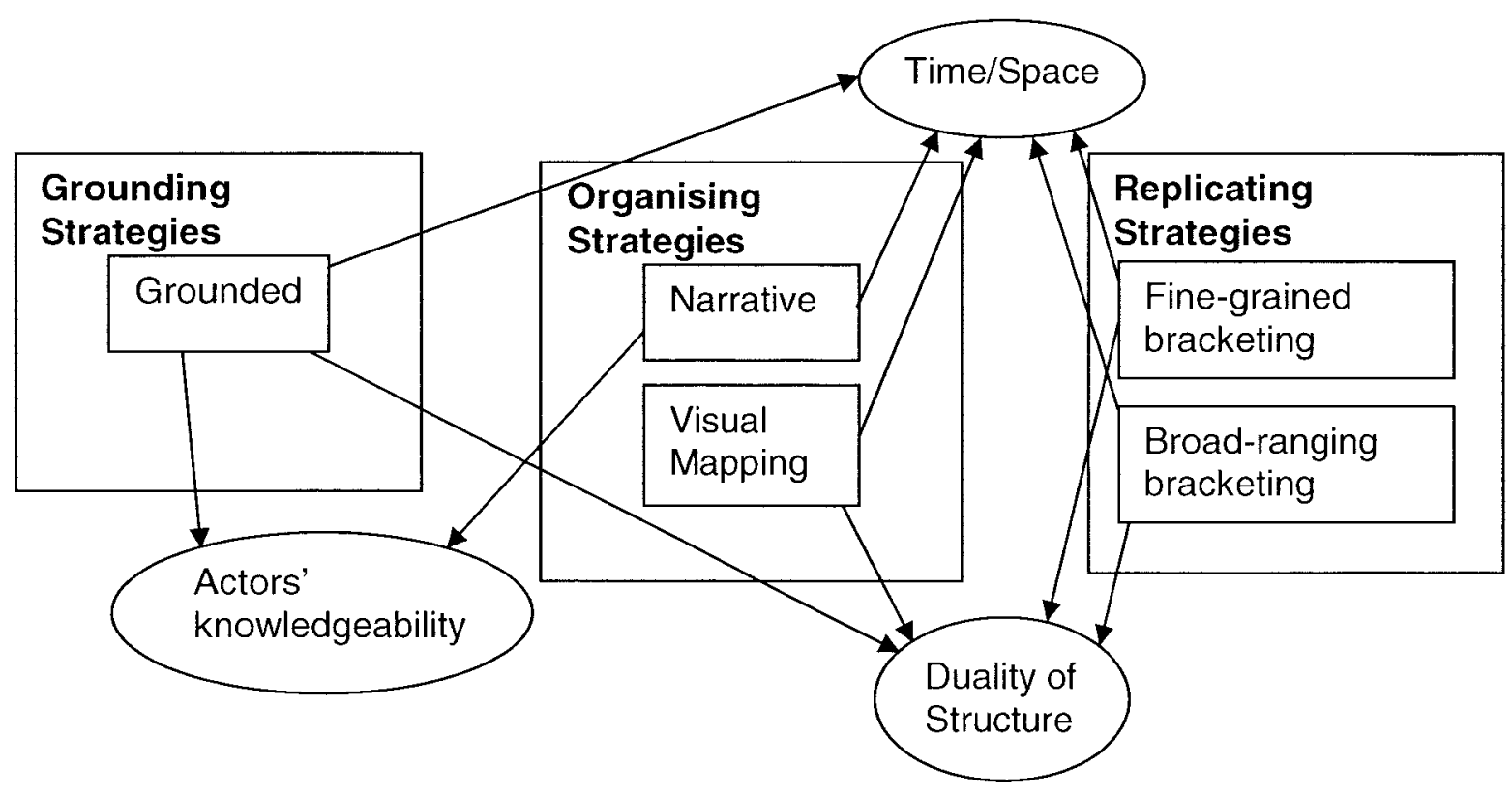

Figure 3-1 A repertoire of strategies for use in structuration theory. Each strategy has particular and complementary considerations of process that can overcome the difficulties in employing Structuration Theory (Pozzebon 2005) 
From this conceptual model of the methodological interrelationships of the structurationist theory framework, Pozzebon (2005) proposed a method to deal with the empirical challenges of the structurationist framework (figure 3-2). This method, or "repertoire of methodological strategies", can be employed by researchers in order to address each of the sensitizing features of structurationist theory in empirical work.

\begin{tabular}{|l|l|l|l|l|}
\hline $\begin{array}{l}\text { Sensitizing } \\
\text { Device }\end{array}$ & Grounded & Narrative & $\begin{array}{l}\text { Visual } \\
\text { Mapping }\end{array}$ & $\begin{array}{l}\text { Temporal } \\
\text { Bracketing } \\
\text { (Fine-Grained or } \\
\text { Broad-Ranging) }\end{array}$ \\
\hline $\begin{array}{l}\text { Duality of } \\
\text { Structure }\end{array}$ & Necessary & $\begin{array}{l}\text { Strongly } \\
\text { Recommended }\end{array}$ & Suitable & $\begin{array}{l}\text { Strongly } \\
\text { Recommended }\end{array}$ \\
\hline Time/Space & Necessary & $\begin{array}{l}\text { Strongly } \\
\text { Recommended }\end{array}$ & Suitable & $\begin{array}{l}\text { Strongly } \\
\text { Recommended }\end{array}$ \\
\hline $\begin{array}{l}\text { Actors' } \\
\text { Knowledgeability }\end{array}$ & $\begin{array}{l}\text { Strongly } \\
\text { Recommended }\end{array}$ & $\begin{array}{l}\text { Strongly } \\
\text { Recommended }\end{array}$ & & \\
\hline
\end{tabular}

Figure 3-2 Strategies to be particularly mobilized in structurationist theory.

Combinations of strategies suggested for dealing with each sensitising device (Pozzebon 2005).

The duality of structure is fundamental to structurationist theory. Consequently, it is an essential device for planning the investigation and interpreting the results. To address the duality of structure, Pozzebon (2005) "strongly recommends" using a combination of narrative and temporal bracketing strategies. In doing so, the narrative provides a rich description that provides the details of the phenomenon under investigation and allows for the observation of events over time and this helps to explain why events or situations occur. Bracketing strategies facilitate tracking of "subtle changes of structural properties" (Pozzebon 2005), that can be used to identify how and when changes occur. 
Pozzebon uses the example of Barley (1990) for dealing with the duality of structure. His research involved the investigation of the role of new technology in organizational change. Pozzebon (2005) found that it was the "strength of his analysis is his methodology", where he used grounded, narrative and finegrained temporal bracketing strategies to explain organizational change.

For dealing with the concept of time and space, Pozzebon (2005) suggests the use of the narrative and temporal bracketing strategies. In addition, grounded strategies "offer the foundations", and visual strategies can provide visual support. Pozzebon refers to research done by Orlikowski (1996), who wanted to show "how subtle shifts in action by organizational actors over a two-year period transformed aspects of their work practices, organizing structures and coordination mechanisms, and to show the implications of such shifts for the organization" (Pozzebon 2005). As a result, Orlikowski was able to offer a way of looking at the structuring of process, whereby slight changes in everyday actions can manifest into organizational changes over time.

Actors' knowledgeability, the concept that promotes social actors as knowledgeable and reflexive players, "is always incorporated in the daily activities that constitute social phenomena" (Pozzebon 2005). Using grounded materials and narrative strategies such as interview transcripts or field notes, one can seek the meanings of processes toward understanding "the role of people's 
reflexivity regarding day-to-day interactions" (Pozzebon 2005) and the bounds of the actors' knowledgeability.

Pozzebon et al. (2005) are instrumental in bringing together the conceptual basis of a structurationist research framework with a methodological plan for carrying it out. In effect, this work has laid the foundation and has removed the guesswork for those conducting research based in structurationist theory. In the following section, the case study approach to collecting the rich data necessary for this research is presented.

\section{Method}

This research uses a case study methodology, employing a semi-structured interview process to obtain narratives of deafened or hard of hearing individuals who have undergone cochlear implantation within the past five years. An interview guide was developed to facilitate the interview process with each subject and provide a systematic interview structure across the cases. Cases were selected using purposive sampling. Interviews were conducted with 15 subjects over a period of five months, from August to December 2007.

The case study approach to data collection and analysis has been well documented (Tellis 1997; Stake 2000). According to Stake, "a case study is both a process of inquiry about the case and the product of that inquiry". The case study is also "multi-perspective" (Tellis 1997) in that the researcher takes into 
account the related "groups of actors and the interaction between them" (Tellis 1997). Using a case study approach for this research project fits well within the framework of structurationism and allows for the identification of secondary actors and their roles in the accessibility picture.

Yin and Stake (1993), strongly recommend developing a methodological process to guide the case study approach (Stake 2000). For multiple case studies such as this, they also suggest developing a protocol that would include an overview of the case study project, field procedures, case study questions and a guide for the case study report (Tellis 1997). The components of the protocol used for this study are presented and explained below.

\section{Case Study Methodology}

In qualitative research there are three primary sources of data for case studies interviews, observations and documents (Merriam 2002). Since the objective of this study is to reveal individual 'experience' of access, interviews are the optimal source for obtaining in-depth and detailed information from subjects. Interviews can be structured in a manner whereby all respondents are asked the same set of pre-determined questions or they can be relatively unstructured, the interview proceeding in a conversational mode whereby questions arise from the immediate context (Merriam 2002; Patton 2002). Or, interviews can be semistructured with a mix of pre-determined questions along with some informal, thematic or conversational type questions. 
Open-ended questions allow for responses that can be detailed, lengthy and varied. The responses can "permit one to understand the world as seen by the respondents", and this, according to Patton (2002), helps to fulfill the purpose of the research study. In gathering and analyzing responses to open ended questions, researchers can gain an understanding of and capture the points of view of other people without predetermining those points of view through prior selection of questionnaire categories (Patton 2002). It is through intensive or indepth interviewing, using open-ended questions, that one can gather data of such breadth that they reveal "respondent's depth of emotion, the ways they have organized their world, their thoughts about what is happening, their experiences and their basic perception" (Patton 2002; Fontana 2000; Miller 1999).

In-depth interviews were the optimal method of data collection for this research. Using open ended and semi-structured questions enable the exploration of experiences of a select group of individuals. Justification for the use of this method can be found in the works of Miller and Crabtree (1999) who found using a depth interview approach to be a "powerful qualitative research tool when the focus of inquiry is narrow, the respondents represent a clearly defined ...unit with an already known context... and the goal is to generate themes and narratives" (Miller 1999). Kaufman (1994) describes in depth interviews as being similar to conversations with friends as they are "informal and engaging emotionally" (Kaufman 1994). In order to accomplish this, she suggests that "conceptual and 
substantive topics of exploration... be recast into open-ended questions designed to invite talk about the topic" (Kaufman 1994).

\section{The Interview Guide}

The interview guide approach to gathering data is created to "explore and answer questions pertinent to the research topic, problem or goal" (Kaufman 1994). Developing an interview guide allows for the inclusion of the themes and subjects that the investigator wishes to cover during the course of the interview with each respondent and helps to keep the research focused within a context which has the potential to become uncontrollably discursive. Interview questions are organized into a guide format that the investigator uses to ensure that all of the topics that need to be addressed as part of the interview are covered during the course of each conversation. Interview themes are noted in point form and the sequencing and wording of the thematic questions can vary from interview to interview as the interviewer attempts to create a naturalistic and conversational 'flow' to the interview (Patton 2002). It is anticipated that during the free flow of conversation, topics will be raised with and without prompts from the interviewer. The guide ensures that a level of consistency in a variable response environment is maintained for each interview conducted and that all themes are visited.

Questions incorporated in the guide are intended to facilitate the exploration of the respondents' experience of being deaf and obtaining a cochlear implant. The interview guide used for this research is located in appendix D. 
Five key questions were developed and included in the interview guide. The first asks respondents to talk about the story of their hearing loss. With this question, geographic, demographic and temporal details can be obtained and used to situate the experience of hearing loss in terms of location, time and employment/education, etc. Probes were used to prompt the respondents to clarify the temporal, structural and geographical details when retelling their stories.

The second question asks about the people involved in the respondents hearing care; health care professionals such as hearing aid specialists ${ }^{8}$, doctors, audiologists or others, over time. This question attempts to obtain a sense of who the actors are that are involved and what role they played, if any, in terms of providing or guiding the respondent towards access to the cochlear implant. In asking this question, one must recognize that cochlear implant technology is relatively new and if the age of the participant is such that there is a lengthy period of deafness, the actors involved in their care will reflect the knowledge of the day in their profession. This question can help present changes over time in how interactions with health care professionals and hard of hearing or deafened persons have evolved as a result of changes and advances in hearing technology as well and how this can impact accessibility. Prompts used in this question included asking participants how often they saw the people involved, what was said, their profession, what was suggested to improve hearing ability if

\footnotetext{
${ }^{8}$ Hearing aid specialists have also been termed "hearing aid fitters", "hearing aid dispensers", "hearing aid dealers" or "hearing aid vendors". JW
} 
applicable, such as adaptive devices e.g. hearing aids and the structures these individuals operated within. Knowing the location and situation of the people involved in each respondents hearing care is necessary in order that they may be situated within the structurationist framework model.

The third query asks respondents to retell the story of their experiences that led to the cochlear implant. Here, the attempt is to elicit the events in time and space and the interactions that led to accessing the cochlear implant. Probes included questions about what started or prompted them to think about this technology; were there difficulties at school, work or elsewhere that were encountered during this time that influenced their actions.

The fourth question asks how the respondents first learned of the cochlear implant technology. This question was often answered in conjunction with the previous question, however, here we want to know the source, and probes used include family, friends, internet, physician or other and how long they had known about the technology before actually speaking with a doctor or audiologist about it.

The final question asks how respondents made the decision to have the surgery. Ideally, answers to this question will provide a sense of how the decision making process evolved; was it a quick and positive decision, did it take much consideration, was there uncertainty about the process, etc. 
It is important to recognize that this approach is not without its weaknesses. Patton (2002) finds that the unstructured nature of the interview, while providing a "richness" of data, can lead to an oversight in covering pertinent topics and that depending on the wording and sequences of questions asked by the interviewer, the responses between respondents can vary, making it difficult to compare for analysis (Patton 2002).

\section{Sensitivities}

As the intensive interviews with study participants consisted entirely of hard of hearing respondents, recognition is made of a number of sensitivities. While having a cochlear implant aims to restore some hearing, it is not a cure for hearing loss - it is an assistive device much like a hearing aid. For some, the hearing loss is seen as a disability, while others might have a different perspective. In preparing for the interviews, there is the awareness that the experience could be emotional for some people as dealing with the issues of disability can bring on very powerful feelings (Miller 1999).

In addition, medical barriers to communication may be present in that the levels of hearing experienced by each respondent will vary. In anticipation, interviews took place in a quiet environment that allowed for speaking louder while maintaining privacy of the conversation. 


\section{Sampling}

Case study research is not sampling research (Tellis 1997). Rather, case studies tend to be selective, focusing on one or two issues that are fundamental to understanding the system being examined" (Tellis 1997). Selection then should be carried out to get the most out of what can "be learned in the period of time available for the study" (Tellis 1997). Patton (2002) suggests that it is important to choose "information-rich" cases in order to undertake an in depth study and terms this 'purposeful sampling'. Since this study aims to elicit a biography or narrative of the experience of access to reveal the various routes of access to a relatively uncommon good and the patterns of similarity and variation, different experiences or biographies are warranted. This study takes a purposeful approach in order to obtain the most information about this distinctive 'phenomenon' (Merriam 2002). Ideally, the selection procedure or interview process of cases using the purposeful approach continues until no new information about accessibility and related themes is reached. However, as the point of saturation is unknown at the onset of the project and given the limitation of finite time and financial resources available to conduct this research, the case study was limited to 15 participants.

\section{The Pilot}

Once the interview guide was drafted and reviewed by the thesis supervisor and Christiane Séguin, the Coordinator of the Ottawa Cochlear Implant Program, pilot interviews were conducted in June 2007 with two people known to me who have 
had a cochlear implant in the past five years. The purpose of the piloting was to test the appropriateness of the phrasing and language of the questions in the interview guide and to get a sense that the questions were eliciting the information needed for the study. By conducting these pilot interviews, changes to improve the interview guide could be made before conducting the case study interviews. The first pilot participant was an elderly woman who had no difficulty responding to the first two questions that asked about her hearing loss and the people that had been involved in her hearing care. However, when asked about the story of her experiences that led to the cochlear implant, the respondent drifted off topic and was vague about details, necessitating a revisit of the question several times to get an appropriate answer. Question five was also problematic for her. The question asked about how she arrived or made the decision to have the surgery and again the response was vague with the subject having difficulty pinpointing how or when she made the decision. Reflecting on this pilot interview for possible ways to improve the interview guide and discussing the pilot interview outcome with colleagues, it was felt to leave the guide the way it was and pilot it again. The second pilot interview was carried out with a mid-aged man who had no trouble understanding and responding to the questions as written in the interview guide. Based on the results of the second pilot interview, the interview guide was felt to be appropriate for use in the case study interviews. 
An application for ethics approval was prepared and submitted to the Carleton University Ethics Board in April 2007. Ethics approval was received in May 2007 with a stipulation that ethics approval also be obtained from the Ottawa Hospital Research Ethics Board as the subjects for the case study are patients of the Ottawa Hospital. An application for research ethics approval was submitted to the Ottawa Hospital Research Ethics Board in July 2007 following the piloting of the interview guide. Ethics approval was received July 18, 2007. As case selection started, it was realized by the Coordinator of the Ottawa Cochlear Implant Program, that the wording in the ethics application stated that participants would be contacted by letter or telephone prior to their next appointment at the Ottawa Hospital audiology clinic. Based on her experiences communicating with patients, it was determined that e-mail correspondence was preferable to a mailed invitation to solicit potential participants. Consequently, an amendment to the study protocol was submitted to the Ottawa Hospital Research Ethics Board to include the use of electronic mail to contact and invite research participants to this study. The amendment was approved in August 2007.

\section{Recruitment}

Cases were selected by members of the Ottawa Cochlear Implant Program audiology team at the Ottawa Hospital. Case selection was limited to English speaking adults (18 years or older) with a severe to profound hearing loss who had had a cochlear implant within the past five years (2003-2007) at the Ottawa Hospital. 
Excluded were children or those participants who had not been implanted within the select time period or who did not speak English. Potential participants that met the selection criteria were sent a letter of invitation along with an information and consent form via electronic mail three weeks prior to a scheduled follow-up visit to the clinic. Those candidates who agreed to participate, communicated their acceptance to the audiologists, who set up the interview appointment either immediately prior to or following the respondents scheduled clinic visit.

\section{Interviews}

Fifteen interviews were conducted at the Ottawa Hospital with people who have had a cochlear implant between 2003 and 2007. Interviews ranged from thirty minutes to just over an hour and they were audio-taped using a digital voice recorder. Notes were taken during the interview and a summary of each interview was completed immediately afterwards to allow for reflection of the content and the investigative process as a whole. The initial two pilot interviews that were conducted were not transcribed and are not included in the analysis of this research. Technical difficulties with the digital recorder on two occasions resulted in the loss of two interviews. One respondent had an extremely strong accent that made transcription difficult. Consequently, a decision was made to discard this interview.

The remaining ten interviews were transcribed verbatim by an experienced medical transcriptionist. 


\section{Analysis}

Perhaps the biggest challenge of any qualitative research study is the analysis of the data (Patton 2002). Patton asks 'how does one make sense of the large amounts of data that is gathered?' and suggests that one method is to reduce the volume of information by reviewing the data and attempting to identify emerging patterns. Patton continues that there are few rules or standards for the analysis of qualitative data and that the best that can be asked of any researcher is to do the very best that you can with your intellect to 'fairly represent the data and to communicate what the data reveal - given the purpose of the study (Miller 2005).

The identification of themes is fundamental in qualitative research (Ryan 2003). Ryan and Bernard (2003) describe the beginnings of analysis as a "pawing" through the transcribed texts several times to highlight key phrases that seem to make some sense on an intuitive level to the purpose of the study and state that pawing "is one of the best ways we know of to begin hunting for patterns in qualitative data" (Ryan 2003).

The analytical process used for this research was continual and inductive. The data came from the transcribed recordings of each interview as well as from notes made during the interview of examples of talk or events mentioned by respondents that supported or countered the overall themes of access to cochlear implant technology. In addition, a post-interview summary of findings was written to record what I considered to be key points made during the 
interview by the respondent - and also to note my thoughts on the interview content and the overall process. In retrospect, the summaries tended to note pertinent points made in response to each question asked; what went well or did not go well in the interview; what comments were interesting or unexpected; my perceptions of the clarity of the responses, etc. These notes and summaries formed the basis of the individual case record along with the transcribed interview data.

The collection, analysis, and reporting of qualitative data requires consistent, diligent attention in order to ensure a rigorous study (Kaczynski 2004). There is in qualitative research today, an increasing use of qualitative data analysis software (QDAS) as a tool for use in the interpretation and analysis stages of research. While most qualitative researchers agree that a concentrated focus on a study's purpose and adherence to an agreed upon conceptual framework are critical to a rigorous study, few agree on the appropriate use of QDAS in this process (Kaczynski 2004).

Initially, it was felt that there would be copious amounts of information and that this warranted the use of a qualitative software program to sort through the data to help provide an audit trail and enhance the methodological rigour of this work. Consequently, Nvivo QDAS was purchased to assist in the data management of the case records and the overall analysis. The Nvivo7 analysis tool is designed for category development, coding and retrieval of coded data. Following an initial 
"pawing" of the data, the researcher identifies emergent themes and enters these into the Nvivo7 program to create an axial coding structure of broad categories into which text from the interviews can be coded or assigned. These broad categories or themes then form the unit of analysis for the research. This software is designed to be flexible, enabling the modification and fine-tuning of the coding structure as other related or interdependent thematic categories emerge from the data. While using QDAS has been criticized by some for providing a patina of "legitimisation" and quasi-scientific rigour (Kaczynski 2004; Bazeley 2007), Bazeley (2007) argues that while the use of a computer for qualitative analysis can "contribute to a more rigorous analysis", it does not make the research process "rigorous", rather it is the "human factor" that plays a part in scientific rigour as poor research skills cannot be blamed on the tools used and vice versa (Bazeley 2007).

After "pawing" through the transcripts and notes of each case record to identify common themes and patterns from the re-telling of each respondent's knowledge and experiences within and across the cases, it was possible to sketch or map a list of these broad ranging and fine-grained themes that emerged. This was a lengthy process and meant re-visiting the texts numerous times to refine and justify the themes till I was satisfied that I had captured the full spectrum. At this point, I started to enter the themes into the Nvivo7 software program and realized that by imputing the data, I was not only I re-doing the work I had just done on paper, I was also experiencing a separation from the data; a phenomenon also 
reported during the early years of QDAS development (Bazeley 2007). On reflection, I was comfortable pawing the data by hand; the volume was manageable and I was able to visualize and organize my findings well on paper using sketches and diagrams to depict themes and relationships in the data. Consequently, I debated the use of the QDAS to help with my analysis for this project. My main concern was that in my mind, using the software would contribute to the methodological rigor of this project, yet after much consideration, I felt confident in my own analytical abilities as the volume of data was not excessive and the narrow focus of the research question precluded copious analysis. Thus, I opted not to continue using the analytical software tool.

\section{Summary}

Qualitative research methods have been discussed and strategies to conduct structurationist research have been presented. The methods employed in this case study have also been described. In the following chapter, the narratives of the study participants are introduced. 


\section{Chapter 4: \\ The Narratives}

The narratives provide a re-telling of respondents' perceptions and experiences of their hearing loss and how they came to access the cochlear implant technology. This rich description of the actors' knowledgeability and the use of grounded or bracketing strategies allows for the identification of emergent themes or patterns within and across the cases that are reflective of the participants knowledge, experiences and daily activities as they move around within the rules and resources of the social and medical systems. From the narratives, we can piece together some common access pathways that lead the respondents to the Cochlear Implant Program at the Ottawa Hospital.

\section{Across the cases}

In all, there were thirteen participants in this case study excluding the two pilot interviews. Ten of the interviews were transcribed and three were based on notes taken during the interview. Their ages ranged from early 20's to mid 70's and were almost equally representative of both sexes. All of the respondents resided in the geographical catchment area of the Ottawa Hospital Cochlear Implant Program which includes the eastern and north-eastern regions of Ontario. While the majority of participants were from Ottawa and nearby areas, several were from more distant towns near Kingston and Sudbury. 
There was diversity in the range of daily activities and routines of the participants. One respondent had just finished school, several were still part of the work force and the rest were retired. The types of hearing loss varied between respondents and ranged from degenerative losses originating in childhood to progressive adult onset hearing losses. Causes of hearing loss included allergic drug reaction, prolonged and unprotected exposure to noises from heavy machinery/artillery, meningitis, genetics and the general effects of aging. All the respondents were involved in the community in one sense or another until the progression or sudden onset of the hearing loss made that difficult to endure. The following section introduces the respondents and provides a snapshot of their unique situations with respect to their hearing loss.

\section{The Respondents (Actors)}

\section{Martin (1)}

Martin is a married, retired man who spent his career with the Canadian armed forces and is now living in the Pembroke area where he farms and raises horses. Martin lost his hearing initially in one ear around the age of twenty-five. He attributed the loss to the noises of tanks firing in training and using "heavy weapons", namely the "106 recoilless rifle, which was so loud they were unbelievable" in the early 1960's. Hearing protection was not thought to be necessary in those days. By the time Martin retired from the forces in 1979, he had lost all hearing in his right ear and the hearing in the left ear was "starting to go". 
Martin started to use hearing aids out of a sense of frustration that stemmed from his inability to hear at Legion meetings. He questioned himself about his continual attendance, asking "why am I here, you know?" when he cannot hear what is being said by the speakers at these meetings. The hearing aids that were to help him hear, were in his words, ineffective; "they gave me the best they could give me and it still wasn't doing the job". Frustration with his hearing aids led to a visit with the audiologist to adjust the remote for his hearing aid to "help him hear better" and that is when (the audiologist) brought up "maybe we can test you for a cochlear implant".

\section{Anita (5)}

On vacation in Scotland, Anita a retired woman from Ottawa became ill quite suddenly with meningococcal meningitis and septicaemia (sic), both relatively rare and dangerous systemic bacterial infections. Hers were serious infections that hospitalized her for five months. Those who survive such an infection "can suffer severe consequences associated with brain damage: blindness, deafness, paralysis and mental retardation" (MRFC 2008). In Anita's case, she lost her hearing as well as some hand and foot extremities that were amputated as a result of repercussions stemming from the infection. During her lengthy hospital stay, Anita acquired a nosocomial infection which caused further systemic injuries; consequently her rehabilitation process was extensive.

While in isolation and intensive care, communication with Anita took a written form. Whiteboards and notepads were used by others to "talk" to her and she 
was able to respond in her own voice. In some way, Anita thought that perhaps her inability to hear would be treated by the doctors like the rest of her body and somehow her hearing would return in some form. But as time went on with no improvement in her hearing, the frustration built as a result of the reliance on written communication, and Anita became pre-occupied with her hearing loss and having someone deal with it medically. She retells her acceptance of the loss when she says "finally I realized that I just wasn't hearing. Everybody was having to write things down," and says, "the big deal became when are they going to do something about my hearing?"

Anita waited three months for an appointment with an audiologist who worked several floors below her hospital room and her dismay is illustrated when she says, "I was a little shocked that I was having to wait that many - I mean I was getting all this immediate attention and (inaudible) myself and all this stuff and yet when it came to it I had to wait my turn kind of thing." Fully expecting that hearing aids would restore her hearing somewhat, Anita was looking forward to the appointment with the audiologist. Anticipating that she would have a hearing test and a suitable hearing aid would be selected, Anita did not expect to be told that she was deaf and that "there is nothing, there's no hearing aids that are going to help you hear, you are deaf".

\section{Sylvia (6)}

Sylvia is a married woman in her 30's who lives near Renfrew and commutes daily to her job in Ottawa. At age five, her mother noticed that she wasn't 
pronouncing her words properly and took her to the Children's Hospital of Eastern Ontario (CHEO) for hearing tests. Being such a young age, Sylvia cannot recall all the details but does remember that she was given a hearing aid for the right ear and that several years later she received another aid for the left ear.

As a teenager, Sylvia was quite self conscious about wearing hearing aids. In high school, she "wanted a normal side" and "stopped wearing the left hearing aid". While Sylvia regularly saw audiologists and doctors at CHEO growing up, there was a period of fifteen years where she did not see an audiologist. "I didn't really have an audiologist. I went to a hearing aid clinic when I needed one. I didn't really follow-up". Her rationale and indifference for this is clear in her comment "so what are they going to tell me, you're deaf?"

Sylvia's attitude towards her hearing changed after a meeting at work. "One day we had this big meeting. It was a lot of people in the room and I had to be really involved in it and it was really, really hard and I thought okay, well you know career wise this isn't going to work because the more I was there the more meetings I found happened and I had to be involved. I couldn't just passively sit back and pretend to follow them and you know you can get away with that up to a point and it just wasn't working anymore". Sylvia's frustration led her to research her options and through her internet search she came across a link to 
the Civic Hospital on a web-site and used the contact link to e-mail the Ottawa Cochlear Implant Program.

\section{Don (7)}

Don is a recently retired middle-aged man who resides with his wife in Ottawa. A year prior to this interview, Don had an adverse drug reaction to an antibiotic prescribed for a toe infection. Initially thinking he was experiencing a head cold while taking the antibiotics, the effects of the drug reaction "killed the cells within the cochlea" and his hearing started to diminish. Within three weeks he completely lost the hearing in his right ear. While being treated for the toe infection and drug reaction in hospital, Don was referred for a hearing test and was measured for a hearing aid in the left ear. In the two weeks that it took for the new hearing aid to arrive, Don lost all his hearing in the left ear. In his words, "so in five weeks I totally lost everything". Sometime during the next two months, Don started to look for help with his hearing loss. "I came and I saw one doctor here (Ottawa Hospital) and he said well an operation won't help...he said well I'm not going to recommend an operation". Don continues, "but then I saw another audiologist and she said well you know you should see a doctor who does that (cochlear implantation)". Later Don corrects himself and says that the first doctor he saw that did not recommend an "operation", saw him while he still had some hearing in his left ear and suggested the hearing aid and that after he lost the hearing completely he saw the audiologist. Don was not sure what kind of doctor he saw initially but thinks it was an audiologist that did not recommend the "operation". 


\section{Michael (8)}

Michael is a retired married man in his mid 70's who lives in the Ottawa area.

Michael started to lose his hearing when he was fifty, hearing bells and a whistling sound intermittently in one ear. Over the next two years, there was a progressive loss; "I'd go in meetings and I couldn't hear everything that was going on especially when there was a lot of talking and stuff". What prompted Michael to "go for a hearing aid" was an incident involving the Deputy Minister at work. "...my boss who was the Assistant Deputy Minister and the Deputy Minister asked me a question and I said "no" when I should have said "yes" and my boss said "Michael, l'm sorry you meant "yes" - since I hadn't heard the bloody question properly".

Michael continued to lose his hearing progressively. Several years ago, when frustrated by hearing aids that "didn't get to be good enough" he expressed his disappointment with the hearing aids to the hearing aid "representative" at the hearing care centre and was told "the two (hearing aids) I had were "the best in the west, okay, top of the line, there was nothing better" and when Michael then asked about the cochlear implants he had heard about, the representative replied "yes and you seem to be a good candidate" (for the implant).

\section{Patricia (9)}

Patricia is a young woman in her mid-twenties from the Kingston area who was diagnosed at 17 months with a severe hearing loss. Near the age of three or four, 
Patricia got her first hearing aids. At the age of 12 , after an ear infection, Patricia suffered "a huge drop" in her hearing ability. Consequently, "they were trying to get my Mom to look into me getting a cochlear implant, but my Mom didn't want to jump in and make that decision for me."Patricia managed well enough with her hearing loss to finish school and start working, but had a difficult time coping, "keeping a job has been a struggle because I can't communicate well on the phone so that kinda made my confidence in myself to be down big time". This prompted a conversation with her family doctor who felt that something needed to be done to help her with her job and put her in touch with an otolaryngologist (ear, nose and throat doctor), who "decided, okay, you need to look into getting a cochlear implant because that's pretty much your only option".

Phil (10)

Phil is a retired man from North Bay who is married with children and grandchildren. Phil began to lose his hearing nearly 25 years ago while still working and has worn hearing aids for nearly as long. Phil has a long history of frustration with hearing aids. "I kept getting new hearing aids and then I seemed to be better but then they weren't better over a long time they weren't doing the job." After a visit to an audiologist in North Bay, Phil "got a digital hearing aid and was really disappointed you know because heck you pay $\$ 1800$ - for it to do something and it wasn't helping". The audiologist said there was "nothing more they could do for him" when Phil mentioned his disappointment, though she did 
suggest "that he would be a candidate for cochlear implant maybe and so she started off everything".

\section{Jackie (11)}

Jackie is a woman in her fifties, originally from Nova Scotia and now retired and living just outside the Ottawa area. Diagnosed at the age of eighteen with a hearing loss by an "ear doctor, a specialist in New Glasgow", who after testing her hearing, said that "a hearing aid probably wouldn't help, it's for old age deafness". Shortly after she started her first job as a nurse in a hospital at the age of twenty-one, Jackie asked a doctor there "if I could get a hearing aid maybe". She was fitted for a hearing aid and found it helped her at work. In the ensuing years, fistulas in her ears contributed to further hearing losses and Jackie had surgery performed on these fistulas to try to stem the hearing loss. Finally a terrible ear infection and a further drop in hearing led her to ask to be referred to a specialist. Thinking the referral would be someone in Ottawa, Jackie was surprised when an appointment was made with an otolaryngologist in Brockville. Seeing the small office and older doctor, Jackie's initial reaction was a sense of disbelief ("oh boy") about her surroundings and wondered, "why didn't they send me to Ottawa"? To her surprise, "he was just a fantastic doctor" and "he took the time with me to really understand what I was trying to tell him which a lot of people haven't done and he just looked at me and he said "do you know you probably qualify to have a cochlear implant?" 
Lise (12)

Lise is a woman in her forties who was living in the United States when she was first diagnosed with a hearing loss at the age of six. A body aid was Lise's first hearing aid, a harness type device that is worn across the body, "that felt like a bra... eight years old and here I am with this harness, and of course the children were teasing me on the playground so I would keep it in my little purse and I only put it on during class time in grade school. I hated if'. Eventually, her mother got her a behind-the-ear hearing aid and Lise was "happy with that". Lise was "in the mainstream program" at school and took speech therapy growing up. She went on to college which "was a struggle". Eventually, Lise "decided to go to the National Technical Institute for the Deaf in Rochester, New York when I was about 27 and I finally learned sign language so this is great. I was meeting people like myself so it was a cultural shock". Lise thrived in this environment. On reflection she says "I'm hanging out with people like myself so that well I love this a lot". Later she moved to Canada and over time her hearing loss progressed further to the point that "nobody could offer me a hearing aid that I was happy with". In her frustration trying to find a suitable hearing aid, Lise went to a number of different hearing aid dealers in Ottawa. A friend who worked at one dealer "was really honest with me and said actually there is nothing we can do for you. There's no stronger hearing aid for you. He didn't say anything about cochlear implants". At one dealer, she enquired about the cochlear implant and was told "you can't have a cochlear implant - you wouldn't want to". Struggling with her 
hearing and unhappy with the hearing aids, Lise turned to the internet and found the Cochlear Implant Program at the Ottawa Hospital and sent out an e-mail.

\section{Paul (13)}

Paul is a middle-aged man who started to go "deaf" in his twenties. Paul's hearing loss is probably hereditary as his grandmother; father and brother are also deaf or hard of hearing. As Paul's hearing loss progressed, he turned to hearing aids and was able to manage at work well enough. A music lover and amateur radio enthusiast, Paul's hobbies and sense of enjoyment centered around being able to hear well and communicate with others. As his hearing loss worsened, his inability to enjoy his hobbies "put a damper on things and I started to get really depressed". While he continued to work, eventually he couldn't use the phone anymore at work and "had to hire somebody to answer the phones". In 2004, he quit his business as it was "too challenging" and he had "lost a lot of my clients".

At the suggestion of someone Paul met at a party who works for the Canadian Hearing Society, he went to see about another hearing aid. When the new aid "didn't help me, they suggested I come to see Christiane (Audiologist at the Ottawa Hospital) and get in the program because they said you will qualify (for a cochlear implant) no doubt." 


\section{Awareness of Technology and Access pathways}

The experiences of the respondents in their journeys to improve their hearing can be organized into three thematic paths. The most common access path is one that respondents "stumble" upon. In five cases $(1,5,7,10,11)$, the respondents were either unaware of, or vaguely aware of, the cochlear implant technology and through either some level of frustration with existing hearing aid equipment or hearing ability, were told of the technology when trying to resolve these issues. In one case, the respondent (8) was marginally aware of the technology through the media and enquired about it when frustrated by the limitations of his hearing aids. In three cases, respondents $(9,12,13)$ were well aware of the technology; however, through either perceived negative perceptions of the technology, inability to make decisions, or unawareness of candidacy, did not pursue access until some critical point was reached. Consequently, these people became "seekers" of the technology. In only one case (6) was there a true "seeker" who actively sought a solution to improve her ability to hear via researching the issue of hearing loss on the internet and discovering the technology. These thematic paths and other emergent themes are organized and presented in table 4.1.

The following are accounts of those who "stumbled' upon the cochlear implant technology.

Part of Martin's social identity is based in his membership and participation in the (Royal Canadian) Legion, and we can see when he remarks, "I was so dedicated to the Legion..." His desire to participate is so strong that he continues to go to 
meetings though he no longer enjoys the experience because of his inability to hear. Motivated by his frustration in his inability to actively engage in Legion activities, as a result of what he perceives to be technological limitations of his hearing aids, Martin stumbles towards access as he asks the audiologist to increase the volume on his hearing aids. From Martin's wife, who was present during the interview, the following is her recount of Martin's experience trying to improve the volume of his hearing aid so that he could hear better:

"So last year the thing he had was like a remote thing that you could adjust. So you had to bring it in and you could adjust it on the computer if you needed so we were in for that reason to help him hear better, and then that's when (the audiologist) brought up "maybe we can test you for a cochlear implant, to see if you're eligible."

By engaging the audiologist, Martin "stumbles" on the discovery that hearing aids have finite limits and that he has reached those limits. He also learns of a "new" technology (cochlear implant) that surpasses the restrictions of the hearing aid and that he may be a candidate for this.

In Anita's case, she is confined within the structural processes of the healthcare environment as a result of a sudden and debilitating illness that requires intensive and lengthy health care resources to address numerous complications and provide an environment for rehabilitation. Anita is physically constrained by the numerous treatments and surgical interventions she has undergone to resolve a variety of serious health conditions and endured a lengthy hospital stay. Communication with family and other agents within the health care structure is a physical and emotional limitation that Anita had to deal with as a result of the 
associated hearing loss. Frustrated that she is able to speak, but not hear and dependent on written communication forms that are slow and sustain only poor communication with and between members of her health care team, Anita became convinced that her hearing loss would also be resolved through some medical intervention just as her other medical conditions were treated. Thus, while Anita did not actively seek a solution to her hearing loss herself, she was reliant on and had every confidence in the structural processes of the health care system to do so in the provision of care. When the time came to address her hearing loss medically, she was told that there was no medical solution. The finality of that statement was "the worst point" for Anita. So much so, that it appears Anita might have expressed an emotional response to the bearer of that news, as this person, who was not clearly recognized in the interview but later identified as an audiologist, acknowledges her disappointment and takes it upon herself to look into a possible solution for Anita.

"I went down fully expecting to get a hearing test and them saying "well we'l have to find the right hearing aid" and away we go kind of thing. I had no idea, it never crossed my mind that they would say "there is nothing, there's no hearing aids that are going to help you hear, you are deaf." Uh, from all l'd been through that was my worst point I think and to this day if people ask me about the meningitis, it was the terrible, terrible disease.... and yet I have to say that losing the hearing was the hardest part."

"So I didn't know but there was a girl that I saw now was it at the Ottawa Hospital and she said she felt bad and she said "let me look into this and see you know if there's anything we can do. I've got something in mind but I don't want to say until I find out". So then she said "well, I'll see you again", so she did see me the following week and she said "there is something called a cochlear implant" which l'd never heard of and uh she said "I think you may be a candidate for that." 
Thus, Anita "stumbles" on the cochlear implant, a technology that she was not aware of and had not considered as a possible solution to her sudden and permanent hearing loss.

Like Anita, Don was also situated within the structural setting of the health care system, receiving a great deal of medical attention during the five week period when he lost his hearing as result of an adverse reaction to an antibiotic prescribed for a toe infection.

I thought that I was developing a head cold and my hearing was sort of slowly going. It was sounding like a cloud in my head just like a head cold and uh little by little I got this and it seemed to be getting worse. I was taking antihistamines and things and then finally with this Clindamycin it started to make me vomit."

He had been admitted to hospital and had numerous investigations done for a number of health conditions. Consequently, Don came into contact with various health care specialists. When he met with the physician who was treating his infection, and who was aware of Don's hearing loss, he recommended that Don have a hearing test. Thus, Don did not actively seek a solution to his hearing loss; rather it was through the actions of the agents operating within the health care system that investigated the possibility on his behalf. In Don's words:

"So I had a hearing test done here and they said it was ya I had gone down a lot and so I should try a hearing aid. So I got measured for a hearing aid.....and I came back two weeks later to pick up the hearing aid and I had absolutely nothing in any ear."

"By the time I came back to get it put in it (hearing) was totally gone. They sent me - the gentleman sent me back upstairs here to go through the test again and then they determined that there was nothing in either ear." 
Don was sent back to the audiologist who confirmed the hearing loss and made arrangements that day to meet the surgeon who performs the surgical cochlear implantation. When meeting with the audiologist, the subject of the cochlear implant is brought up and this marks the first time that Don is made aware of the technology. As he says:

"I think it was suggested first that it might be a possibility and of course at that time I didn't know what a cochlear implant was."

At no time does Don place any blame on the agents of the health care system for his hearing loss or express any related constraints. Quite clearly, he persisted with the recommended treatment for his toe infection even though he was sick after taking one of the prescribed antibiotics. The realization that he was not getting a head cold (to which he had attributed his hearing loss) came only after he was admitted to hospital for an unrelated medical condition. Don was able to cope well with his hearing loss, carrying an erase board for others to use to communicate with him.

Phil also stumbled on the technology as he, like Martin, expressed frustration with his poor hearing ability due to the technological limitations of his hearing aids. As he says, "I you know kept getting new hearing aids and then I seemed to be better but then they weren't better over a long time they weren't doing the job." After spending $\$ 1800$ for a new digital hearing aid and still experiencing difficulties, he complains to his audiologist, who in turn tells him "if that (new digital aids) doesn't do it uh then there's nothing more we can do for you as far 
as hearing aids. That was the latest technology", then states that "he would be a candidate for cochlear implant, maybe and so she started off everything and it took off from there." Phil admits, "at first I know I wasn't too anxious to have it. I didn't know very much about them."

Jackie resides in a town south-west of Ottawa. With a long history of hearing losses, she was looking for help as she had recently experienced changes in her hearing as a result of a severe ear infection and was referred to a specialist when she was first made aware of the cochlear implant.

"So they sent me to this doctor in Brockville... He said "do you know you probably qualify to have a cochlear implant?" He said, "do you know what that is?" I said I have a vague idea but I thought you had to be profoundly deaf in both ears and I considered myself to be moderate to severe because I managed."

Jackie was self-conscious of her hearing loss from an early age, admitting that when she was in her early 20's that she "didn't want a hearing aid in my ear" when she was in social situations, though did wear it at work and "it did help". Even later in life, when hearing aids in both ears were recommended by an audiologist, Jackie says, "I hated wearing two hearing aids to (sic) I persisted with one in the better ear and struggled." Later, she does resort to wearing two aids though admits that "I never learned to use my hearing aid with the phone so I just struggled." In addition, Jackie has trouble admitting that she really has a difficult time coping with her hearing loss. The evidence of this lies in her comment above, where she views herself as having a moderate to severe loss because she "managed". What Jackie is describing, when she says that she 
"manages" is probably a coping mechanism that many people use to deal with difficult situations where they minimize the circumstance. This coping mechanism or illusion that is created can shatter for the simplest of reasons. When Jackie received an important phone call, she broke down in the realization that her hearing loss was so severe that she could not make out the context of the conversation and indeed she was not "managing" the phone call well. Recounting the experience, Jackie says, "and I cried almost because I couldn't understand what she was saying to me. I knew it was important but I couldn't get the time."

Initially, Paul did not seek out the cochlear implant to address his hearing loss, though he was aware of the technology. When Paul ordered his last hearing aid (in 2000) though the Canadian Hearing Society (CHS) he says, "it really didn't help me so they suggested I come to see Christiane (audiologist at Ottawa Hospital) and get into the program because they said you will qualify no doubt." When asked when he learned of the technology, he responds: "I had heard about the implants um in the mid-90's but I didn't research it until they told me at the CHS about it." What arises from Paul's re-telling is that while he was vaguely aware of the technology, he did not consider it for himself until it was put forward by the CHS. In 2000, Paul met with audiologists at the Ottawa Hospital Cochlear Implant program only to learn that he did not qualify at that time for surgical implantation. Paul recounts this experience:

"I investigated their equipment and the operation and how it was done and that but after I wasn't qualified for the operation I let it go and didn't investigate it and lived with my deafness for a long time" 
Paul was disappointed that he did not qualify, lamenting "I don't know why I didn't qualify" and goes on to say that as a result he became complacent with his hearing loss. In 2006, his partner prompted him to go back to see the audiologists at the Cochlear Implant Program.

"My partner kept telling me, "you should go back because you are even more deaf than you were in 2000' so other people were telling me that I was - sometimes you get complacent with your deafness and you think you can still function but until you hit a brick wall it's got to hit you in the face sometimes."

Sometime between 2000 and 2006 his continued hearing loss reached some threshold that would allow him to meet the candidacy requirements for surgical implantation. Although, because of his complacency and lack of follow-up with audiologists at the Cochlear Implant Program, Paul did not learn of the opportunity until prompted by his partner to seek access.

In the above examples of people who have "stumbled" upon the technology and including Paul's story, the structural processes dominate through the intervention of its representative agents; the physicians, the audiologists and others working within the health care system and its peripherals to provide hearing care. These stories illustrate that the health care structure is providing accessible hearing care.

In the following two examples, the active behaviours of individual actors dominate. In these cases $(8,9)$, the respondents knew of the cochlear implant technology and deliberately went in search of access. Thus, it is here that the 
actors' knowledgeability plays a pivotal role in gaining access to structural resources.

Michael was aware of the cochlear implant technology. In addition to having read about the cochlear implant he also saw a television program about two children with cochlear implants. So when he went to his hearing aid dispenser because of difficulty hearing with two new hearing aids, he asked her about the cochlear implant.

"...because I was having problems hearing at that point with the two of them and Louise was telling me that the two I had were "the best in the west" okay, "top of the line", there was nothing better. I had read about cochlear implants and I mentioned it to her and she said "yes and you seem to be a good candidate."

When Michael first realized that he needed help with his hearing his first action had been to visit a hearing aid dispenser. He did not go to a family physician or get a referral to an audiologist. Consequently he relied on the services provided by a local hearing aid dispenser. When asked where he went to get help with his hearing Michael says:

"I went directly to (name of hearing aid dispenser). They gave me the test. The family doctor, I don't remember him no, I didn't go to the family doctor really for the hearing test. I got a hearing doctor afterwards....but this was after the fact.... and I had my hearing aids.

From this retelling, it appears that Michael saw the hearing aid dispenser as the logical place to obtain help with his hearing. Subsequently, over the next fifteen years, whenever he had issues with his hearing, this was where he went for help. One wonders what would have happened if Michael had not asked about the cochlear implant when told that there wasn't anything technologically better in 
terms of hearing aids when he was clearly frustrated by his inability to hear well with hearing aids that were termed the "best in the west".

Patricia knew about cochlear implants from a young age. Though diagnosed with a hearing loss at 17 months, it was when she was 12 and became quite ill and subsequently experienced a significant drop in her hearing that a cochlear implant was suggested.

"I was seeing different audiologist regularly and then when I was about 12 I was really sick. I had like an ear infection and it kinda affected my hearing a little so they weren't too concerned at the time and they wanted to wait and then 3 months down the road my hearing went down a huge drop. At that time they were trying to get my Mom to look into me getting a cochlear implant, but my Mom didn't want to jump in and make that decision for me."

Patricia mentions several times during the interview that her mother did not want to make a decision about the cochlear implant, preferring that Patricia make it when she was ready. Consequently, Patricia remained indecisive about the cochlear implant and struggled to keep a job where communication with others and on the phone was difficult. She states:

As the years went by my hearing kinda I did have a job but on account of my hearing was affected by it. People didn't really understand how to communicate with me. They were not looking at me, and they are thinking I'm ignoring them, but really I can't hear them and stuff and getting and keeping a job has been a struggle because I can't communicate well on the phone so that kinda made my confidence in myself to be down big time so um I was talking to my family doctor and my family doctor said there's got to be something that would help you to find a job better so he send me back to Hotel Dieu and I (saw) the ear, nose, throat doctor and he tested my hearing."

After seeing audiologists regularly every year, Patricia stopped these regular hearing check-ups and did not see anyone about her hearing outside of her 
family doctor from the ages of 20 to 24 . Admitting in hindsight that this might have not been a good idea, Patricia rationalized her decision by saying that she couldn't afford to have a hearing test done on a regular basis because OHIP wasn't covering it. Is this further proof of her indecisiveness about investigating the possibility of a cochlear implant or was it a form of avoidance, not dealing emotionally with her hearing loss or perhaps both? When Patricia finally does seek help, she goes to her family doctor about her low self-confidence and finding a better job; "I just needed something to help boost my self-confidence and my self-esteem" and instead is referred to an otolaryngologist for further hearing tests. The meeting with the otolaryngologist was a turning point of sorts for Patricia.

"He couldn't believe that I was still going on with such low hearing and still had good speech so he decided "okay, you need to look into getting a cochlear implant because that's pretty much your only option" beyond that".

Patricia does not embrace the idea of a cochlear implant straight away, as she says:

"So he (otolaryngologist) wasn't forcing me to make that decision, he's saying that's the only option you have left. So I kinda thought about it and then I decided okay I'll just go ahead and have the hearing tests and stuff and see if I'm a candidate for it."

Two weeks after all the tests had been performed to ascertain her eligibility for cochlear implantation, Patricia finally comes to a clear decision that this is what she wants:

"Just one day I started to feel going to work that I wanted to have it done." 
In the fifteen years of her adult life, Sylvia wasn't in regular contact with audiologists about her hearing status. Sylvia accepted her hearing loss as part of her life and this pragmatic approach extended to her decision not to have regular contact with hearing professionals, as she says: "so what are they going to tell me, "you're deaf?". Instead, Sylvia goes to a hearing aid clinic only when she needs a new hearing aid or ear moulds replaced. It is only when Patricia comes to the realization that she can no longer "fake" hearing at important meetings at work that she decides it is time to seek out solutions.

"So it was harder (at work) and I couldn't fake it as easy, if you know what I mean. So, I don't know, one day I just thought, okay, well this isn't working so I'll see what I can do. So I did a lot of research and found it (information on the cochlear implant) and made an appointment and that was it".

In Lise's case, she had heard of the cochlear implant when she was younger, though it is not clear in the transcript just when that was. She recounts:

"I had heard horrible things from learning about cochlear implants. How you have a hole in your head, you can't do anything."

In the interim, Lise went to hearing aid dispensers only when she felt her hearing aids needed changing, so her contact with hearing professionals was sporadic. In fact, between the ages of 8 and 21 , she did not have a single hearing test performed. The only contact with a hearing aid specialist was through her mother who regularly purchased batteries for Lise's hearing aids.

In 2002, Lise recalls how she was struggling with her hearing and developed a renewed interest in cochlear implants: 
"So I was trying to deal with it on my own thinking what can I do, what can I do and I was working for the Canadian Association for the Deaf and I think something was mentioned about cochlear implants. There were a lot of pros and cons about it and I got kind of interested in it from there."

Lise also says that at some point she saw something visually that changed her earlier negative perception of the cochlear implant:

"I might have come across some cochlear implant information that uh I found out it was more modernized. You no longer had a hole in your head. I must have seen something. I was so busy there. Off of work. Well, I was doing work with everybody, the boss, the people that didn't want to do the work so I had a bad job. So I came across something that triggered me to look further into it. It must have been a picture of it or something."

Having been told that there were no stronger hearing aids that would help her with her hearing and a new perspective towards the cochlear implant, Lise did some research on the internet, piqued by the fact that it's "used too often so it must be better technology" and decided to contact the Cochlear Implant Center at the Ottawa Hospital.

"I was thinking about it for a year before I sent the e-mail off to the clinic here."

"So sure enough, I went on the internet. I saw the cochlear clinic, the cochlear implant program and send out my first e-mail. I got a catalogue in the e-mail pretty fast. I read it over, I thought about it, I did some more research on the internet. I made an appointment with (audiologist) at the Ottawa Hospital."

\section{Care Gaps}

Reading through the transcripts and reflecting on my own experience, there is evidence of care gaps among the majority of respondents that echo the current state of the health care system. Because of the range of health care providers and ancillary health professionals within the various health models that can be 
involved in a person's hearing care and the lack of a continuous and structured care programs for deaf or hard of hearing Canadians, there are gaps not only in the provision and management of hearing care but also in the knowledgeability of the agents involved as well that has impacted accessibility to the cochlear implant technology.

\section{Structural Gaps}

\section{Continuity of Care}

In the narratives, there are examples of gaps in the regular and continual provision of hearing care to those with established hearing losses. The current structure of health service in Ontario has seemingly spread the provision of hearing care among a number of health care agents and this structural malfunction has resulted in disjointed processes within which hearing care is provided. For most health issues, the general practitioner or family doctor is typically the first health professional to whom most people turn. Ironically, while hearing loss is the third most prevalent chronic condition in older adults (Cohen 2005), only $16 \%$ of older adults in the $U S^{9}$ receive a hearing test during a physical examination (Newman 2004). If a doctor suspects the patient has a hearing loss, a referral is usually made for the patient to see an otolaryngologist, a medical specialist who treats diseases and disorders of the ear, nose and throat (ENT). If it is decided that the patient would benefit from a hearing assessment to determine the extent of the hearing loss, an audiologist may be consulted for an assessment and may recommend a hearing aid.

\footnotetext{
${ }^{9}$ The only country where statistics are available on screening activities in adults - JW
} 
Otolaryngologists ${ }^{10}$, like general practitioners are medical doctors and as such are paid for their services by OHIP. These medical practitioners can operate independently from health institutions or they can be affiliated with one or more institutions through admitting privileges, or they can be a full-time member of the medical staff in a hospital. Audiologists are not physicians, but have advanced university degrees in audiology, specializing in the study of hearing disorders and rehabilitation (HHCC 2009). Audiologists are usually located in private hearing aid dispensing centers, while others may be part of the global health care team in a hospital setting, working within an audiology or ENT department.

Hearing instrument specialists are perhaps the most accessible agents to deaf or hard of hearing Canadians as most are situated within the offices of a private hearing aid vendor. These specialists have extensive training in the selection and fitting of a wide variety of hearing instruments, and are licensed by the province to test hearing and to recognize the need for a full diagnostic evaluation with an Audiologist. The number of private hearing aid vendors offices has grown in recent years in response to the increases in the aging population with hearing difficulties. These offices are located in towns and cities across Ontario and quite often one can walk in and make an appointment for a hearing evaluation either within the same day or within the week.

Family physicians do not appear to be very involved in their patients' hearing care, and while some respondents received good care and advice from

${ }^{10}$ Otolaryngologists are also known as ENT's, ear, nose and throat specialists. 
specialists such as otolaryngologists, others did not. This project did not uncover evidence that access to otolaryngologists was lengthy and typically a precursor to obtaining a referral to an audiologist. However, the number of respondents who used the services of hearing aid dispensers may reflect the ease of access to their services over those of the otolaryngologist. The following stories provide examples of some of these care gaps.

Martin, who had progressive hearing loss attributed to his experience in the artillery, had regular hearing tests through his career with the military. In retirement, he also had steady contact with an audiologist and made regular visits to the audiology clinic at the Ottawa Hospital every two to three years for hearing tests. Martin's story serves as an example to illustrate that the responsibility for managing and monitoring hearing is placed on the individual.

Lise, like Patricia and Sylvia, lost her hearing at an early age. Growing up in the United States, Lise experienced a slightly different model of health care than the rest of the respondents. In Lise's retelling, she says that she only had two hearing tests done by audiologists over a 13 year period, and relied on hearing aid dealers for new hearing aids when she felt her existing ones were not helping her or when she needed adjustments or other related accessories. The gap in hearing tests does not seem to bother Lise as she says below - it was not a priority in her life. 
"The Belltone people only sold hearing aids. The doctor that was the ear doctor was the one who did the hearing tests and I think I only had one hearing test when I was young and then one again maybe when I was about 21. So for a period of time I was like 8 years old up to 21 no hearing tests."

"Let's see when I was a freshman if I had a (sic)l was out of town at college so I would just go to any hearing aid dealer and have the tube replaced or uh if I thought my hearing aid was needed to be replaced I uh just I would go to a hearing aid dealer and ask you know if I had the money so like I was really concentrating on getting it-focusing on getting a better hearing aid. It certainly was not a priority in my life."

When Lise moved to Canada, she continued the same pattern of using various hearing aid dealers for hearing aids and still had an occasional hearing test performed by their audiologists.

\section{Structural agents - Compartmentalization of care}

The compartmentalization of the provision of services could be considered a type of care gap. Michael states that all of his hearing care was provided by a hearing aid dealer even though he was also under the care of an otolaryngologist for nasal polyps and wax build-up in his ears. At no point in his narrative does he talk of his ENT suggesting types of hearing aids or a cochlear implant, rather it is his hearing aid dealer who suggests he might be a candidate for a cochlear implant after being prompted by Michael. Thus, it appears there is some compartmentalization of care between the ENT and the hearing aid dealer; where one takes care of the wax and polyps and the other takes care of the hearing. 
Structural process - the way care is delivered

There are a number of structural agents with different levels of knowledge and expertise who provide hearing care. From Paul, we learn that all of his hearing care was provided by a hearing aid dispensing centre and that he never saw a medical practitioner about his hearing loss. Paul states that he was simply following the behavioural practices of his father and brother who are also deaf and use the services of hearing aid dealers.

"I was seeing Davidson about once every 6 months because um the hearing aids kept breaking down and I was trying digital hearing aids and that didn't work out so I was only seeing Davidson's I wasn't coming into see a medical practitioner about my hearing or professional doctor or anything like that."

"I never did see a real audiologist. I just followed what people were doing at the time. Like what my father did. My father was deaf so, my brother is deaf."

What is quite disconcerting is Paul's comment about the lack of assistance with respect to his hearing loss from both his family doctor and psychiatrist. Again this appears to be another example of the compartmentalization of the services offered by health care providers or it could reflect the current state of awareness by providers as to the issues and services needed by deafened people.

"Well I would go to the GP and he knew I was deaf but he never offered any and you know the same thing with my psychiatrist. She didn't know how to handle deaf people."

To return briefly to the issue of hearing aid dispensers possibly being biased towards hearing aids, Paul makes the following comment: 
People that sell hearing aids I think they were more concerned about selling a hearing aid than really advising me to go see a doctor.

\section{Continuity and transition of care}

The current model of health care is structured to address the specialized needs of specific populations. In many cities, children and adolescents up to the age of 16 are cared for by paediatricians and when necessary, are treated at a children's hospital. Adults, on the other hand, are cared for by family or general practitioners and treated at general hospitals. When people with specialized needs transition from adolescence to adulthood, they also transition from one provider to another. This transition is often not seamless and can result in care gaps for patients.

In the case of Sylvia, who was a young child when she started to lose her hearing, we find evidence of this type of structural care gap. When asked how often she went to the children's hospital for hearing care, she replies that "I went a few times a year." When prompted if she knew what kind of a health care provider she saw about her hearing care, she responds: "I really don't remember. I saw a lot of people. There was an ear nose and throat doctor. There was an audiologist but I really don't remember anything other than that."

The regular visits for hearing check-ups with a paediatric audiologist stopped as Sylvia reached adulthood and could no longer use the services of the children's hospital. Instead of a seamless transition to the care of an audiologist at a 
general hospital or clinic, Sylvia is left to fend for herself. She remarks that for the next 15 years she just went to a hearing aid clinic when she felt she needed a new ear-mould for her hearing aids.

"Yes, then it changed... I didn't really have an audiologist. I went to a hearing aid clinic when I needed one. I didn't really follow-up... Which is really awful to say but I went to the hearing aid clinic a lot just to get new moulds made but I didn't really see an audiologist...For about maybe 15 years."

When Sylvia finally does make an appointment with an audiologist, it is with the Ottawa Cochlear Implant Program at the Ottawa Hospital.

\section{Continuity of Care - Structural process for funding - gap}

Patricia, who was 25 , also lost her hearing as a young child and had a similar experience to Sylvia's, though in her case, the gap in her hearing care was shorter, between ages 20-24 and it was attributed to the costs associated with hearing tests.

"Well I used to see them (audiologists) every year then I stopped which probably would have not been a good idea and then I started to notice a difference in my hearing and my Mom did too so that's when my doctor decided on the referral but this time it wasn't coming under OHIP so I couldn't really afford it on a regular basis."

"It's just that OHIP (Ontario Health Insurance Plan) wasn't covering it so I couldn't really afford it because they stopped paying for the visits so basically you have to. I don't know about it now but at that time I couldn't afford it." 
A Complex Case - an atomistic approach to care

The care gaps experienced by Anita, who lost her hearing due to meningitis and was hospitalized for six months, are attributed to the lack of or poor communication within and between hospital staff and patients and the structural inadequacies of the health record system. As Anita says:

"___ and it came down to communication."

While Anita had to wait till she was discharged from isolation before she could have her hearing tested, it seems that the sheer number of people involved in her care and the copious notes in her medical chart made it difficult to know who or what had been suggested with regards to evaluating and treating her hearing loss. In the following excerpt, Anita describes one example of miscommunication; in this case, it is a mix-up of dates between a booked appointment (possibly made three months earlier) and the scheduled transport to that appointment. As well, Anita expresses disbelief that these providers do not want to verify her knowledge of her care; in fact, she says that their attitude towards her was dismissive.

"So this one day they came and started to put me on a stretcher and.... I kept saying ... where am I going, what's happening... and where am I supposed to be. I know that it was the audiologist because there was nothing else that I could think of. l'd already had all the surgery l'd hoped they were going to give me. And.... I said no that's tomorrow and it's like oh what do you know, you know you're deaf you don't know (laughing). When we got down there and the lady the receptionist was sitting there with her head in her hands. I guess she'd tried calling up to where I was and she said Oh l'm so so sorry you're appointment isn't until tomorrow" (laugh)." 
In addition, appointments were made for her that she was unaware of and in this next example, not only was Anita surprised by the visit, but was annoyed by the inappropriateness of some of the suggestions with regards to her using sign language (when she has no fingers). Overwhelmed by the impact of four people using various methods of communication, the outcome of the visit found Anita upset and feeling that she had no control over her options for hearing care or rehabilitation.

"I was coming back from that (Rehabilitation appointment) one day and my husband was waiting for me and he said there's some people here to see you from the Ottawa Hearing Society or the Ontario Hearing Society or whatever and there was actually 4 people there. ... There was a lady called $C J . .$. and she had a person from sign language there who was interpreting what we were saying to a person who was also deaf I guess to show me how it all worked you know and CJ and I didn't get off to a very good start either but that changed but the odd time I tried to tell her you know of course she had a computer and I was talking to her through the computer thing. She was telling me all my options in sign language and this and that or whatever. It had been such an ordeal that this time I wasn't even joking about having no fingers I think and I basically said to her you're running off with this and I'm not ready. Your taking away my one hope and I want to wait and see if I can do this cochlear thing. I don't want to hear about sign language."

Anita found that the health care providers involved in her care did not seem to have the information needed to treat her or perhaps they did not have time to read her medical history in her records. In the next example, Anita talks of the various people involved in her care and her amazement that within one hospital providers are not aware of her medical history which includes the amputations done due to the severity of her meningitis.

"But you know to go back to the CJ thing I think that's part of it. .... I didn't know CJ was coming...... It was only -it wasn't their fault I was taken by surprise-I had social workers, people coming in-you know but nobody 
came in and said would you like to see this person and so. you know the communication was not good. I was in that same hospital, l've been in it many times you know kinds of tests over the past year because of the meningitis thing and l'm always amazed when they say "what happened to your fingers?" (laughing) and I just say to them "well you've got them" (laughing)

Anita concluded with a final example of the gap in communication with a retelling of a visit by a first year medical student.

"The only person to my knowledge that read my entire file was a 1st year medical student and he came into my room about 11 o'clock one night and I was so glad to see anybody you know and he came and advised me he had read my entire file and he would like to visit with me. He was just enthralled you know. It was probably amazing at that time (yes). I said to the nurse the next morning you know about this young lad coming and that and she looked at me and said "he read your entire file?" (laughing) "nobody does that" you know. So I think there was a problem maybe I don't know how it works in the hospitals but to me there was a great lack of communication. It's fine if you can talk and hear and you can ask questions you know but you can't ask questions when you don't know what the situation is (yes) you know."

Reading Anita's narrative, I found I was having difficulty determining where she was first seen by an audiologist. Initially Anita talked about how long it took for an audiology appointment to be made when the department was one floor below. Then the audiologist who saw her, told her that there was nothing that could be done, and then said that she needs to check with someone in the hospital to see if she might be a candidate for the cochlear implant. Why did she say this to Anita? Why couldn't she just have said that her hearing loss was such that she needed to send her for further assessment before commenting on it? If the Ottawa Hospital is to be considered one institution, though it physically has two campuses and the Cochlear Implant Program is part of the Ottawa Hospital Audiology department, though located at one campus while she was an in-patient 
at another campus, why did this audiologist make that statement and why did it take a referral? It appears from a review of the Ottawa Hospital web-site, that audiology services are provided at both campuses, though the Cochlear Implant Program is located at the Civic campus. As well - Anita says, "but I did finally get referred to the hospital and I'm not sure who I saw first, I have a feeling it was Shelley right from the beginning."

Knowledge gaps - structural agents (agents within the structure) Health care providers are unquestioningly perceived by many to be experts in their chosen field or discipline, whereas in some instances poor levels of knowledge or expertise can impact on the health and well-being of their patients or clients. There is evidence within the narratives to support the notion of knowledge gaps among health care providers.

The earliest example comes from Jackie, who at the age of 18 was told by an "ear doctor" after testing her hearing that "a hearing aid probably wouldn't help it's for old age deafness". This perception by the "ear doctor" that hearing aids wouldn't help because of her young age could be considered a knowledge gap, reflecting the doctor's lack of knowledge. However, it could also reflect some form of misinformation or the current thinking of that era - so whether it is a true knowledge gap remains questionable. 
In Lise's narrative, she encountered several "experts", who misinform her of her potential for a cochlear implant. When Lise started to experience higher levels of frustration due to increases in her hearing loss, she tells the story of talking to a friend who is a hearing aid dealer. The friend tells her there is no stronger hearing aid on the market that can help her. No mention was made of the cochlear implant, though most likely he was aware of it. In addition, Lise recalls another person at that dealer who had in the past mentioned that a cochlear implant would not work for her - though never said what this decision is based on. Could both of these providers be biased towards hearing aids over the cochlear implant?

"Actually one person discouraged me from getting the cochlear implant so that was at Hellix in Stittsville. She said you can't have a cochlear implant. She kind of said you wouldn't want to."

"I was struggling with my hearing and was so unhappy with the hearing aids I had a friend Jeff who is a hearing aid dealer and he also worked at the same place at Hellix and he was the one who was really honest with me and said actually there is nothing we can do for you. There's no stronger hearing aid for you. He didn't say anything about cochlear implants he just said there's was nothing more for you. "

Structural process - care coincides with funding structure

Phil's wife remarked in his narrative that he went for hearing aids/tests to coincide with the eligibility criteria for financial support for new hearing aids. While Phil stated that he saw an audiologist for his hearing care, it is not clear where the care was provided, that is, in a hospital or hearing aid clinic. As well, it is not known if the eligibility criteria for a new hearing aid are based on some private health insurance plan or the provincial plan (OHIP). 
Not bother, I don't know, do you remember whether I went back or was there a time I went back for tests? From the time he (wife responding) first got it, it was I think it was. It wasn't annually though. No it wasn't annually because at that time I think like for the coverage that he had it was only every 5 years or something like that and he went to the audiologist 4-5 years later and then 4-5 years later again.

\section{Care gaps - structural processes and candidacy}

The current eligibility criteria for a cochlear implant allow for more potential candidates than when they were first introduced in Canada in 1984. However, there still remains a narrow band of potential candidates that sit at the edge of these criteria, waiting for their hearing to worsen or for the eligibility criteria to expand. In addition, there are possibly other deafened people that are likely missing this opportunity for a cochlear implant; unaware of the degree of their hearing loss that could qualify them for a cochlear implant or unaware of the technology, or both. In the narratives, we read the stories of frustration that people experience when they are having real difficulties hearing or communicating. It must also be frustrating for those who know that there is a potential technological solution, yet it is out of reach.

Three respondents did not meet the eligibility criteria established by OHIP. Both Michael and Phil were experiencing major frustrations with "state-of the art" hearing aids that were not helping them to hear and were prompted to contact the Cochlear Implant Program. Paul contacted the Cochlear Implant Program on his own after experiencing issues with large losses in his hearing over a short period, and trying to mitigate the losses with new hearing aids without success. 
Luckily for Michael and Phil, there was a clinical trial ${ }^{11}$ that was being conducted during the period that they came to the Cochlear Implant Program for assessment. The trial was a joint study conducted at the Ottawa Hospital by a company that had a new cochlear implant on the market with expanded candidacy criteria. It was the Coordinator of the Cochlear Implant Program that suggested this option to both Michael and Phil. In the following examples, we see the influence that the Coordinator, as a structural agent, has in helping them to obtain access to the technology though other channels when other agents might not.

In Michael's words:

Now uh I had the tests with Christianne (audiologist at the Ottawa Cochlear Implant Program) and at the time it seemed that my hearing was still good enough that I wasn't eligible for the Provincial-I didn't meet the criterion or criteria for the Provincial stuff. At that point she said yes so I'm having a clinical trial, maybe you could qualify for that. So she had me pass a bunch of tests and I did qualify for the clinical trial.

So she sidetracked into the clinical trial (um hum) because apparently they had changed the clinical trial had changed the criteria and I did meet them for eligibility there. (o.k.) So it took off from there with tests and everything and then well about $11 / 2$-yes the operation was about one year after the whole thing started

From Phil, we learn a little bit more about the actual qualification for the clinical trial study that both he and Michael took part in. It seems that while the provincial criteria limited eligibility to those who obtained less than $50 \%$ speech recognition in sentence tests the clinical trial was based on speech recognition of single words tests.

\footnotetext{
${ }^{11}$ This might be the clinical trial conducted by Cochlear in which candidates that obtained less than $30 \%$ word recognition in monosyllable word tests, regardless of sentence recognition scores. (Séguin 2008)
} 
Well she (audiologist at the Cochlear Implant Program) did tests, a bunch of tests and it turned out I didn't qualify. I was very disappointed because I didn't believe I wouldn't qualify under the way the funding goes for funding to get a cochlear implant. But she turned around and said "I think we can get you in a clinical trial." (o.k.) So that's what did we do after that?

Well stepping back (this is his wife speaking now) a bit the reason he didn't qualify was because he was able to gradually figure out what the sentences were but with words he couldn't and the clinical trial was on words and he didn't pass the test, he failed miserably on the words.

In Paul's case, we find a clear example of a care gap as a result of the structural process that controls candidacy and does not implement follow-up guidelines for those who are borderline candidates for a cochlear implant. Paul was turned down for a cochlear implant in 2000 because he failed to meet the eligibility criteria and was not followed up as his hearing continued to deteriorate. It is only at the encouragement of his partner, six years later, that Paul returns to the Cochlear Implant Program where he is re-assessed and found eligible for a cochlear implant under the current guidelines. Clearly, the agents involved in Paul's hearing care knew that he had a degenerative condition and could have impressed the importance of regular follow-up to Paul. Paul says that after his initial and disappointing experience, he became resigned to his situation, though he did not cope well.

I was in here at the hospital in 2000 for an assessment for a cochlear implant but I was borderline. The criteria changed in the last year so in $2002^{12}$ for how deaf you had to be before you got an implant so in 2000 I didn't qualify even though I was severely impaired at that time.

\footnotetext{
${ }^{12}$ I am not sure what criteria Paul is referring to as the eligibility criteria used by OHIP expanded once, in 1993. I suspect he might be referring to a clinical trial's eligibility criteria - which is established in the study protocol and can be different from the provincial criteria. (The Author)
} 
Paul says that after finding out that he did not qualify for a cochlear implant, he resigned himself to his situation for another six years till his partner prompted him to seek help.

"After I wasn't qualified for the operation I let it go and didn't investigate it and lived with my deafness for a long time."

"...my partner kept telling me you should go back because you are even more deaf than you were in 2000 so other people were telling me that 1 was-sometimes you get complacent with your deafness (yes) and you think you can still function but until you hit a brick wall it's got to hit you in the face sometimes"

Care gaps - structural processes that govern the distribution and availability of implants - waiting times for surgery.

The longest wait period from the time of eligibility for a cochlear implant as determined by audiologists with the Cochlear Implant Program to surgical implantation was one year and that was for Michael who was eligible for implantation through a clinical trial study. Where the length of waiting time could be determined, five out of the nine respondents were implanted within three months of meeting the candidacy criteria, either through the provincial guidelines or clinical trial criteria. This quick turnaround time could be attributed to the time period of implantation. All of the respondents were implanted between 2003 2007 , shortly after an increase in the number of annual implantations funded by the provincial government occurred around 2002. This period also coincides with the one-time funding bonus provided to the Ottawa Cochlear Program for 20 additional surgeries to clear up back-logs in wait times. 


\section{Summary}

The narratives are a rich and descriptive expression of individual experiences that are representative of the accessibility "diorama". In this chapter, the cases were described and introduced, and the stories of how each came to access the cochlear implant presented. Themes that emerged from the analysis of the transcribed narratives were discussed. The discussion in the following chapter will examine how structurationism helps articulate access to cochlear implant technology. 


\begin{tabular}{|c|c|c|c|c|}
\hline 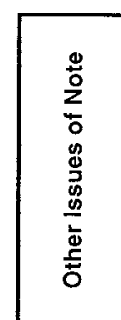 & & 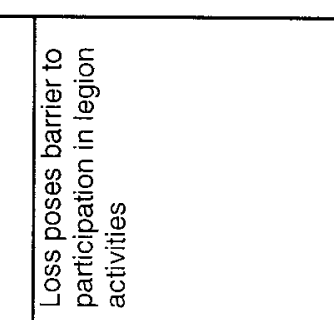 & 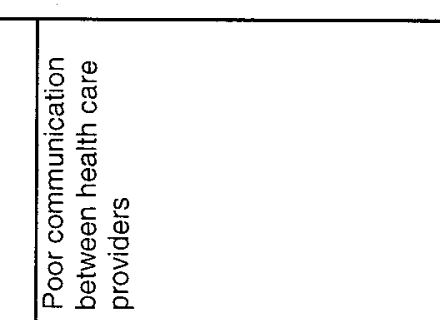 & \\
\hline 亨 & & 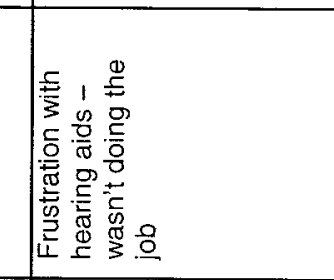 & 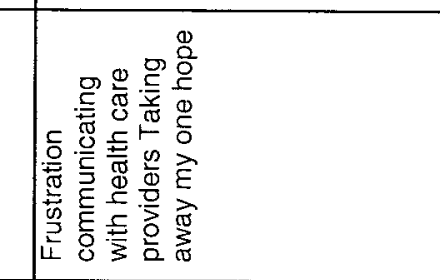 & 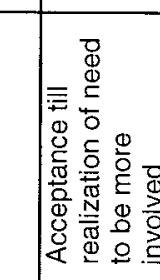 \\
\hline 产 & & & 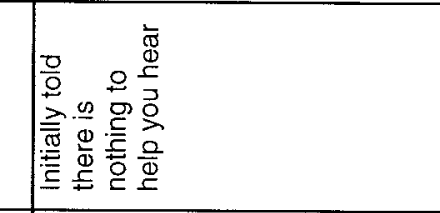 & \\
\hline 毫言 & 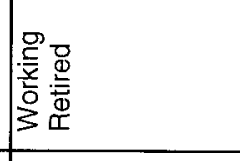 & 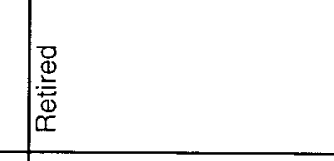 & 递 & 量 \\
\hline \begin{tabular}{|l|l} 
\\
\end{tabular} & & 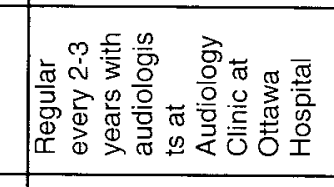 & 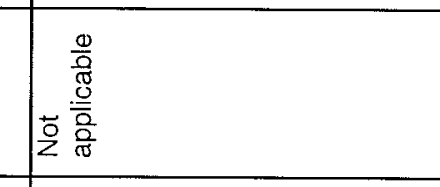 & 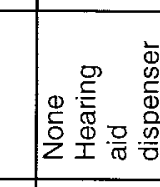 \\
\hline 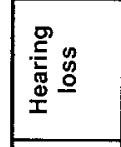 & 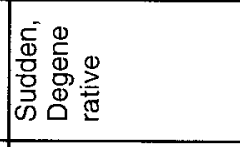 & 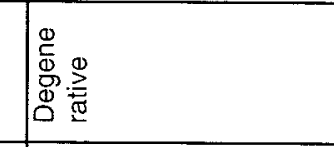 & 䃈 & 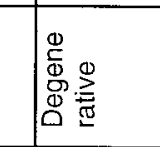 \\
\hline 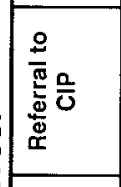 & 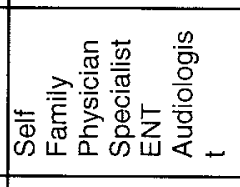 & 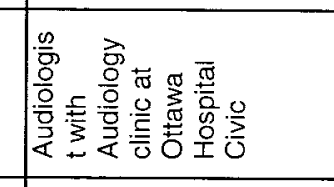 & 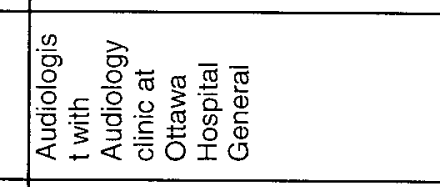 & \\
\hline 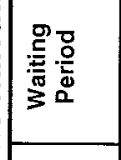 & 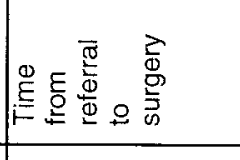 & 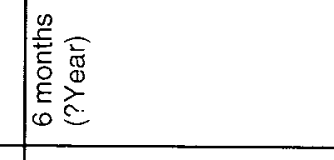 & 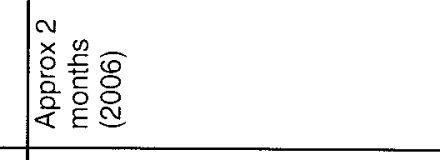 & 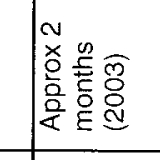 \\
\hline 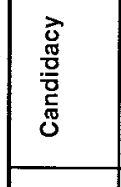 & 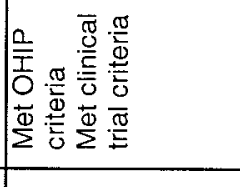 & 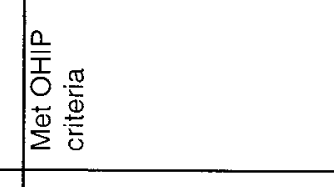 & 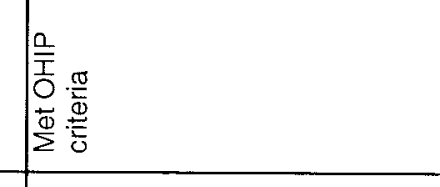 & 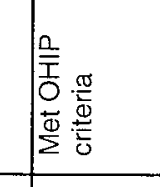 \\
\hline 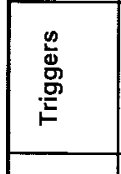 & 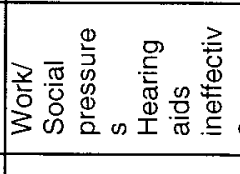 & 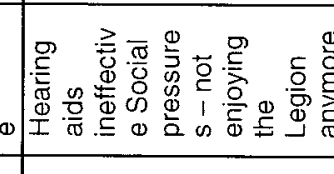 & 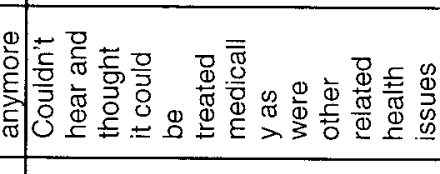 & 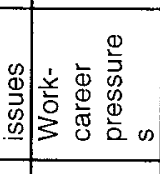 \\
\hline & 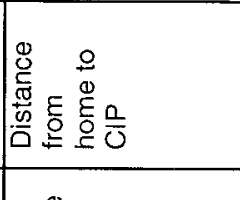 & 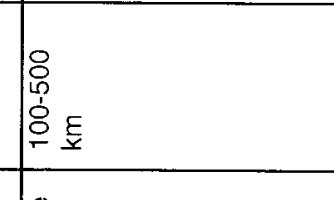 & 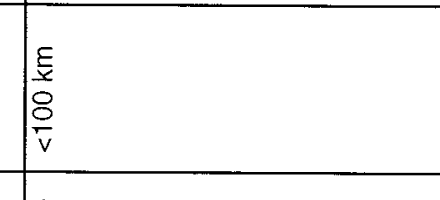 & \begin{tabular}{|l|}
$\frac{5}{2}$ \\
$\frac{5}{v}$ \\
\end{tabular} \\
\hline 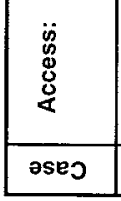 & 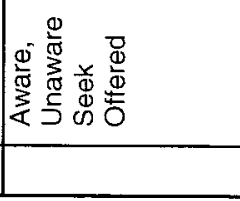 & 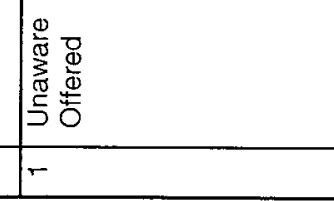 & 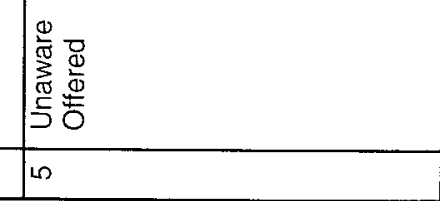 & 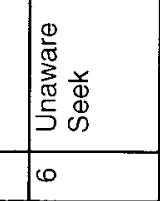 \\
\hline
\end{tabular}




\begin{tabular}{|c|c|c|c|c|}
\hline 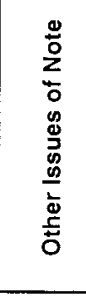 & & & & 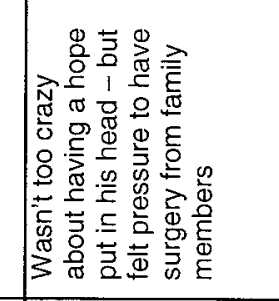 \\
\hline & 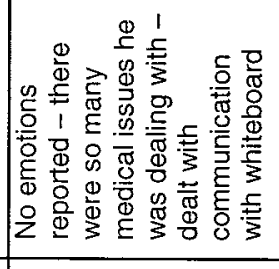 & 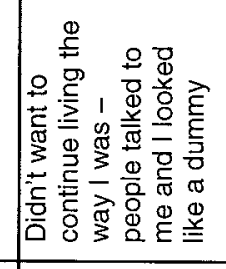 & 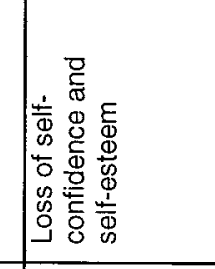 & 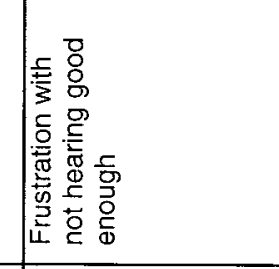 \\
\hline 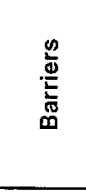 & & & 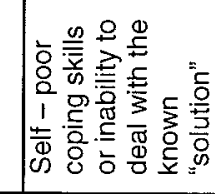 & 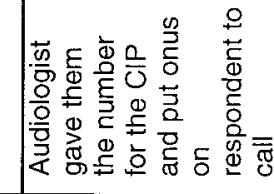 \\
\hline 旁言 & 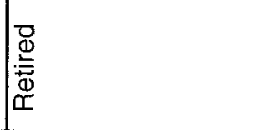 & 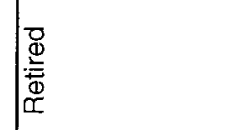 & 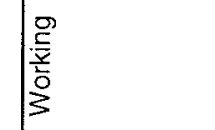 & 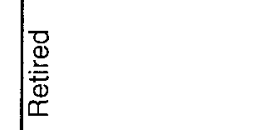 \\
\hline 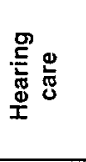 & 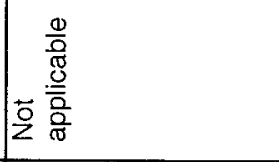 & 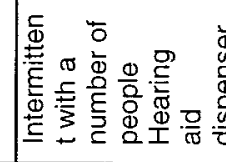 & 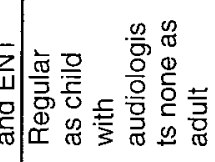 & 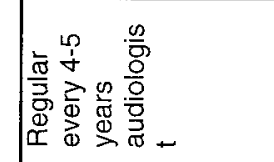 \\
\hline & 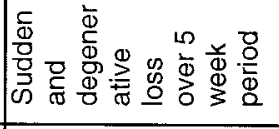 & 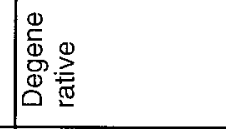 & 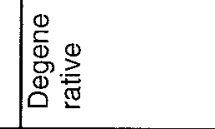 & 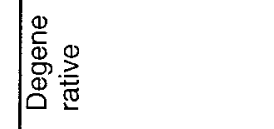 \\
\hline & 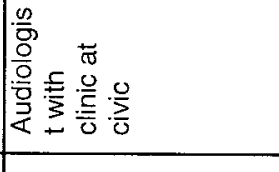 & 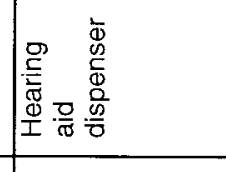 & 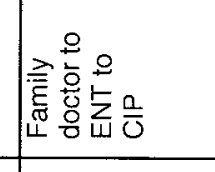 & 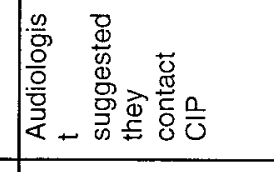 \\
\hline & 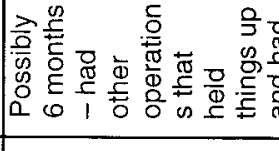 & 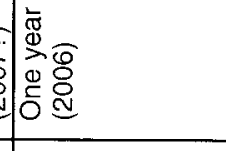 & 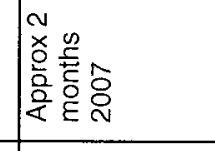 & 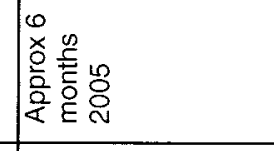 \\
\hline 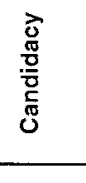 & 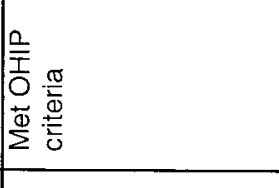 & 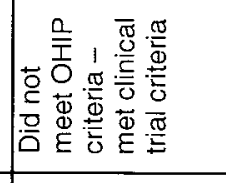 & 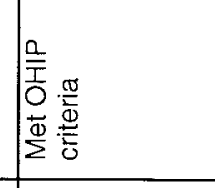 & 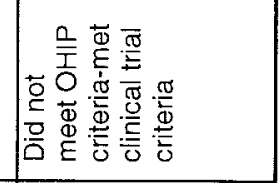 \\
\hline 墨 & 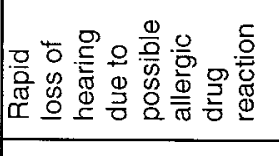 & 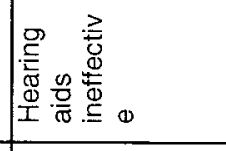 & 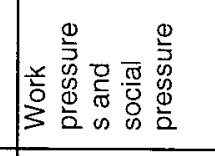 & 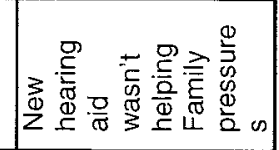 \\
\hline 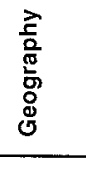 & \begin{tabular}{|l}
$\frac{E}{2}$ \\
$\frac{\partial}{v}$ \\
\end{tabular} & \begin{tabular}{|l}
$\frac{E}{2}$ \\
$\frac{\partial}{v}$ \\
\end{tabular} & 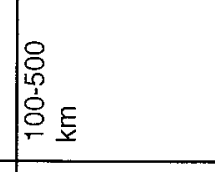 & 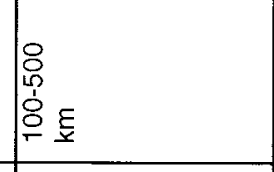 \\
\hline & 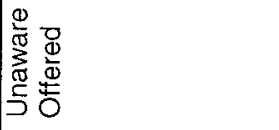 & 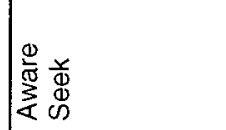 & 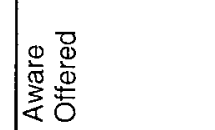 & 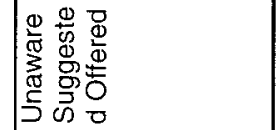 \\
\hline әseJ & $\Lambda$ & $\infty$ & $\infty$ & -0 \\
\hline
\end{tabular}


$\stackrel{2}{\exists}$

\begin{tabular}{|c|c|}
\hline 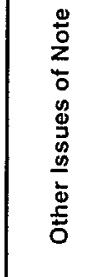 & 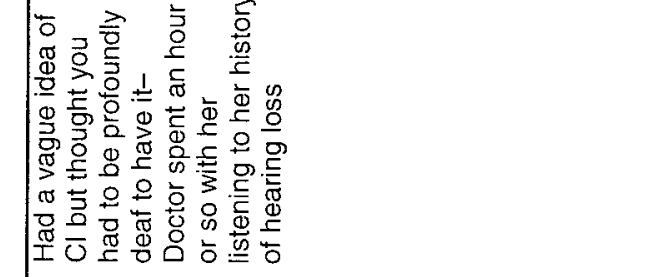 \\
\hline 哭 & 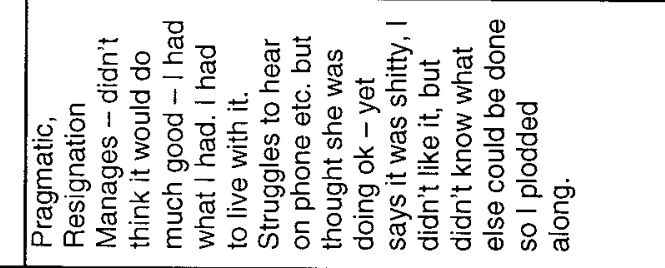 \\
\hline 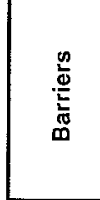 & 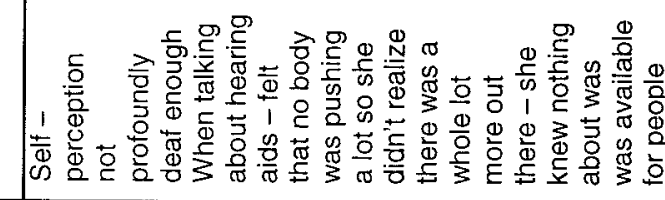 \\
\hline 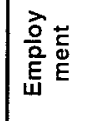 & 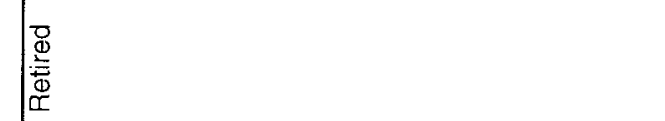 \\
\hline 总 & 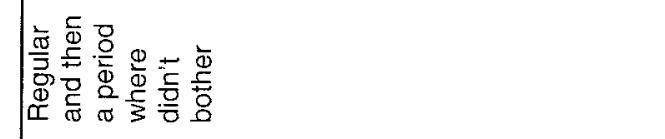 \\
\hline 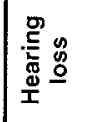 & 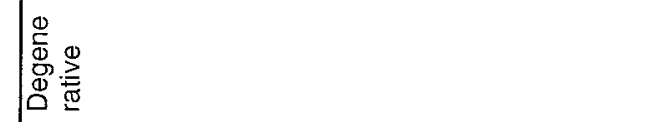 \\
\hline$\frac{8}{\frac{9}{\pi}}$ & 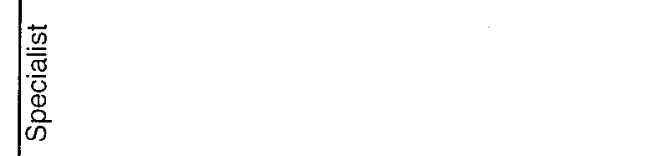 \\
\hline 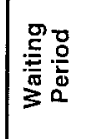 & 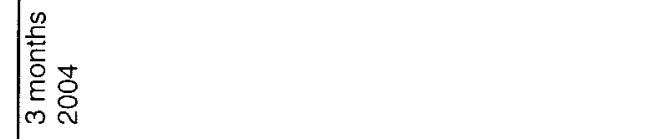 \\
\hline 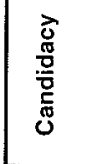 & 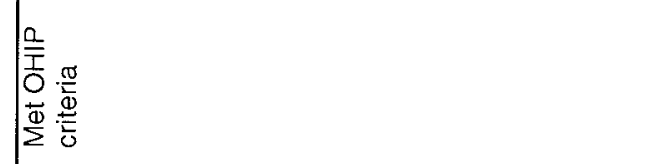 \\
\hline 另 & 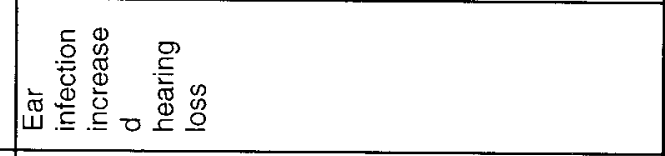 \\
\hline 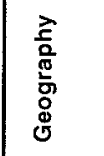 & $\begin{array}{l}\frac{E}{5} \\
\frac{8}{8} \\
\frac{v}{v}\end{array}$ \\
\hline $\begin{array}{l}\ddot{0} \\
\dot{8} \\
\dot{8}\end{array}$ & 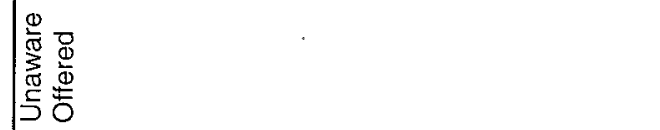 \\
\hline oses & -+ \\
\hline
\end{tabular}


$\stackrel{0}{=}$

\begin{tabular}{|c|c|}
\hline 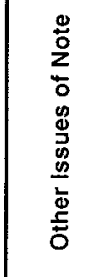 & 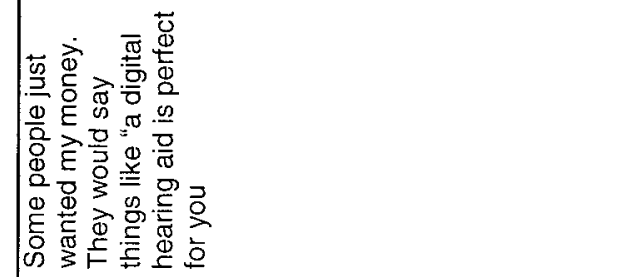 \\
\hline 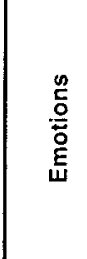 & 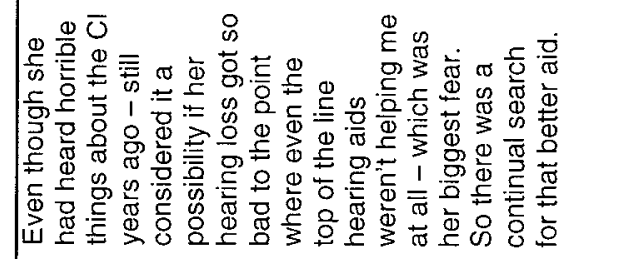 \\
\hline 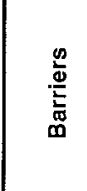 & 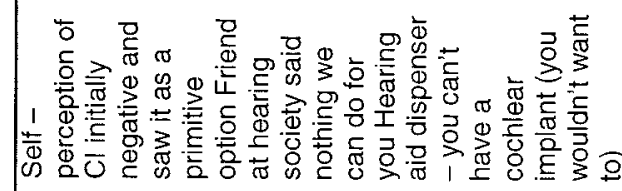 \\
\hline 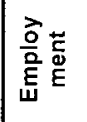 & 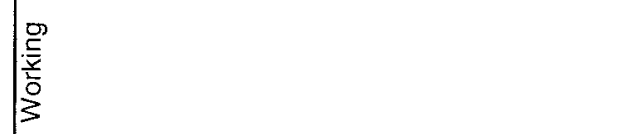 \\
\hline 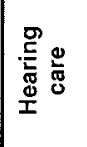 & 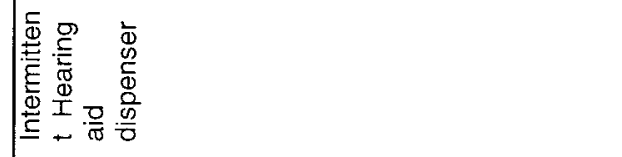 \\
\hline 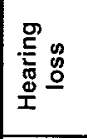 & 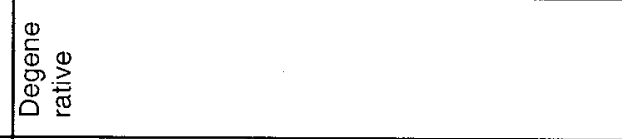 \\
\hline$\frac{8}{\sqrt{9}}$ & $\mid \begin{array}{c}\overline{\bar{\omega}} \\
\bar{\infty}\end{array}$ \\
\hline 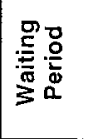 & 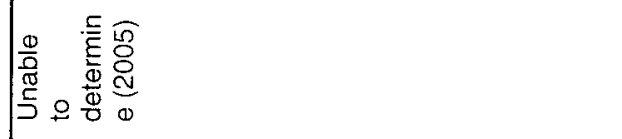 \\
\hline 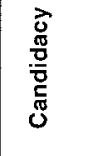 & 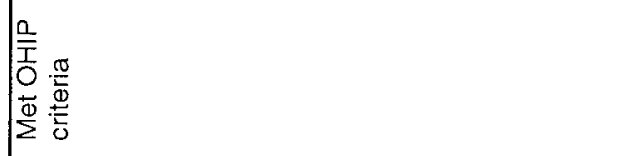 \\
\hline 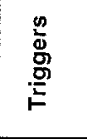 & 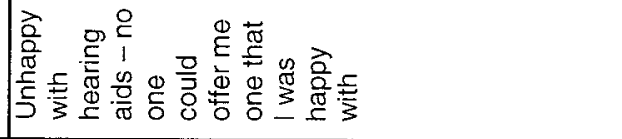 \\
\hline 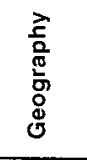 & \begin{tabular}{|l}
$\frac{E}{y}$ \\
$\frac{\partial}{2}$ \\
$\frac{D}{v}$ \\
\end{tabular} \\
\hline 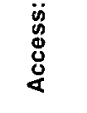 & 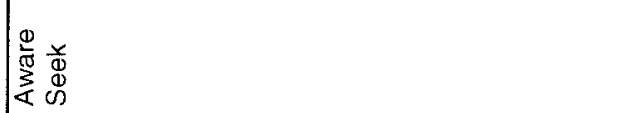 \\
\hline oseJ & $-\alpha$ \\
\hline
\end{tabular}


$\Xi$

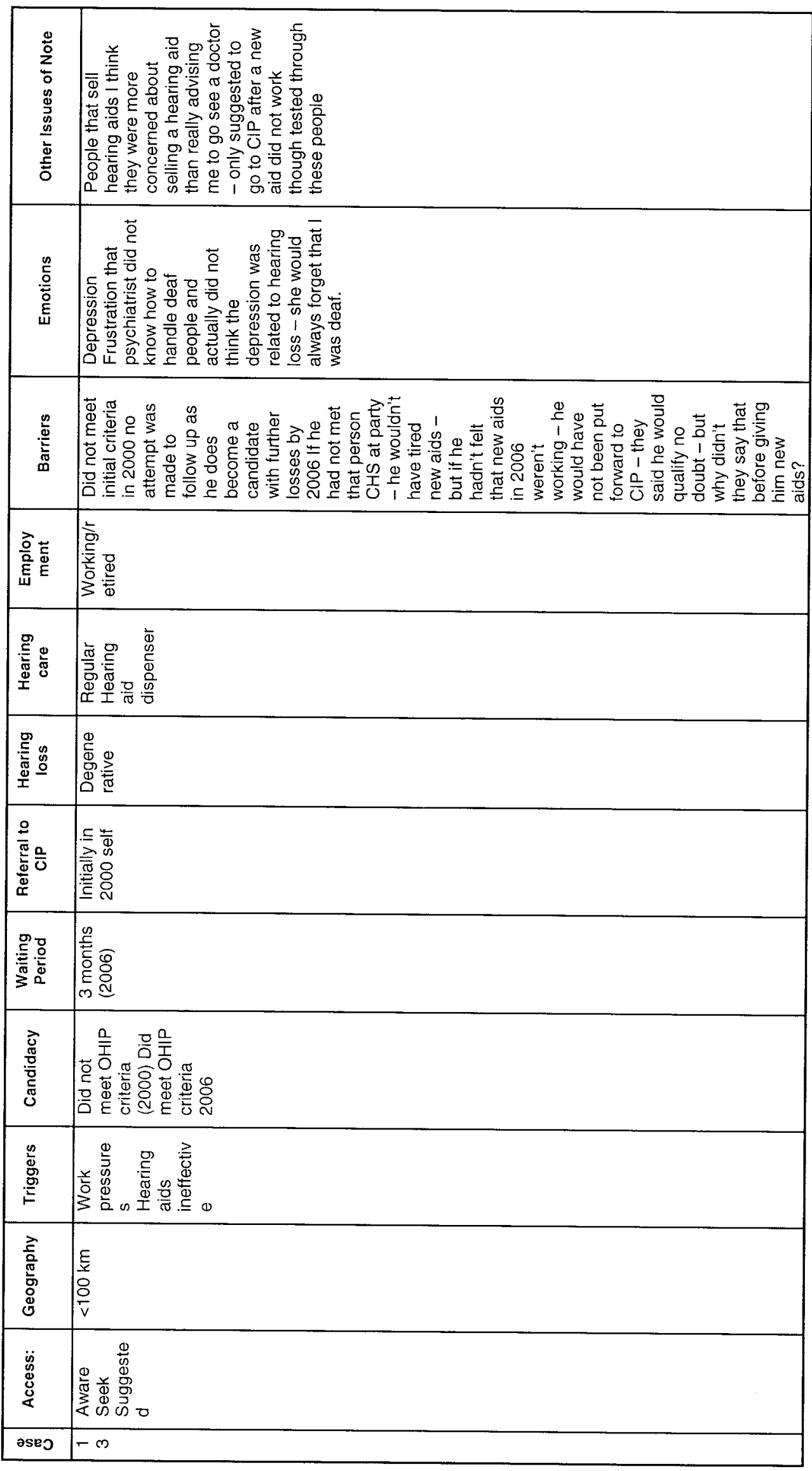




\section{Chapter 5: \\ Summary, Conclusions and Future Work}

\section{Summary}

This research project stemmed from questions I had about access to cochlear implant technology. These questions came about as a result of my personal experiences. The project consists mainly in the stories of ten people who have had cochlear implants. This now, is the story that triggered this project. This is my story.

When I went in to the audiology clinic to get my hearing tested in December 2003, I fully expected to get a "prescription" for a stronger hearing aid to address hearing losses that had been occurring over the previous few years. Two hearing tests were performed that day. The first was a word recognition test, in which I was to listen to, and repeat, a one-syllable word with no context within which to guess and this was followed by a sentence recognition test. I thought I did tolerably well, guessing my way through the 50 one-syllable words. But when the first sentence was played in the next test, I knew I was in trouble. I tried to guess the sentence based on the number of words I heard mumbled, yet after the second sentence was played, I realized I couldn't understand anything that was said, asking aloud "what language is this"? I started to cry. The sentence sounded foreign, almost Russian to me. The audiologist stopped the test. When I came out of the testing booth to talk to her, I was feeling emotional but fairly positive and asked how many words did I repeat correctly? 
I was dismayed to hear that I only repeated one word out of the 50 correctly. I was dumbfounded that my score was so low, but even so, I wasn't expecting the audiologist to tell me that my hearing threshold had surpassed the technological abilities of current hearing aids. Consequently, I was stunned when she said that there wasn't a hearing aid on the market that would help me to hear better. The cliché "my life flashed before my eyes" rang true in those few moments. I couldn't believe that this was how the rest of my life was going to play out. I was having difficulty communicating with colleagues and customers at work. I was relying on lip-reading and watching body language to contextualize conversations. My ability to hear on the phone had diminished to the point where if I did hear it ring, I didn't want to answer it because I wouldn't be able to comprehend what was being said. I would either give the phone to someone who was nearby, or I would let the voice mail take it and then get someone to listen to the messages later. I was now totally reliant on close-captioning to enjoy the television and the radio was just a hum. Going out to restaurants or parties was no longer enjoyable. In fact, if I was honest with myself, I was becoming reclusive, avoiding social situations because it was such a struggle to understand what people were saying and I hated to look stupid to others when I spoke out of context unknowingly. How had I let myself reach this point?

When my audiologist asked me if I had heard of the cochlear implant, I replied that I was vaguely aware of it, and in my mind, I associated this with people who were severely deaf and who could not benefit from a hearing aid and my self- 
perception at that time was that I was still not a "severely deaf" person. My audiologist said she would like to give me some literature to look at that would explain what the cochlear implant was and suggested that I might be a candidate for this surgery. I was trying to adjust and absorb what was being said, that there was a potential window that might open to better hearing for me. When I asked how people with hearing similar to mine that had a cochlear implant scored on the one-syllable word test post-implant, the audiologist replied that it varied by individual, but could range anywhere from 13 to 20 or more words. Somewhere intuitively, that response helped to make the decision that if I was a suitable candidate for the surgery, I would do it. My rationalisation for this was based on my reasoning that if I scored two out of 50 one-syllable words post-implant, that would be a hundred percent improvement over the score of one that I had just obtained.

Over the next few weeks, as I underwent other tests and spoke to family and friends about the upcoming surgery, I had time to think about this whole experience and began to wonder how many other people there were like me, who were experiencing similar or worse difficulties hearing and coping in their everyday lives and did not know about this technology, or if they did, did they think that it applied to them? 
So, after my surgery, when I came in for my first hearing test at one month post activation $^{13}$ and I scored 13 out of 50 on the one-syllable word test, I was ecstatic. At three months my score was 27 out of 50 and at six months it was 36 . These were phenomenal numbers when compared to the results from that benchmark test in December 2003. My quality of life as a result of improved hearing ability was greatly enhanced and my future outlook on life became very positive. I felt so fortunate to be able to benefit from living in an area that has a first rate audiology clinic within one of Canada's largest teaching hospitals and one of twelve surgical cochlear implant sites; being able to make an appointment within a short time frame for a hearing evaluation at the clinic; and to have the surgery within two months of diagnosis.

Yet there was some anger simmering inside as numerous questions surfaced and troubled me. Why had I not been aware of this technology sooner and how close had I been to the candidacy criteria over time? What if I hadn't registered in the Master's program and felt prompted to look for solutions to my diminishing hearing, how long would I have continued to "manage" with the hearing I had? What if I lived somewhere else where there was limited or no access to audiologists, or other knowledgeable agents? What if I had gone to a doctor or other audiologist or hearing aid specialist instead and been told that there was no other option outside of hearing aids? How fortunate was I to have this experience? If indeed my story of access to the cochlear implant technology is a

\footnotetext{
${ }^{13}$ Activation involves initializing the software in the external cochlear device to communicate with the internal device and "activate" sound. This process is usually done four to six weeks post surgery. JW
} 
result of the intersection of my personal geography and the health care system, I wondered what other stories from others who shared this experience would depict. Do their individual intersections with the structures and agents of the health care system and what would these stories say about accessibility within our universal health care system? Would I find that others were as fortunate as I?

In October 2008, four and a half years after being implanted, I started to experience brief "cut-outs" or interruptions in hearing as a result of some technical issues with the device itself. These brief "cut-outs" became more frequent and eventually the device was termed a "failure" by the manufacturer in January 2009. In February 2009, my cochlear implant device was surgically removed and new one implanted.

There was much discussion among the audiologists at the Ottawa Cochlear Implant Centre as to what the problem could be with the cochlear implant and representatives from the manufacturer came to look at the device and perform series of diagnostic tests. Some were optimistic that the external hardware was the issue and that the manufacturer would be able to rectify the problem, others were not so optimistic. This technical failure left me with a single hearing aid that picked up the louder environmental sounds. Like the pre-cochlear days, I became reliant again on my lip-reading skills and the help of others to answer and make phone calls. The experience again reminded me that while these technical solutions are marvellous in that they provided me with the freedom and 
autonomy to communicate well, there are limitations to their abilities and longevity. Cochlear implant "failure" is a rare event and occurs in less than one percent of implanted patients (Lefrançois 2009). Again I was fortunate to have the device removed and a new one put in place quickly ${ }^{14}$. The audiologists were able to prioritize my situation to get the first available surgical date.

This research was conceptualized around issues of agency and structure as they influence access to a locationally delivered resource, the cochlear implant. This is the first study in Canada to explore experiences of access to cochlear implant technology by deaf and hard of hearing Canadians. It provides qualitative insights to the subject of accessibility using a structurationist framework.

Structurationism recognizes that there is a duality of structure and agency that shapes social practices and actions (Gatrell 2002). Using this framework has enabled this research to make use of the drama metaphor to illustrate this duality, using primary actors, adults with a severe to profound hearing loss who have had a cochlear implant and other actors who had some influence on the journey to accessing the technology. These other or secondary actors are part of the health care system and they are also part of the social fabric of everyday activities. The roles or behaviours that the actors played influenced the re-telling of the individual narratives; recounting the journey in time and space. Individual biographies have provided a rich narrative of the journey, describing events,

\footnotetext{
${ }^{14}$ Though fortunate to have a quick turn-around time for surgery, post-implantation, the rehabilitation process for hearing remains the same as for the initial implant. JW
} 
people and the milieu within which these stories took place. From these narratives, the model previously established to organize accounts of accessibility can be fine-tuned and the emergent themes that relate to access can be identified and discussed.

When this research project was conceived, there was no intention to draw an unflattering picture of our health care system. Rather, there was the idea that the behaviours and biographies of individuals that intersect with a locationally constrained resource could be described within a time-notation system or time geography diorama to show the temporal and spatial attributes of access pathways and the interconnectedness between the different biographies. However, the evidence from the narratives and other sources gives us a more complex picture of access such that the "language" of time geography and the time notation system cannot adequately capture the full expression of the dualism of agency and structure that emerges. The Popperian tripartite worldview which views the world in all its realities is perhaps better suited to studying access to the cochlear implant technology as it can be representative of the interactions of the first or physical world and its structures; the mental and psychological second world of experiences, thoughts and decision making and the third world that includes the re-telling of these experiences and actions taken as a result of thought processes in the second world. One can also factor in the micro and macro framework to examine the big picture of the structural 
influences and activities that impact on access and availability of the cochlear implant technology.

The framework of Pozzebon et al. (2005) to operationalize structurationism was instrumental in organising accounts of accessibility for this research. In this framework, the dualism between structure and agency can be described in temporal and spatial terms through narratives of human agents and provide insight to the structural properties of social systems. Figure 5-1 illustrates a more detailed description of the accounts based on research findings and the narratives obtained.

\begin{tabular}{|c|c|c|}
\hline Human Agents & Interaction/Duality & $\begin{array}{l}\text { Social Systems } \\
\text { and Structures }\end{array}$ \\
\hline $\begin{array}{l}\text { Actors } \\
\text { - } \quad \text { Deaf or hard of } \\
\text { hearing (early, late, } \\
\text { sudden) } \\
\text { - Experiences } \\
\text { - Knowledge } \\
\text { Activities/Routines } \\
\text { - Work } \\
\text { - School } \\
\text { - Family } \\
\text { - Social } \\
\text { - Medical }\end{array}$ & $\begin{array}{c}\text { In time and space } \\
\text { this is where the } \\
\text { interaction happens } \\
\text { between }\end{array}$ & $\begin{array}{l}\text { Political System } \\
\text { - Canada - federal parliamentary } \\
\text { democracy with provincial jurisdictions } \\
\text { Health care system } \\
\text { - } \quad \text { Public funded health programs } \\
\text { provincially administered and delivered: } \\
\text { hospitals, clinics, primary care practices, } \\
\text { other health programs (Assistive } \\
\text { Devices Program - Ontario) } \\
\text { - Funding: global budget (Ontario) } \\
\text { - Privately owned and operated hearing } \\
\text { aid dispensers } \\
\text { Agents within the system } \\
\text { - Health services and financial } \\
\text { administrators (hospital level, provincial } \\
\text { level) } \\
\text { - Physicians } \\
\text { - Audiologists, hearing aid specialists } \\
\text { Other allied health care professionals } \\
\text { and administrators }\end{array}$ \\
\hline
\end{tabular}

Figure 5-1 Organizing accounts of accessibility to cochlear implantation: redrawing the model. 
Organising accounts of accessibility in this way provided evidence that shows access to cochlear implant technology is not linear, and in fact, it is weighed down with temporal, spatial, structural and other constraints that makes access easy for some and difficult for others. By examining the components that make up the structurationist framework, one can clearly identify the structural influences and constraints as they impact on access to cochlear implant technology. The following section describes these influences and constraints.

\section{Does structure matter?}

The current health care system is said to be a reflection of the wider social system in Canada. It is based on core values of equity, justice and unity to provide Canadians with universal and equal access to medically necessary health services. Framed this way, the structural processes do matter as they relate to issues of access.

The structural processes that created the provincial hospital funding system in Ontario, (the Ministry of Health and Long-term Care through the Public Hospitals Act) where "funding is based on a principle of global funding budgets provided to each hospital annually" (MOHLTC. 2009), influence how many cochlear devices will be available to eligible health institutions. These budgets are based on past allowances with annual adjustments for any year-to-year changes in costs (MOHLTC. 2009). Other structural processes include the individual hospitals, which allocate funds from their global budgets based on priorities established to meet the needs of its community (MOHLTC. 2009). 
Where people go for their hearing care reflects the way in which care is delivered or structured. While general and family practitioners are uniquely situated to screen patients for hearing loss and to direct them for appropriate audiological assessments, those experiencing difficulties with their hearing often pursue help outside mainstream medical services. The use of alternative services such as hearing aid dispensing clinics can be attributed to a number of factors: the perception that these services are the primary source of hearing care; that they are easily accessible in many areas; and that they provide one-stop (single tier) shopping with the full range of services under one roof. In many cases, fees for hearing tests are waived by private vendors as they cannot bill OHIP, while publicly funded hospitals can charge fees related to testing for hearing aids.

\section{Does agency matter?}

Agency refers to the flow of people's actions, consequently the influence of structural agents is relevant to issues of accessibility.

There are a number of medical and other allied health care professionals that can be involved in hearing care, and they include general and family practitioners, otolaryngologists, audiologists and certified hearing aid specialists. While physicians operate within the publicly funded health care system, as do hospital based audiologists who are supported by global hospital budgets, the audiologists and hearing aid specialists located in private hearing aid dispensing clinics are supported through a combination of private health insurance, profits and public funds through the provincial Assistive Device Program (Ontario). 
The agents who have a good understanding of hearing loss and current audiological amplification technologies and know how to identify those who have hearing losses that have surpassed the technological upper limits of hearing aids can be considered the gatekeepers to cochlear implant technology. Currently, not all of the agents involved in hearing care have this knowledge and this can be problematic in terms of imparting misinformation to potential candidates for a cochlear implant.

Within hospitals and at the provincial level, resource allocation decision makers are other influential agents who have an impact on the number of devices available on a year to year basis. As well, at the hospital level, there are also resource allocation decision makers working in tandem with other, within hospital agents, such as departmental administrators who decide how many cochlear implant devices will be budgeted for and it is those decisions that determine how accessible a device may be.

\section{Does time matter?}

Social practices have temporal and spatial attributes. The availability of cochlear implant devices for Canadians has increased over time in response to the success of implantations, increased funding for devices and the expansion of available services. These changes reflect system responses to increased demands for devices and services across Canada. In addition, changes to candidacy requirements over time show further evidence of structural influences 
on accessibility, as Health Canada adopted the initial and subsequent changes of the FDA eligibility guidelines.

Temporal attributes are evident in terms of obtaining hearing care. Constraints include lengthy waits to get appointments with audiologists or other hearing and health professionals. To overcome these delays, private hearing care centres have emerged to provide quick and easy access to hearing care. Temporal attributes are also evident in terms of eligibility for candidacy; that point in time when a deafened or hard of hearing individual's hearing reaches a threshold that equals or surpasses the eligibility criteria established by Health Canada or clinical trial studies. As most hearing loss is degenerative over time, time plays a crucial role in terms of access and the point of eligibility is not something that a person instinctively knows and reacts to. In most cases it is unknowingly surpassed till acknowledged by a hearing care professional. Surgical wait times are representative of spatial attributes of accessibility that reflect structural influences. Waiting times for surgery have varied depending on the availability of devices which is controlled by funding structures and the number of sites performing implantations, and this has changed over time.

There is evidence that there are temporal elements involved in the continuity of care and this ties in with the delivery structure of services to defined populations. Children with hearing losses and other chronic conditions appear to incur more consistent or regular hearing and health care than adults and part of this can be 
attributed to the structural divide between the provision of paediatric and adult health care services. As children mature and shift to using adult health care services, the continuity of care is often broken as the provision of hearing care services becomes the responsibility of the new adult.

Time can play a pivotal role in terms of what one knows or believes to be true and this knowledge can influence behaviour over time. In the biographies, there were several examples of this. One involved the development of a negative perception about the cochlear implant device based on a visual experience that was considered unpleasant as it portrayed the device at a time when the design was not aesthetically appealing. Later, this same person saw another visual presentation of the device, and this time it was much more aesthetically pleasing. In another example, a respondent was dissuaded from considering the cochlear implant by an individual at a hearing aid dispensing clinic. While the reasons for the dissuasion are not clear, it raises the possibility that the individual could have a negative perception of the device and how or when this knowledge came about, one can only guess.

Does space matter?

There are spatial attributes that can influence or constrain access to the cochlear implant technology. While most of the respondents for this case study are from the Ottawa area and proximate to the Ottawa Hospital and the Cochlear Implant Program, those from outlying geographical areas made no mention in their narratives that location was an access issue. On the contrary, there was an 
example of small town specialist physician who was aware of the technology, its availability and candidacy requirements that dispelled the perception that one respondent had about the poor knowledgeability of rural physicians.

The sites and types of service delivery are influential to where a person may go for their hearing care. In Ottawa alone, in addition to publically funded audiology clinics at the Ottawa Hospital, the Children's Hospital of Eastern Ontario (CHEO), and the Canadian Hearing Society, there are 23 ENT's registered with the Royal College of Physicians and Surgeons of Ontario. Compared with 27 private hearing aid dispensing clinics that serve the area, it is easy to see that there are a high number of point-of-entry locations for hearing care in the private sector, making access to hearing care easier than to the public sector. In addition, these for profit centers have made good use of media to market the accessibility of their services to a wide geographical audience.

\section{Conclusions}

Influence of structural processes on hearing care

The evidence from the narratives gives strength to the argument for regular or coordinated hearing care and follow-up for those with hearing losses. There are currently no structural processes in place to screen adults for hearing loss, nor are there guidelines or strategies for monitoring hearing losses that are typically progressive, on a consistent and regular basis. The onus is on the individual to seek help when experiencing difficulties hearing. This is a barrier to optimal hearing care, as a fragmented approach to health care can contribute to poor 
health or quality of life outcomes for people, especially when hearing losses unknowingly reach severe to profound thresholds. As a result, those with severe to profound hearing losses may miss out on the opportunity for a potential technological solution.

Currently, there is only one program in Ontario that screens for hearing loss and that is the Ontario Infant Hearing Program (IHP), which is a province-wide program operated by the Ministry of Children and Youth Services, designed to screen hearing in infants within the hospital and community settings (Sinai 2010). There are no other provincially funded hearing screening programs for youths and adults in Ontario. It would seem that there is an argument for regular screening especially for those with a family history of hearing loss, to identify the first signs of hearing loss, as well as for those with a degenerative hearing loss which typically changes over time. With regular and consistent monitoring, both health care providers and patients can be proactive in helping to manage the many issues related to hearing loss. Notably, routine hearing screening for those with a moderate to severe hearing loss could help identify potential candidates for the cochlear implant. This, along with a provincial or federal registry, would track the number of people who physiologically are potential candidates for surgery, thus creating a known or concrete figure with which to forecast or base funding decisions for implant devices. This data could potentially be used to eliminate the waiting times for surgery, which now stand at nearly three years for adults. 
In addition to a screening program, there is also a need to even out the baseline knowledge of cochlear implants among those involved in the provision of hearing care. From the narratives we have heard stories of misinformation or poor perceptions of what the technology is and what it can do by agents who are assumed to have specialized knowledge and expertise in matters of hearing care.

The gap in hearing care is an issue acknowledged by the Canadian Hearing Society and it has undertaken actions to address the problems raised. In its 2007-2010 strategic report, it states that one of its core strategies is to improve the range of services, noting that there is a "perceived gap in services to people with cochlear implants" and remarks that as part of their strategic plan activities, it aims to close this gap (CHS 2007). However, the specifics of the gaps are not outlined in their report.

Motivations of access - interactions in time and space

Obtaining access to the cochlear implant to improve one's hearing is motivated mainly by constraints experienced as result of the inability to hear well.

There is a point in time for most of the respondents where a high level of frustration related to an inability to hear is expressed and this motivates them to find a better solution. For some, it is expressed as a frustration with the technological limits of their hearing aids. For others it is an inability to fully participate socially and this is conveyed through feelings of depression or 
isolation. While some actively seek a solution to improve their ability to hear, others are more latent and by chance encounter the cochlear implant.

\section{Future Work}

This research has illustrated that access to the cochlear implant is either facilitated or constrained by the various structural processes and agents that are involved in hearing care. We have seen examples in the narratives, where respondents are uncertain of the qualifications of the people they involve in their hearing health, perhaps not recognisant of the many different hearing care providers that exist. We have also seen examples where respondents were misinformed by various providers about the potential benefits of a cochlear implant. We have also seen that the provision of hearing care is not consistent, leaving the responsibility for regular monitoring to the individual. We have seen that with progressive hearing loss, candidacy thresholds may be unknowingly surpassed because of this lack of regular hearing care, leaving potential candidates to "manage" in quiet frustration.

This research has laid the groundwork for future investigative work in this area. As well, it has developed a strong argument for the development of clinical practice guidelines for the screening of hearing in adults and for the coordination of regular and continuous hearing care for individuals at any age diagnosed with a hearing loss. In addition, there is a need to reduce current wait times for surgical implantation. Does anyone actually know how many people in Canada 
currently meet the eligibility requirements for a cochlear implant? Policy makers and other health care decision makers should be interested in these issues. By publishing this work in the literature, some of the data presented here will be made available, based on which further investigations may possibly lead to the development of a national network and reporting system to promote consistent dialogue with regards to accessibility and to monitor implantations and reimplantations on a national scale. 


\section{References}

AAA. 2008. Facts About Hearing Loss. American Academy of Audiology No date [cited July 5 2008]. Available from http://www.audiology.org/resources/consumer/Documents/FSHearingLoss 08.pdf

Agrawal, Yuri., Elizabeth Platz, and John K. Niparko. 2008. Prevalence of Hearing Loss and Differences by Demographic Characteristics Among US Adults. Archives of Internal Medicine 168 (14):1522-1530.

Aitken, Stuart C., and Timothy Fik. 1988. The Daily Journey to Work and Choice of Residence. The Social Science Journal 25 (4):463-475.

Akhtar, Rais. 2003. Medical Geography: Has J.M. May Borrowed Sorre's Concept of Pathogenic Complexes? European Journal of Geography 12.

Armstrong, Pat and Hugh Armstrong. 2003. Wasting Away. 2nd Ed ed. Don Mills: Oxford University Press.

Armstrong, Pat, Hugh Armstrong with Claudia Fagan. 1998. Universal Health Care: What the United States Can Learn from the Canadian Experience. New York: The New Press.

ASLHA. 2009. Type, Degree and Configuration of Hearing Loss. American Speech Language Hearing Association 2008 [cited July 7 2009]. Available from http://www.asha.org/public/hearing/disorders/types.htm.

Barrett, Frank A. 2002. The role of French-language contributors to the development of medical geograph (1782-1933). Social Science and Medicine 55:155-165.

Bazeley, Pat. 2007. Qualitative Data Analysis with NVivo. London: SAGE Publications Ltd.

Bennett, David. 2003. Personal communication. Ottawa.

Browne, Paul Leduc. 2000. Unsafe Practices: Restructuring and Privatization in Ontario Health Care. Ottawa: Canadian Centre for Policy Alternatives.

CAD. 2008. Statistics on Deaf Canadians. Canadian Association of the Deaf 2007 [cited May 5 2008]. Available from http://www.cad.ca/en/issues/statistics on deaf canadians.asp.

Cameron, David and Fraser Valentine. 2001. Disability and Federalism. Montreal and Kingston: McGill-Queen's University Press. 
Chisholm, Theresa Hnath, Carole E. Johnson, Jeffrey Danhauer, Laural J.P. Portz, Harvey B. Abrams, Sharon Lesner, Patricia A. McCarthy,, and Craig W. Newman. 2007. A Systematic Review of Health-Related Quality of Life and Hearing Aids: Final Report of the American Academy of Audiology Task Force on the Health-Related Quality of Life Benefits of Amplification in Adults. Journal of the American Academy of Audiology 18 (2):151-183.

CHS. 2009. Strategic Plan 2007-2010. Canadian Hearing Society 2007 [cited July 9 2009]. Available from

http://www.chsprotosite.com/index2.php?option=com content\&do $\mathrm{pdf}=1 \&$ $\underline{i d=246}$.

Clark, J. G. 1981. Uses and abuses of hearing loss classification. Asha (23):493500.

Cohen, Seth M., Robert F. Labadie, and David S. Haynes. 2005. Primary care approach to hearing loss: the hidden disability. Ear Nose Throat 84 (1):2931.

Cohen, Seth M., Robert F. Labadie, Mary S. Dietrich and David S. Haynes. 2004. Quality of life in hearing-impaired adults: the role of cochlear implants and hearing aids. Otolaryngology - Head and Neck Surgery 131:413-422.

Davis, A.C. 1989. The Prevalence of Hearing Impairment and Reported Hearing Disability among Adults in Great Britain. International Journal of Epidemiology 18 (4):911-917.

Deber, Raisa B. 2000. Who wants to pay for health care? Canadian Medical Association Journal 163 (1):43-44.

Ellegård, Kajsa. 1999. A time-geographical approach to the study of everyday life of individuals - a challenge of complexity. GeoJournal 48:167-175.

Fitzpatrick, Elizabeth, Andree Durieux-Smith, Doug Angus, Janet Olds, David Schramm, and Joanne Whittingham. 2006. Economic Evaluation of Cochlear Implants in Children. Journal of Speech Language Pathology and Audiology 30 (4):215-223.

Fontana, A., and J.H. Frey. 2000. The Interview From Structured Questions to Negotiated Text. In Handbook of Qualitative Research, edited by N. K. Denzin, Y.S. Lincoln. Thousand Oaks: Sage Publications.

Gatrell, Anthony C. 2002. Geographies of Health. Oxford: Blackwell Publishers Ltd.

Gergen, M.M., and K.J. Gergen. 2000. Qualitative Inquiry: Tensions and Transformations. In Handbook of Qualitative Research, edited by N. K. Denzin, Y.S. Lincoln. Thousand Oaks: Sage Publications. 
Giddens, Anthony. 1984. The Constitution of Society, the outline of a theory of structuration. Cambridge: Polity Oress.

Hallin, Per Olof. 1994. Energy, Lifestyles and Adaptation. Geografiska Annaler 76B (3):173-185.

Hawthorne, Graeme and Anthony Hogan. 2002. Measuring disability-specific patient benefit in cochlear implant programs: developing a short form of the Glascow Health Status Inventory, the Hearing Participation Scale. International Journal of Audiology 41:535-544.

Hawthorne, Graeme, Anthony Hogan, and Ellen Giles 2004. Evaluating the health-related quality of life effects of cochlear implants: a prospective study of an adult cochlear implant program. International Journal of Audiology 43:183-192.

HHCC. 2010. Our Quality Care. Hellix Hearing Care Centre 2009 [cited May 10 2010]. Available from http://www.helixhca.com/quality.asp.

Hinderink, Johannes B., Paul F. M. Krabbe and Paul Van Den Broek. 2000. Development and application of a health-related quality-of-life instrument for adults with cochlear implants: The Nijmengen cochlear Implant Questionnaire. Otolaryngology - Head and Neck Surgery 123:756-766.

Hoepfl, Marie C. 1997. Choosing Qualitative Research: A Primer for Technology Education Researchers. Journal of Technology Education 9 (1).

Johnston, R. J. 1994. The Dictionary of Human Geography, edited by D. Gregory, David M. Smith. Cambridge: Blackwell Publishers Ltd.

Kaczynski, Dan. 2004. Examining the Impact of Qualitative Data Analysis Software upon the Analysis Process. In Australian Association for Research in Education Melbourne, Australia.

Kaplan, Daniel M., David B. Shipp, Joseph M. Chen, Amy H. Ng and Julian M. Nedzelski. 2003. Early-Deafened Adult Cochlear Implant Users: Assessment of Outcomes. The Journal of Otolaryngology 32:4.

Kaufman, Sharon. 1994. In-Depth Interviewing. In Qualitative Methods in Aging Research, edited by J. Gubrium, and Andrea Sankar. Thousand Oaks: Sage Publications.

Kochkin, Sergei. 2005. 35 Million North Americans suffer from hearing loss. Hearing Review July.

Krabbe, Paul F. M., Johannes B. Hinderink and Paul Van Den Broek. 2000. The Effect of Cochlear Implant Use in Postlingually Deaf Adults. International Journal of Technology Assessment in Health Care 16 (3):864-873. 
Kunimoto, Masaru and Noboru Yamanaka. 1999. The benefit of cochlear implantation in the Japanese elderly. Auris Nasus Larynx 26:131-137.

Lefrançois, Renee. 2009. Cochlear implant surgeries in Canada. Ottawa, November 2, 2009.

Lenntorp, Bo. 1999. Time-geography - at the end of its beginning. GeoJournal 48:155-158.

Livingstone, David L. 1992. Statistics Don't Bleed: Quantification and is Detractors. In The Geographical Tradition: Episodes in the History of a Contested Enterprise. Oxford: Blackwell

Macintyre, Sally, Anne Ellaway and Steven Cummins. 2002. Place effects on health: how can we conceptualize, operationalize and measure them? Social Science and Medicine 55:125-139.

Meade, Melinda S. 1988. Medical Geography. New York: Guildford Press.

Merriam, Sharan B. and Associates. 2002. Qualitative Research in Practice. San Francisco: Josey-Bass.

Miller, Harvey J. 2004. Activities in Space and Time. In Handbook of Transport 5: Transport Geography and Spatial Systems, edited by K. B. P. Stopher, K. Haynes and a. D. Hensher: Pergamon/Elsevier Science,.

Miller, Harvey J. 2005. A Measurement Theory for Time Geography. Geographical Analysis 37:17-45.

Miller, W.L. and B.F. Crabtree. 1999. Doing Qualitative Research. 2nd ed. Thousand Oaks: Sage Publications.

MOHLTC. 2010. Health Services in Your Community. Ontario Ministry of Health and Long Term Care 2009 [cited 2010]. Available from http://www.health.gov.on.ca/english/public/contact/hosp/hospfaq dt.html.

MRFC. 2008. What is Meningitis? Meningitis Research Foundation of Canada 2008 [cited August 10 2008]. Available from http://www.meningitis.ca/en/what is meningitis/causes.shtml.

Newman, C.W, , and S.A. Sandridge. 2004. Hearing loss is often undiscovered, but screening is easy. Cleveland Clinic Journal of Medicine 71 (3).

NIDCD. 2008. Cochlear Implants. National Institute on Deafness and Other Communication Disorders 2007 [cited May 7 2008]. Available from http://www.nidcd.nih.gov/health/hearing/coch.asp. 
Pattison, William D. 1964. The Four Traditions of Geography. The Journal of Geography 63:211-218.

Patton, M. Q. 2002. Qualitative Research and Evaluation Methods. 3rd edition ed. Thousand Oaks: Sage Publications.

Pearce, Jamie. 2003. Emerging new research in the geography of health and impairment - editorial. Health and Place 9:107-108.

People, Royal National Institute for Deaf. About deafness and hearing loss 2003 [cited. Available from http://www.rnid.org.uk/information resources/.

PHAC. 2006. Hearing Loss Info-Sheet for Seniors, edited by P. H. A. o. Canada: Minister of Public Works and Government Services Canada, 2006

Phonak. 2009. Hear the World 2009 [cited July 13 2009]. Available from http://www.hear-the-world.com.

Pitt, Jane. 1995. Social Justice in Contemporary Schooling: some methodological considerations. In Australian Association for Research in Education Conference. November 26-30.

Popper, Karl. 1978. Three Worlds. Paper read at The Tanner Lectures on Human Values, at University of Michigan.

Pozzebon, Mariel and Alain Pinsonneault. 2005. Challenges in Conducting Empirical Work Using Structuration Theory: Learning from IT Research. Organization Studies 26 (9):1353-1376.

Pred, Allan. 1981. Social Reproduction and the Time-Geography of Everyday Life. Geografiska Annaler 63B:5-22.

Rakel, R. E. 2008. Textbook of Family Practice (6th edition). WB Saunders 2005 [cited May 2 2008]. Available from http://www.umm.edu/ency/article/003044.htm.

Rioux, Marcia H. and Sherri Torjman. 1992. A Study of Personal Supports in Ontario North York: L'Institut Roeher Institute.

Romanow, Roy J. 2002. Building on Values: The Future of Health Care in Canada - Final Report In Commission on the Future of Health Care in Canada. Ottawa.

Rose, Jeremy and Rens Scheepers. 2001. Structuration Theory and Information System Development - Frameworks for Practice. In The 9th European Conference on Information Systems. Bled, Slovania. 
Rosenberg, Mark S. 1998. Medical or Health Geography? Populations, Peoples and Places." International Journal of Population Geography. International Journal of Population Geography 4:211-226.

Ryan, Gery W. and J. Russell Bernard. 2003. Techniques to Identify Themes. Field Methods 15:85-109.

Saxon, John P., Alice E. Holmes and Ronald J. Spitznagel. 2001. Impact of a cochlear Implant on Job Functioning. Journal of Rehabilitation 67 (3):4954.

Schaerström, Anders. 1997. Pathogenic Paths? A Time Geographical Approach in Medical Geography Geografiska Annaler, Series B, Human Geography 79 (1):57-59.

Séguin, Christiane. 2008. Cochlear Implant in Canada - Background. Ottawa, May 29, 2008.

Sinai, Hospital Mount. Infant Hearing Program 2010 [cited. Available from http://www.mountsinai.on.ca/care/infant-hearing-program.

Soderstrom, L. 1978. The Canadian Health System. London: Croom Helm.

Stake, Robert. 2000. Case Studies. In Handbook of Qualitative Research, edited by N. K. Denzin, and Y.S. Lincoln. Thousand Oaks: Sage Publications.

Statistics, Canada. 2007. Health and Activity Limitation Survey: Household Component (HALS). Government of Canada 1989 [cited May 3 2007]. Available from http://www.statcan.gc.ca/cgibin/imdb/p2SV.pl?Function=getSurvey\&Survld $=3251 \&$ SurvVer $=2 \&$ Instald $\equiv 16705 \&$ InstaVer $=2 \&$ SDDS $=3251$ \&lang $=e n \& \mathrm{db}=i m d b \& a d m=8 \& d i s=2$.

Statistics Canada. 2007. Health and Limitation Survey: Institutional Component. Government of Canada 1994 [cited April 30 2007]. Available from http://www.statcan.gc.ca/cgibin/imdb/p2SV.pl?Function=getSurvey\&SDDS=3252\&lang=en\&db=imdb\& $\mathrm{adm}=8 \&$ dis $=2$.

Tellis, Winston. 1997. Application of a Case Study Methodology. The Qualitative Report 3 (September).

TOH. Cochlear Implant Program. The Ottawa Hospital 2008 [cited. Available from http://www.ottawahospital.on.ca/hp/dept/audiology/cochlear-e.asp.

Torjman, Sherri. 2001. Canada's Federal Regime and Persons with Disabilities. In Disability and Federalism: comparing different approaches to full participation, edited by D. Cameron, and Fraser Valentine. Montreal and Kingston: McGill-Queen's University Press. 
WHO. 1998. Report of the International Workshop on Primary Ear and Hearing Care. Cape Town: World Health Organization

WHO. 2008. Fact Sheet 300: Deafness and Hearing Impairment. World Health Organization 2006 [cited May 6 2008]. Available from http://www.who.int/mediacentre/factsheets/fs300/en/index.html. 


\section{Appendix A: Information Sheet and Consent Form}

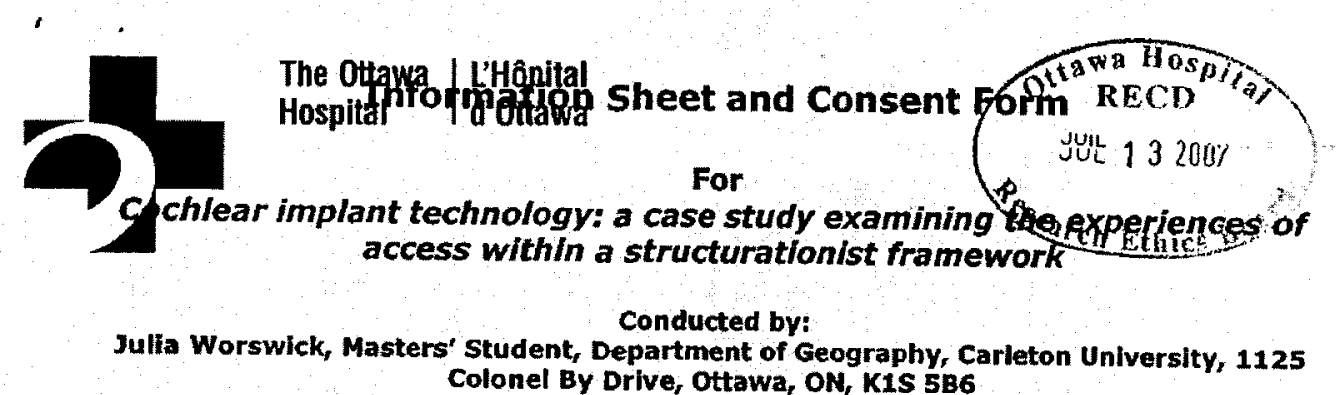

\section{Background and Purpose of Study:}

I am conducting a research project to fulfill the requirements of my Masters thesis under the supervision of Professor David Bennett. This is a study of adults who have had a cochlear Implant in the past five years. The objective of this research is to gain an understanding of the experience that deafened or hard of hearing people have accessing this technology.

You are being asked to participate in this research project because you are a patient of the Ottawa Cochlear Implant Program. We will investigate how access to cochlear implant technology varies between some individuals in time and space. I would like to conduct a one on one interview with you and ask you some general open-ended questions about your experiences that led to obtaining a cochlear implant.

It is anticipated that interviews will take approximately one hour. Interviews will be coordinated with your scheduled audiology follow-up visits and will take place in the Audiology Clinic at the Parkdale Clinic of the Ottawa Hospital Civic Campus. The interviews will be recorded.

\section{Risks:}

For some, talking about hearing loss can be difficult. While there are no anticipated risks to you as a respondent in this project, you may find that discussing your experiences might bring forth different kinds of emotional feelings and responses.

\section{Benefits:}

You will not benefit directly from this study. However, the information from this study may be used to provide feedback to health organizations involved In lobbying support for cochlear Implants for deafened or hard of hearing Canadians. This research will bring depth to an under-researched health topic and increase our awareness and understanding of accessibility to health care technology.

\begin{tabular}{lrc}
\hline$\square$ Civic Campus Civic & $\square$ Generai Campis Géneral & $\square$ Riverside Campus Riverside \\
1053 av. Carting Avenue & 501 chemin Smyth Road & 1967 prom. Riverside Drive \\
Ottawa, Ontario K1Y AE9 & Otawa, Ontario K1H 8L6 & Ottawa, Ontario K1H 7W9
\end{tabular}


Costs:

There will be no remuneration associated with the study, however, I do appreciate your participation and parking expenses (If applicable) will be reimbursed.

\section{Confidentiality:}

All information obtained from you will remain confidential. The information you provide will not be used for any other purpose than this study without your. permission. Your name will not be identified in any publication, report or presentation resulting from this research. No identifiable Information will leave the hospital. Instead, pseudonyms will be on documents leaving the Ottawa Hospital. The Ottawa Hospital Research Ethics Boards may review your relevant study records for audit purposes.

\section{Voluntary Participation:}

Your participation in this project is voluntary. Should you decide not to participate, or to withdraw from the study at any time, your treatment in the Ottawa Cochlear Implant Program will not be affected in any way. If you agree to participate, your clinical audiologist or Julia Worswick will be avallable to answer any questions.

\section{Questions:}

This project is being supervised by Professor David Bennett of Carleton University and the co-investigator at the Ottawa Hospital is Christiane Séguin. The study has been reviewed and approved by the Carleton University Research Ethics Committee. If you have any questions or concerns regarding this project, you may contact me or any of the following:

Professor David Bennett Department of Geography Carleton University 1125 Colonel By Drive Ottawa, Ontario K1S $5 B 6$

Masters Thesis Supervisor $613.520 .2600 \times 3578$

Professor Antonio Gualtieri, Chair Carleton University Research Ethics Committee Carleton University

613.520 .2517

Christiane Séguin Coordinator - Ottawa Cochlear Implant Program Department of Audiology Ottawa Hospital - Civic Campus

$613.798 .5555 \times 18003$ 
Julia Worswick

\section{Consent}

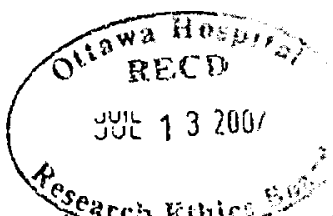

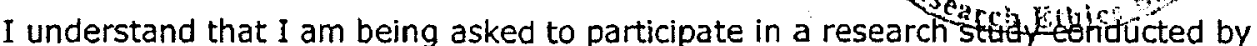
Julia Worswick, a graduate student in the Master's Program with the Department of Geography at Carleton University in Ottawa. I have read the above aspects of the study in this three page consent form. The information I provide will be used to complete a Masters' research study project.

I will be asked a number of open-ended questions about my experiences accessing the cochlear Implant technology in an audio recorded interview that may take approximately one hour in length. The nature of the interview might elicit some emotional feelings about my experiences. I have been able to ask questlons and the questions have beeri answered. I have been advised that I may choose not to answer any question and am free to withdraw my participation in this study at any time and this will not affect the quality of clinical care that I will receive. If I do withdraw my participation from this study, I will advise Julia Worswick in writing at that time of my wishes concerning the use and/or return and disposal of my interview data. A sample letter will be available upon request.

I waive no legal rights by choosing to participate in this study.

\section{Signatures}

By signing this consent form, I am indicating that I agree to participate in this research study.

Printed name (of patient/respondent)

Signature (of patient/respondent)

Date

Printed name of Investigator/delegate

Signature of Investigator/delegate

Date

I have explained this research study to the particlpant and I am satisfied that s/he is aware of any implications of this study.

Signature of investigator

Date

(valid until July 18, 2008) 


\section{Appendix B: Notice of Withdrawal from Study}

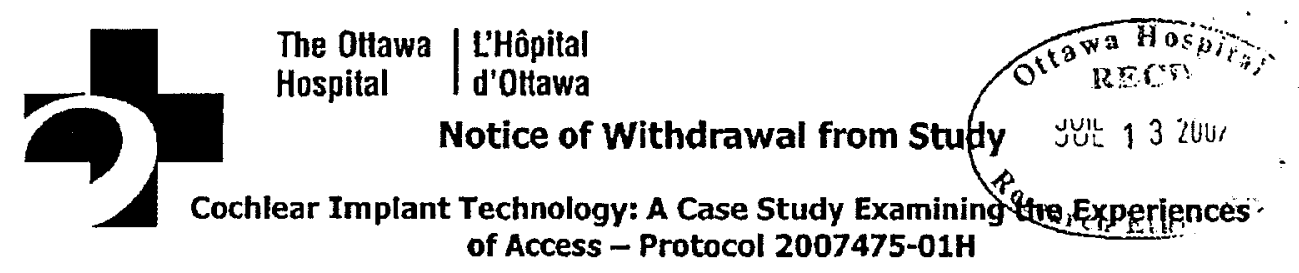

I wish to inform Julia Worswick that I would like to withdraw my particlpation from the above mentioned study.

In withdrawing:

$\square$ I would like to have all information that I have provided removed from the study and destroyed.

I agree to the use of any data I have provided thus far.

Name of study participant (please print):

Signature of study

participant: Date:

Please forward this notice to:

Julia Worswick

c/o

Christlane Séguin

Department of Audiology

Ottawa Hospital - Civic Campus

Floor 2, 242

1053 Carling Avenue

Ottawa, ON

K1Y 4E9

(valid until July 18, 2008)

\begin{tabular}{lrc}
\hline$\square$ Chic Campus Civic & $\square$ Generol Campus Gëndral & $\square$ Aiverside Campus fiverside \\
1053 av. Carling Avenue & 501 chemin Smyth Road & 1967 prom. Riverside Orive \\
Ottawa, Ontario K1Y 4E9 & Otlawa, Ontario KIH BL6 & Ottawa, Ontario K1H 7W9
\end{tabular}




\section{Appendix C: Ethics Approvals}

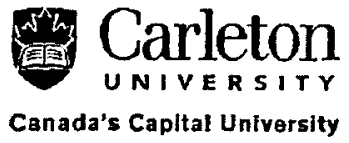

Carleton University Research Office 5 th Floor Tory Building 1125 Colonel By Orive Ottawa. ON K1S 586 Canada Tel: (613) 520.2516

Fax: (613) 520.252

muw.carleton.ca/cu/research/curo/

\section{Ethics Approval Form}

This is to certlfy that the Carleton Unlversity Research Ethics Committee has examined the application for ethical approval. The committee found the research project to meet appropriate ethical standards as outlined in the Tri-Council Policy Statement: Ethical Conduct for Research Involving Humans and, the Carleton University Policies and Procedures for the Ethical Conduct of Research.

$X$ New approval

口 Renewal of original approval Orlginal date of approval:

Date of approval

Researchers

Status

Department

Supervisor

Title of project
11 May 2007

Julia Worswick

M.A. candidate

Department of Geography \& Environmental Studles

David Bennett

Cochlear implant technology: A case study examining the

experiences of access within a structionist framework

Ethics approval expires on: 11 May 2008

Conditions: Approval from the Ottawa Hospital REB is required.

\section{All researchers are governed by the following conditions:}

Annual Status Report: Ethics clearance is valid for one year from date of approval. You are required to submit an Annual Status Report to either renewal approval or close the file. Fallure to submit the Annual Status Report will result in the Immediate suspension of the project. Funded projects will have accounts suspended until the report is submitted and approved.

Changes to the project: Any changes to the project must be submitted to the Carleton University Research Ethics Committee for approval. All changes must be approved prior to the continuance of the research.

Adverse events: Should any participant suffer adversely from their particlpation in the project you are required to report the matter to the Carleton University Research Ethics Commiltee. You must submit a written record of the event and indicate what steps you have taken to resolve the situation.

Suspension or termination of approval: Failure to conduct the research in accordance with the principles of the Tri-Council Pollcy Statement: Ethical Conduct for Research Involving Humans and the Carleton University Policies and Procedures for the Ethical Conduct of Research may result in the suspension or termination of the research project.

Léslie J. Macbonato-Hicks $r$

Research Ethics Committee Coordinator

For the Chair of the Carleton University Research Ethics Committee

Prof. Antonio Gualtieri 


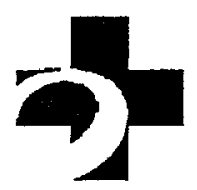

The Ottawa L'Hôpital

Thursday, July 19, 2007

Dear Ms. Worswick:

\section{Re: Protocol \# 2007475-01H Cochlear Implant Technology: A Case Study Examining the Experiences of Access Within a Structurationist Framework \\ Protocol approval valid until - Friday, July 18, 2008}

I am pleased to inform you that your study (listed above) was given expedited review by the Ottawa Hospital Research Ethics Board (OHREB) and is approved. Approval is for the English Information Sheet and Consent Form, and the English "Notice of Withdrawal from Study" form. No changes, amendments or addenda may be made in the protocol without the OHREB review and approval.

The validation date should be indicated on the bottom of all consent forms and information sheets (see copy attached). Approximately two months prior to the expiration dale listed above, a single renewal form should be sent to the OHREB office.

The Tri-Council Policy Statement requires a greater involvement of the OHREB in studies over the course of their execution. The OHREB will review the new information to determine if the protocol should be modified, discontinued, or should continue as originally approved.

Yours sincerely,

Raphael Saginur, M.D.

Chairman

Ottawa Hospital Research Ethics Board

Encl.

/If 


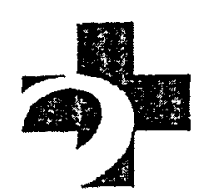

The Ottawa L'Hôpital

Hospital d'Ottawa

Research Ethics Board Conseil d'éthlque en recherchos $798-5555$ ext 14146,14902 or 15072 Fax No. $-761-4311$ http://www.ohrlcarohreb/

Thursday, August 23, 2007

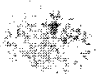

Dear Ms. Worswick:

Re: Protocol \# 2007475-01H Cochlear Implant Technology: A Case Study Examining the Experiences of Access Within a Structuratlonist Framework

Thank you for your letter received August 14, 2007 with the enclosed Protocol Amendmeet Report dated August 14,2007. Your request to amend the study to include e-mail as a format for inviting patients into the Cochlear Implant Program is approved.

Ethical approval remains in effect until July 18, 2008.

Yours sincerely,

Raphael Saginur, M.D.

Chairman

Ottawa Hospital Research Ethics Board

MAL/f 


\section{Appendix D: Interview Guide for Study Respondents}

Good morning/afternoon. My name is Julia Worswick. I am conducting this interview as part of a research study on access to cochlear implant technology. This study is the basis for my Master's thesis which I am completing at Carleton University. This research is done under the supervision of Professor David Bennett and with the assistance of Christiane Seguin. I am conducting interviews with people who have had a cochlear implant in the last five years to learn more about the individual stories of access to this technology.

During the interview, I will be asking you some questions about your story.

This information will contribute to a better understanding of the state of knowledge and awareness of the cochlear implant technology by deafened or hard of hearing persons. As well, this research will show that there are various pathways that people have taken to obtain this technology. By gaining a better understanding of the accessibility patterns, we can determine what barriers exist, if any, to improve timely access to deafened and hard of hearing persons who can benefit from this technology.

All of the information we collect in this interview will be kept confidential. We'd like your help, It won't take more than one hour.

\section{Let's talk about your story. Tell me about your hearing loss.}

2. Let's talk now about the people involved in your hearing care. What interactions have you had with health care professionals with respect to your hearing loss from the beginning?
Probe

When did it happen

What age were you

Where did it happen

Degenerative, sudden loss

Over time has it changed

\section{Probe}

Who diagnosed you first?

What was said?

What was the prognosis?

What was the intervention?

How often did you see audiologist, GP etc. about hearing loss.

Monitoring done and frequency.

Assistance with assistive devices

Location of people involved geography distance. 
3. What is the story of your experiences that led to the cochlear implant?

4. How did you learn of the cochlear implant technology?

5. How did you arrive at your decision to have surgery?

\section{Probe}

What started the journey? Trigger(s)

Hearing becomes worse

$\square$ Difficulties at school or work

- How you were coping or not coping with your hearing loss?

$\square$ Barriers encountered - geography distance

Asked or offered implant?

Probe

$\square$ Internet, friend, family

- GP

$\square$ Audiologist

- When - time from learning about it to speaking with doctor/audiologist

Probe

- Obstacles

Geography

Tests

Family discussion

Research 


\title{
Appendix E: Recommended Wait Times for Speech-Language Pathology and Audiology Related Services
}

\author{
Recommended Wait Times for Speech-Language Pathology \\ and Audiology Related Services ${ }^{i}$
}

\begin{abstract}
The Canadian Association of Speech-Language Pathologists and Audiologists and its members are committed to taking a leadership role on the important issue of reducing wait times for services. Establishing reasonable wait times is the first step. The following data was developed through the Pan-Canadian Alliance Wait Times Project. Recommendations for additional diagnostic areas will be forthcoming.
\end{abstract}

\section{Definitions for Wait times}

- Date referral received until date of first offered appointment.

- Date of initial assessment to date of offered treatment.

\section{Cochlear Implants}

Paediatric

The maximum time paediatric patients/clients should wait from the time they receive a referral until the date of the first appointment is 2 months.

The maximum time patients/clients should wait from the time cochlear implant candidacy is determined until implantation is 3 months.

The maximum time patients/clients should wait with Sensorineural Hearing loss requiring cochlear implant after meningitis is 6 weeks.

Adult

The maximum time adult patients/clients should wait from the time they receive a referral until the date of the first appointment is 3 months.

The maximum time adult patients/clients should wait from the time cochlear implant candidacy is determined until implantation is 6 months.

The group of cochlear implant experts that met agreed that setting a wait time between the time of initial assessment until implantation is highly variable, and that there are justifiable reasons for this (e.g., complexity of the case or need for a trial with appropriately fit amplification). Consequently making a recommendation for a wait time between when an assessment begins and when an individual is implanted is not a particularly useful marker. It was felt that a better wait time marker, particularly of surgical wait time is the time between determination of candidacy and surgical implantation.

During the meeting it was identified that that there is a Canadian Surgeon Committee that has been formed that is also addressing the issue of cochlear implant wait times. This group recommends that this Committee be contacted for input and that the two groups work together to ensure continuity on recommendations regarding cochlear implant surgical wait times.

\footnotetext{
i Taken from CASLPA: http://www.caslpa.ca/english/profession/wait_list_cochlear_implants.asp
} 